SF 489

.N9 



\title{
EGG MONEY
}

\section{HOW TO INCREASE IT}

A Book of Complete and Reliable Information on the More Profitable Production of

Eggs on the City Lot, the Village Acre and the Farm.

\author{
BY H. A. NOURSE
}

and Twenty-four Other Successful Poultrymen.

\section{FULLY ILLUSTRATED}

\author{
Price Twenty-five Cents
}

WEBB PUBLISHING COMPANY

ST. PAUL, MINNESOTA 


\section{$5 F \times 8^{8}$}

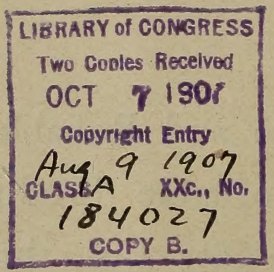

Copyright, 1907.

WEBB PUBLISHING CO.,

St. Paul, Minn. 


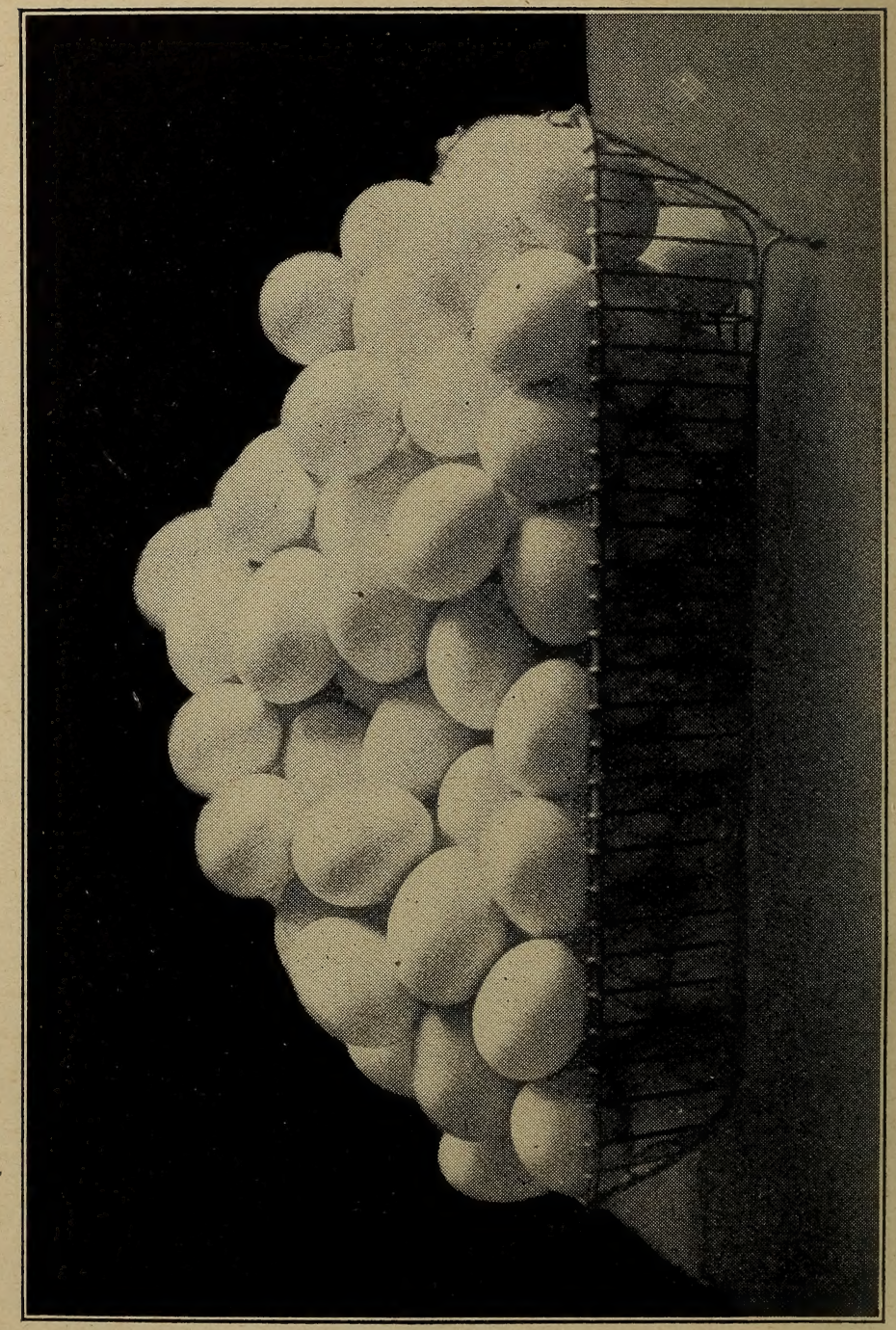




\section{EGG MONEY}

\section{IN T RODUCTION.}

The production of eggs to be consumed as food has been, is, and probably always will be the mainstay of the poultry industry. The fancy poultry business, or the breeding of fowls primarily for exhibition, interests but a small - per cent of the total number of poultry keepers; the production of poultry meat, as a separate branch of the industry, is comparatively small-the greater part of the immense supply that finds its way to market annually is furnished by those who make the rearing of it secondary, or incidental to the production of eggs.

For no product of agricultural or animal industry is there a more stable demand, year in, year out, than for this product of the domestic hen. Within the past few years the number marketed and consumed has increased tremendously; yet the prices have increased also, proving that the demand is more than keeping pace with the supply, and indicating very positively that the business will not be overdone or become unprofitable, certainly not during the lifetime of the present generation.

As will be noted in following chapters, the equipment required is neither extensive nor costly; no one breed or variety of fowls is pre-eminently superior for the purpose; the main requirements are knowledge of how to conduct the business and willingness to attend faithfully to the work.

The production of eggs is profitable. No legitimate department of agricultural industry offers richer returns on equal capital invested to those who work diligently and understandingly. When prices are lowest, in the summer months, there is an opportunity for a fair profit on the cost of production; when prices reach twenty, thirty and forty cents a dozen in the open market, as they do in early winter, the poultryman whose flock is presenting him a fair yield should pocket a one hundred per cent profit on the cost of production, as pay for his labor. A special 
trade with families, clubs or ultra highclass hotels sometimes secures a standing price of fifty cents or more per dozen for eggs of choice quality delivered regularly and in stated numbers.

Under ordinary circumstances and conditions, with the cost of foods and prices of eggs about the average for the United States, profits of one dollar to two dollars per hen have been realized by those who make eggs the main feature but do not neglect to profit by the sale of what may be called the incidental products, as, the surplus males, the discarded layers and the poultry manure. Under specially favorable conditions of location, market, etc., greater profits have been made and are made today. The keeper of a small flock usually makes the greatest profit on each fowl, for a considerable part of the cost of maintenance is saved by substituting table scraps and kitchen waste for much of the grain, beef scraps, etc., that must otherwise be bought and paid for. The farmer's flock can be fed for a very small money outlay, especially in summer when fifty hens will obtain most of their living if allowed to range over the average farm. The exclusive poultry keeper finds the cost of supporting his fowls heaviest for he almost invariably buys all the food stuffs; yet his profits are satisfactory if his methods are right.

It is our purpose to present in this book such information as may be followed with success by the city back-lot poultry keeper with a dozen fowls, the village mechanic with his half-acre to devote to the production of eggs, the farmer with his barnyard flock, or the exclusive poultry raiser who depends upon the difference between income and expenditure to pay the grocer and the clothier and provide the means to educate his children. It is a matter of record that no one method can be described which will prove adequate and suitable under all conditions with which the egg farmer on a large or small scale may be confronted. On that account we present the advice of different successful poultry keepers, which, taken as a whole, thoroughly covers the field of information on the more profitable production of eggs. 


\section{EQUIPMENT REQUIRED.}

\section{The Kind and Amount of Land Needed-Location and Drain= age-The Question of Large Versus Small Houses-Neces= \\ sary Coops, Fixtures and Utensils-Comparative \\ Cost of a Complete Outfit.}

\section{By H. A. Nourse.}

The amount of land required depends, of course, upon the size of the business carried on. There must be a certain relative proportion of the number of fowls kept to the amount of room occupied, or, as a general rule, results will not be satisfactory.

Where it is the intention to keep fowls profitably for eggs, with the least expenditure of time in caring for them, at least one hundred square feet of ground should be allowed each mature fowl to range over, when the weather permits them to be outdoors a large proportion of the time. Therefore a flock of ten hens would require approximately one thousand square feet, or a piece of ground ten feet wide and one hundred feet long, or about thirty-two feet square. On city back lots, where a less space must be used to accommodate this number of layers, additional labor is required to keep the surroundings sanitary, i. e., to prevent the ground itself from becoming "tainted" or loaded with filth which in time becomes poison.

On farms where free range may be provided during the greater part of warm weather, yards need not be as large, for the ground has opportunity to become cleansed through the growth of fresh vegetation in such months as the flock is not confined. As a rule, however, one hundred feet of yard room is the minimum space compatible with good health of the fowls, which in turn is necessary for a high rate of production of eggs.

\section{The Character of the Soil.}

The exact make-up of the soil is not so material as is 
frequently claimed in articles of advice to poultry keepers. Formerly, very light, sandy soil was considered most desirable because of the contention that in such soil impurities were quickly driven below the surface by heavy rains, thus making the yards self-cleansing, as it were. On such ground it is almost impossible to maintain a good sod and steady growth of grass, something of no little importance in a poultry yard. It is a fact that a good growth of vegetation will do more in a month to cleanse the soil of impurities caused by the presence of the fowls than will all the rains that may beat upon it in a year. For this reason soil that is capable of producing a good crop of grass is to be preferred.

The selection of exceedingly rich soil is not to be advised because the additional richness, or fertility, is not required for this purpose and may be put to better use in other lines of agricultural industry.

\section{Location and Drainage.}

A good location, with reference to securing protection from the cold winds of winter and making the most of the sun during the cold months, as well as comparatively good drainage, is decidedly important. The ideal location is in an orchard protected on the north by hills or groves, on land sloping to the south sufficiently to afford good surface drainage.

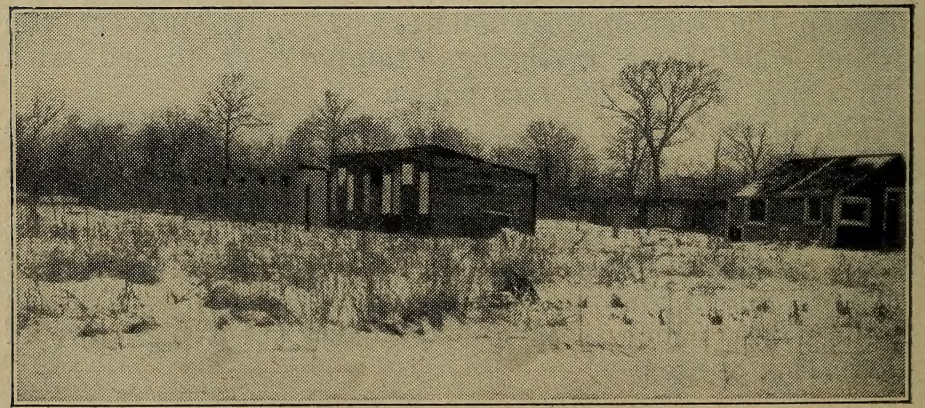

Inexpensive and Practical Continuous Houses in Use on a Well-Known Poultry Farm Where Producing Eggs is the Main Business. 


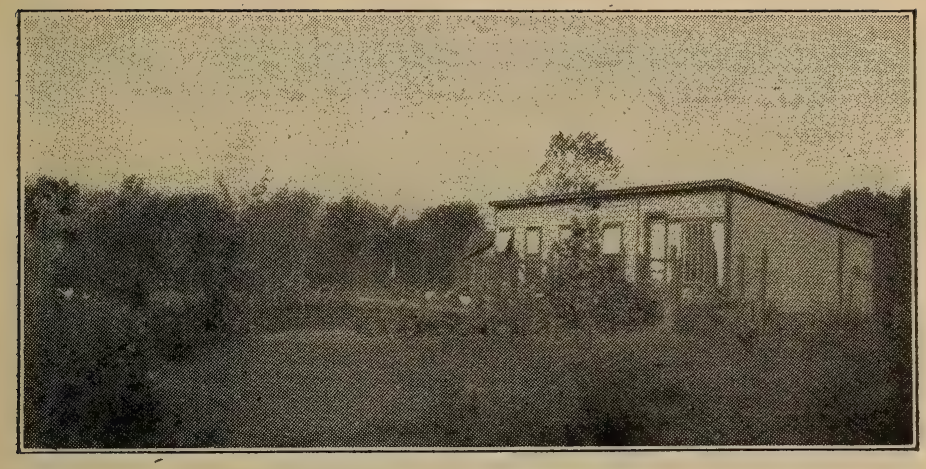

A Substantially Built Continuous House Which is Typical of the More Expensive Style of Construction.

Of these matters good drainage is the most important since dampness under or around the poultry house is a sure forerunner of unhealthful conditions. The orchard is especially well adapted for the purposes of a poultry yard because its trees furnish shade in summer, and in the winter, when the leaves have fallen, interpose but little obstruction to the rays of the sun which in that season are a valuable aid to the health and comfort of the egg producers. Also, the presence of the fowls is of much value to the trees which receive more nourishment from the better fertilized ground and suffer less from the attacks of worms, since the latter are consumed in great measure by the fowls.

Where it is a case of poultry yards first and orchards later, it is advisable to set out fruit trees of whatever variety does best in that location, in all of the yards which are permanently located and also on the land which is intended for use in rearing the young stock each season. The person who keeps poultry in thickly settled portions of a village, or on a city lot or part thereof, sometimes finds himself unable to secure any of these favorable conditions for his flock. Sometimes his location is so hemmed in by buildings that the sun strikes it only at noonday, and the shade obtained is only that furnished by the surrounding buildings and provided by structures erected for the purpose. In 
such locations much additional labor is required to produce good results from the fowls kept, but it is done time and time again and good egg records and satisfactory profits. are made.

\section{The Necessary Buildings.}

It is decidedly important that the house for the laying fowls provide certain conditions favorable to health and productiveness. The exact manner of providing these conditions is of less importance. An investigation of the houses on the plants of a dozen poultrymen who make the production of eggs the main object of their poultry business is likely to reveal the same number of different constructions. Yet these buildings may all serve the purpose with about equal efficiency. The main points to be considered are provision for reasonable warmth, proper ventilation and sufficient light. It makes little difference whether comfortable, healthful quarters are obtained by the use of one combination of building material, whether ventilation is provided by means of straw lofts or curtain fronts, or whether light is admitted through glass windows or cloth-filled apertures; that no method is entirely superior in all respects all experience proves.

If the amount of money invested is considered in figuring the profits, the houses should be built as simply and cheaply as is consistent with requirements. It is a fact that on most. successful poultry plants where the owner depends upon the profit for his support, as well as in many back-lot poultry houses, the lumber used is of the cheapest kind, covered and made tight with tar paper or some brand of prepared roofing and siding. Double-wall houses, that is, houses boarded up on the inside and outside of the frame and either packed tight with some sort of filling or made tight to serve as a dead air space, are rapidly going out of use. The single-board structure, covered on the outside with one or two thicknesses of prepared fabric manufactured for the purpose, and perhaps with lining added back of and above the roosts, are proving more satisfactory, even in the coldest parts of the United States and in Canada. It is a fact, usually easy to demonstrate, that a double- 
wall house contains an atmosphere with a perceptible chill during cold weather which is not found in a single-wall structure on the same plant.

\section{How Much Glass?}

A fault of the past has been the use of too much glass in the fronts or south sides of poultry houses; but people now appreciate the fact that glass will radiate heat one way

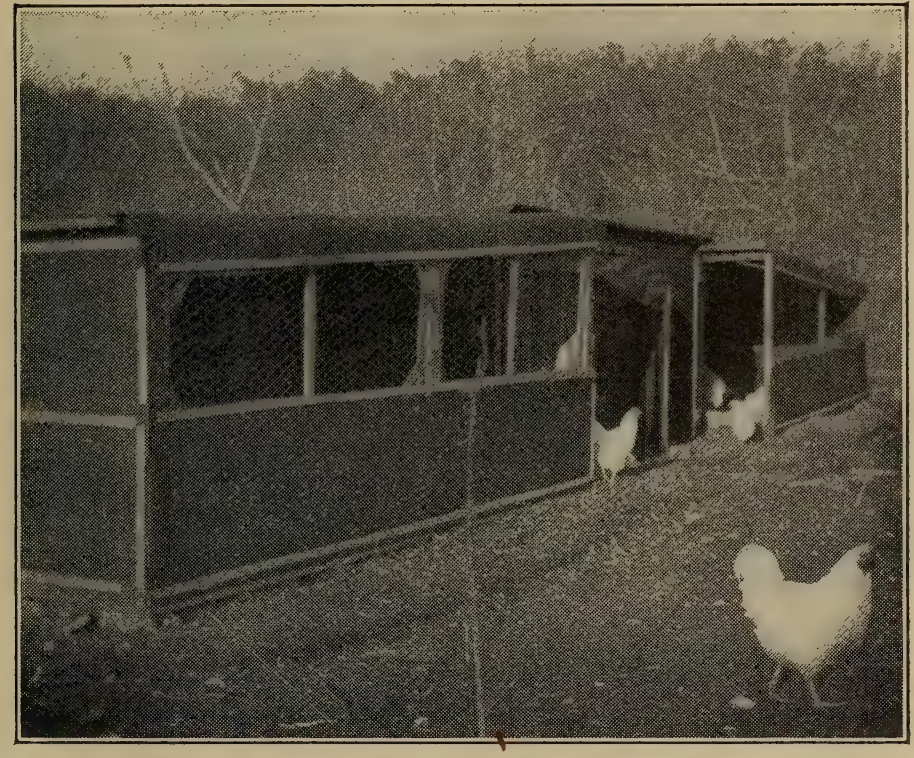

A Poultry House Consisting Only of Frame Covered with Tar Paper, with a Central and Warmer Roosting Pen.

as fast as another and a temperature of sixty degrees on a sunny day when the fowls are at work in the house scratching in the litter, followed by a temperature of some degrees below freezing the following night when the fowls are on the roost, is not at all conducive to good health or a profitable yield. A greater or less amount of ordinary cotton cloth is beginning to appear in the place of glass in poultry houses 
north and south, as the means of providing more fresh air for the fowls to breathe, thereby enriching their blood with the oxygen it contains and making them better able to resist cold. Some poultrymen have gone so far as to replace the entire south walls of their poultry houses with cloth, but the safer rule appears to be to divide the space that would ordinarily be occupied by glass in equal parts, filling one part with glass and one with cloth. In parts of the country where the thermometer records very low temperatures, additional protection is furnished on cold nights by a cloth curtain in front of the roosts. This com-

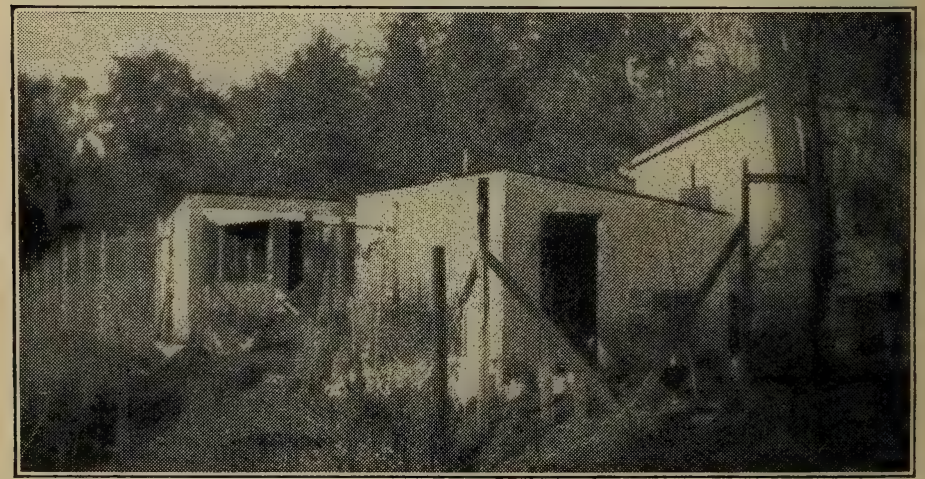

A Group of Coloný Houses on a Suburban Poultry Farm Where Fine Table Eggs are Produced.

bination of cloth in the south wall and the curtain in front of the roosts has proved satisfactory in Maine, Minnesota and Canada, as well as in states in warmer latitudes.

\section{Large Versus Small Houses.}

The question of large or small houses is an open one. Whether the colony system or the continuous house system is best for housing the laying stock depends considerably on the prevailing conditions of environment, the size of the business to be conducted and other factors too numerous to mention. 
There is no question that five hunderd layers can be cared for at less expense, especially in winter, if accommodated in a continuous house than if divided in small flocks and scattered over a large area in colony houses. On some large egg farms where no fences are used, the colony house plan is used because the owners believe that the flocks are more easily kept separate if the buildings are scattered widely. To the contrary of this may be mentioned one of the best known egg farms in the United States where no yards are used and practically all the fowls are accommo-

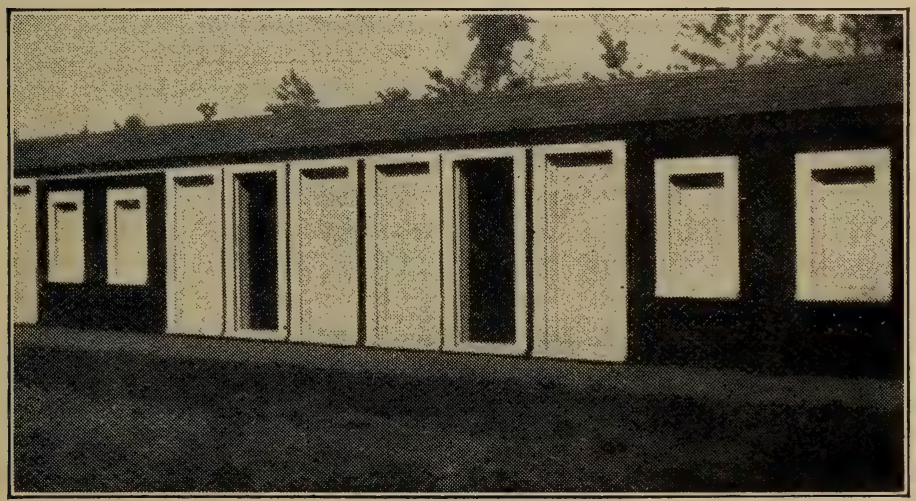

A Continuous House in Which the Windows of the Roosting Pens and the Fronts of the Scratching Pens are of Cloth.

dated in continuous houses, some of which are more than three hundred feet long. In general it may be said that if yards are to be used the long houses enable the caretaker to do the work in less time, therefore for less expense, but the flocks divided among colony houses are less likely to contract disease one from the other, provided a careless attendant allows disease to gain a foothold.

\section{Coops and Utensils.}

The successful egg farmer of today, whether he handles few or many fowls, raises his own stock each season. Where one hundred laying hens are wintered, we advise the use of 
incubators and brooders. If a less number are handled we doubt if their use is to be advised in a majority of cases. It may be urged that by the use of incubators and brooders, chicks may be hatched and reared early in the season when sitting hens cannot be obtained. But we must remember that in order to secure eggs when the price is high, in the early fall and winter, we must have early hatched fowls. These in turn will show a desire to incubate in the early spring-early enough to have the chicks hatched at the proper time. This, of course, does not apply in cases where the breed used is of the non-sitting class.

Brood coops are needed where hens do the rearing, and roosting coops are required whatever the method of hatching and caring for the little chicks. In addition to the houses, coops, incubators and brooders, very little in the way of equipment and utensils is necessary. Cookers for heating water and cooking food, troughs and shovels for mixing mashes, and pails for carrying the food to the houses complete the equipment, aside from that in the houses themselves which includes feeding troughs, dry food hoppers, grit and shell boxes, nests and water fountains. Shovels and hoes are required for caring for and cleaning the houses and a chest of tools is needed for making repairs, building coops and utensils.

\section{The Comparative Cost.}

With lumber and other building materials selling at the present high prices, with no prospect of lower prices in the future, it is, of course, impossible to construct a plant for egg production without considerable outlay; but from the cost of erecting barns and stables for horses and cows and the cost of erecting brooding houses, incubator cellars, etc., for broiler plants, it is evident that the cost of making a practical poultry plant where the production of eggs is to be the main feature is not by any means high. There is no one thing required for the business that is costly to purchase or construct and the chief expense of producing eggs is in the labor of caring for the fowls and the feed required. 


\section{SELECTING THE STOCK.}

\section{Strength, Vigor, Health and Increased Power of Production are More Important Than Any Particular Breed or Varie= \\ ty-Standard Bred Fowls are Best on Account of Greater Uniformity in Production and Product.}

\section{By H. A. Nourse.}

The question, "What fowls are the best layers?" is frequently asked and the answer varies considerably. If the reply is made by one who has bred a certain variety of the American class from which he has secured a good egg yield, he recommends that variety. A man who has bred Leghorns or Minorcas with the same result advises the inquirer to select a variety of those breeds. A breeder of Langshans or perhaps one who has secured a heavy yield from a flock of Light Brahmas will be equally solicitous that the would-be poultry keeper adopt Langshans or Brahmas, as the case may be.

The fact of the matter is this: the Langshans may produce more eggs for a certain breeder than a flock of Leghorns upon which he lavishes the same good care; again a flock of White Faced Black Spanish may outstrip all its competitors in a certain man's yards and be selected as the egg producer par excellence by that particular breeder. This is done with good reason; the fowls that produce the most eggs for the same amount of food and care are the most profitable fowls to keep, but the fact that one flock of a certain variety produced more eggs than a certain equal number of another variety of the same breed or a variety of another breed, is not positive proof that all fowls of the first mentioned variety will excel all fowls of the competing varieties. It is the breeding that makes the layer and not the breed or variety. Careful selection of the best layers and intelligent breeding of the same for several genera- 
tions, together with proper care and feeding, will build up a strain of heavy egg producers in any variety.

The fact that the Leghorn breed is regarded as typical of greater egg production is due largely to the fact that since its body is too small to be profitable for the production of meat, the tendency of its breeders has been to improve its usefulness for egg production. Its nervous, energetic disposition has made it a good forager and a constant exerciser, which in turn have given it stamina and health.

\section{Characteristics of the Heavy Layer.}

First of all, the productive hen must have strength and health. Without these she cannot stand the physical tax that accompanies the production of one hundred and fifty to two hundred eggs per annum. This strength and health come only as the legacy of vigorous ancestors.

Again, the heavy layer must be active and energetic; must be possessed of a considerable amount of nervous energy, the force that keeps her moving in almost a constant search for food, therefore preventing a sluggish circulation of blood and at the same time improving its quality by the added number of red corpuscles that are obtained from the oxygen of the air that is more rapidly drawn from the lungs. These attributes alone, however, will not produce an egg yield of over average number. The latter is obtained only from fowls which have been bred for heavy layers as we have before stated, and so fed and cared for that the strain of laying has not weakened their vitality, and which have transmitted to their offspring that activity of the organs of reproduction which make the two hundred egg hen possible.

\section{Standard=Bred Fowls are Best.}

The old idea that the mongrel hen was the healthiest hen and the best layer and that a mixture of different breeds was required for vigor is fast fading away. The properly handled standard-bred fowl is not only a better layer, but is capable of being handled by man in such a manner as to produce more uniform results.

Not only is it possible to secure a greater percentage of 
high-power producers from standard-bred stock, but the product itself is more uniform and therefore more salable and capable of returning a higher price in discriminating markets. The fact that some trials with standard breeds have proved unsatisfactory, either from lack of productiveness or lack of health and vitality, or both, is due to the fact that the particular strain from which the fowls sprung was bred with a view to producing certain color and shape characteristics without proper attention being given to the basic principles of breeding. The intelligent breeder looks well to the vitality of his stock, the careless or ignorant poultryman does not, and the latter is the worst enemy of standard-bred poultry.

\section{Consider the Market.}

There is, however, one consideration that may not be safely overlooked, and that is the color of the shell preferred in the market to which the prospective egg farmer desires to cater. In a majority of markets in the United States the discriminating trade is in favor of an egg with a dark brown shell, while in other markets, though they are less in number, an egg with a white shell is preferred. The finest trade will pay slightly more for the tint of shell that pleases; therefore, if the poultryman is to cater to the fine trade in New York City, a breed which produces white shelled eggs, for example Leghorns and Minorcas, should, perhaps, be given the preference, provided, of course, not much attention is to be given to producing poultry meat in connection with the egg business. Where a dark shell is preferred, Boston for example, varieties of the American or Asiatic classes, namely: Plymouth Rocks, Wyandottes, Rhode Island Reds, Langshans, Brahmas and Cochins, should be given the preference. But when every point is considered, the laying-bred fowl has the call rather than that of any particular breed or variety. 


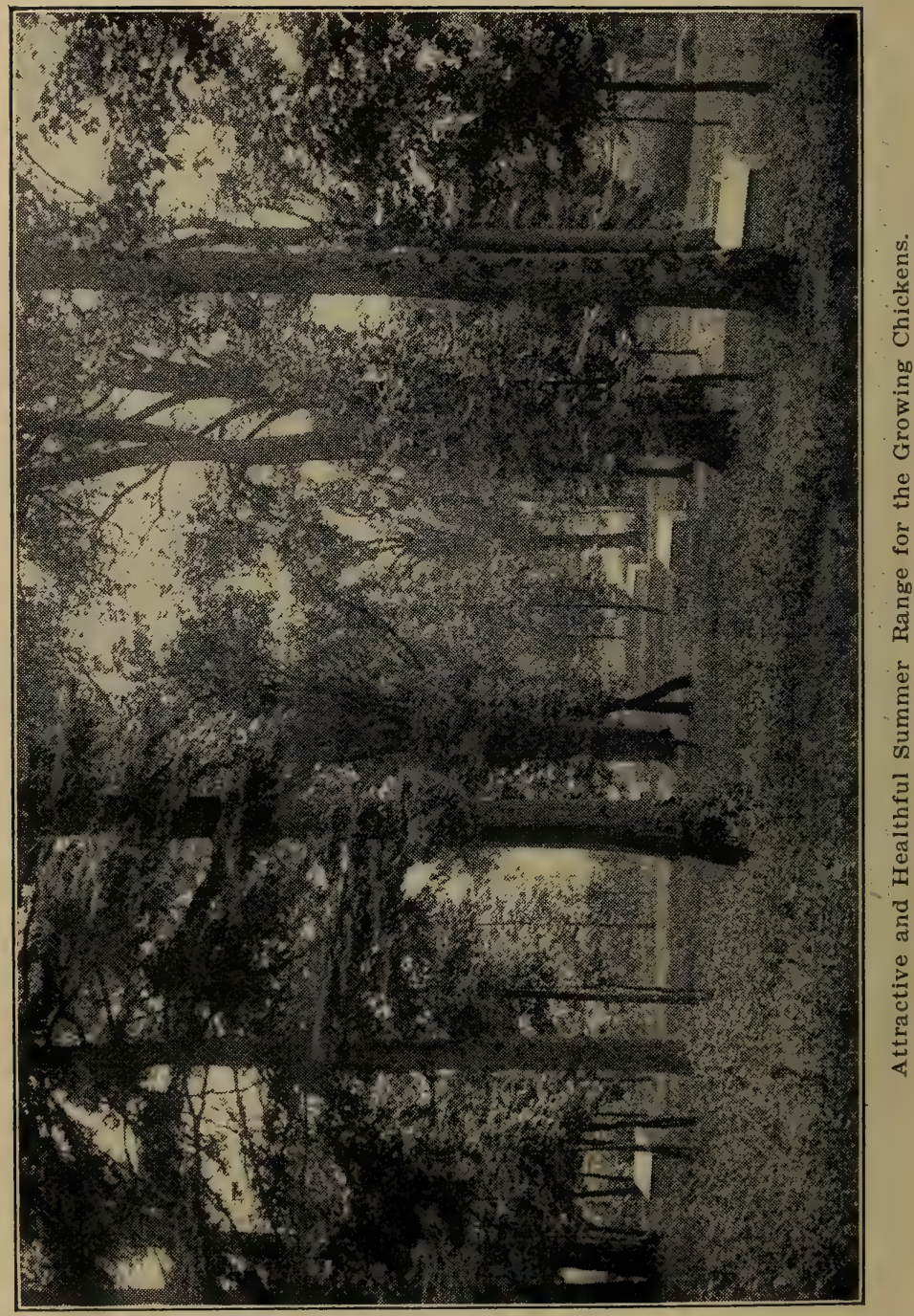




\section{HATCHING AND REARING.}

\section{The Importance of Adopting Methods of Hatching and Rearing Which Tend to Produce the Highest Degree of Vitality- Uniform Development at a Normal Rate is Better Than a Rapid Growth.}

\section{By H. A. Nourse.}

It is not our intention to go into the details of operating incubators, caring for sitting hens, operating brooders, etc., because definite instructions for all thesc things are more fitly the subject for another volume. There are, nevertheless, certain features in the hatching and rearing of chicks intended for the purposes of an egg farm which differ materially from those affecting the production of stock destined to the market. In the latter instance the business of the poultry keeper is to grow the youngsters to marketable age in the shortest possible time and to place upon their frames as much soft meat as possible, together with a reasonable amount of fat. Chicks started in life in this manner never possess the strength and stamina required for the best service as profit makers in other lines; they never recover from the effects of the unnatural conditions of the first weeks or months of their lives, whatever the environment, care and food may be later.

The future egg producer should make its entrance in the world and pass its early life under such conditions as promote perfectly normal growth, or the growth that nature intended it should make under the most favorable conditions. We have mentioned in previous chapters the necessity of strength in parent stock and the further necessity of so conserving that strength that it will be transmitted to the chick. A chick from such stock, properly incubated, begins life under favorable auspices and requires intelligent care only to develop within it the vitality of its parent.

Heavy feeding of overnutritious foods, too long con- 
finement in overheated brooder houses and lack of sufficient exercise in pure air have seldom produced a developed chick with the constitution and vigor required to make it a first rank egg producer.

\section{Conditions That Affect the Hatch.}

Oftentimes a lack of success in rearing the chicks is attributed to improper brooding or feeding when the real fault lies in the manner of incubating. When the hatching is done by healthy hens which perform their work faithfully, the chicks, as a rule, come from the shell strong and vigorous. This is due in large measure to the fact that the sitting hen is almost invariably surrounded by an atmosphere pretty near as pure as the outdoor air. This air, circulating constantly through her plumage, applies to the eggs that amount of oxygen which is highly important to a successful hatch. Incubators are frequently operated in cellars, rooms above ground or in especially constructed incubator houses, where fresh air is pretty nearly excluded in an endeavor to maintain a reasonably constant temperature, or, in the early season, a fair degree of warmth. However well an incubator may operate under such circumstances, it brings chicks out of the shell in no condition to take up the business of proper growth and development. A chick not well hatched is never a profit-maker.

\section{Healthful Brooding.}

Occasionally a hen avoids the best laid plans of her owner and makes a nest for herself in a brush pile in a secluded corner of the farm or perhaps under the floor of a poultry house, lays there a sitting of eggs and in due time brings off a flock of chicks. If she is not molested by her owner, by four footed enemies or by hawks or crows, in nine chances out of ten she will raise a large per cent of the chicks she takes from the nest, without brood coop or other apparatus of later day poultry keeping and ofttimes without any food from her owner's bins. Chicks so raised are almost invariably strong. Their growth is not so rapid as is possible under different conditions, but their development is thoroughly normal and of the kind that accompanies health and vigor. 
The reason for this is largely the exercise they take during the day in the open air and the freedom they enjoy from stuffy, poorly ventilated and perhaps overheated coops or brooders at night. If it were possible to reproduce these conditions, chicks in brooders or with hens in brood coops would be equally strong and fit for their life work. But in actual practice we find conditions much different in a majority of cases. We find brooders and brooder houses to which the pure air of nature is denied admittance or in which so much filth exists that the air is quickly contaminated and loses its power to sustain the chick; wo find chicks crowding at night in brooders and allowed to overheat by careless operators; we find hens with broods confined in coops which offer excellent protection from wind and rain but which are closed tightly at night, thereby preventing proper ventilation and in summer time raising the temperature to a high degree. Reverse these conditions and we approach the conditions afforded by the hen of the stolen nest which reared her brood in the open air and produced chicks with strong constitutions.

\section{Foods and Feeding.}

The manner of feeding and caring for the chicks has fully as much to do with their growth and development as the exact make-up of the ration. A scientific feeder can figure out on paper a perfectly balanced ration containing exactly the right proportion of protein and carbohydrates, together with mineral matter, or ash, for the bony structure of the bird. This ration may be fed at regular intervals and yet fail to produce proper growth, or indeed to prevent a high death rate. The failure of such a ration to produce good results is not the fault of the chemist that compounded it or the ration itself, but is because the conditions surrounding the chicks are such that they cannot make proper use of it after they consume it.

Good food is useful only when it is properly assimilated and becomes a part of the blood, flesh and bone of the living body and this assimilation is possible only when the digestive organs are healthy. A well-ordered digestive apparatus in such cases depends almost solely upon the proper warmth, 
sufficient exercise and an abundance of pure air for the chick. That is why the chick brought up by the mother hen on the range seldom has digestive troubles.

Formerly the poultry keeper mixed various mashes with milk or water, or baked a johnny cake of corn meal and bran, for the broods during their younger days. In late years this method of feeding has given way to the use of prepared chick foods which are made of various grains and seeds, with some meat food added, and which are fed dry. These foods produce excellent results and this manner of feeding appears to be nearer nature.

When the chicks are weaned, that is, when they graduate from the care of the mother hen or are separated from the brooder, they begin their real period of growth and development and require larger quarters and more extensive range, The poultry keeper who can scatter his weaned broods in flocks of twenty-five, in colony houses, and allow them to run over the broad acres of a farm is fortunate, for under. such conditions the chicks attain that development which is. required for best results and do it at the lowest cost for food and care.

He who must keep his chicks within yards must see to it that these yards are clean and that special inducements to. exercise are furnished the youngsters. In most cases this. must be done by feeding them the grain part of their bill of fare in a deep litter from which they must scratch it out. To sum up, the factors absolutely necessary for the production of the profit makers are: correct incubation, correct brooding, correct feeding and a clean, healthful environment. from the time of exclusion from the shell.

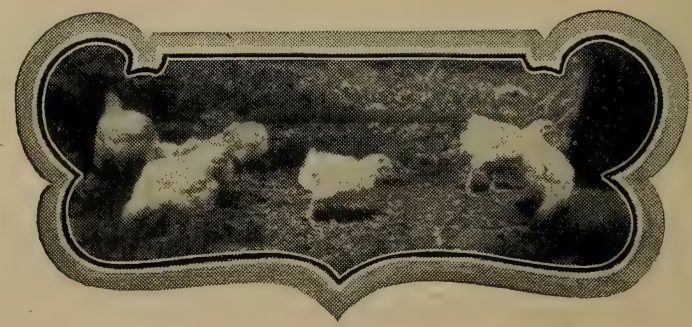




\section{REARING HEAVY LAYERS.}

\section{Methods of Selecting the Eggs and Hatching and Rearing the Record Layers-Feeding for Eggs- Improving the Flock.}

\section{By L. B. Rich.}

Have your chickens laid well during the winter? If not, now is the time to figure on raising stock that will lay next winter. It takes no more time nor does it cost any more money to raise winter layers than it does those that lay only in spring and summer.

Select some standard breed, one that you like, and then stick to it. You will find the varieties of the American class, Wyandottes, Rocks, or Rhode Island Reds, to be good money makers.

Like begets like-so don't expect a hen that lays only in the spring and summer to breed daughters that will be winter layers, for she won't do it. Make certain of one thing first, that the eggs you incubate in spring came from hens that as pullets laid in the winter and you will have made a good beginning towards obtaining winter eggs.

\section{Hatch in April.}

Hatch your chicks during April and up to May 15th. You will find an incubator is the best investment you can make to accomplish this. When the chicks are hatched; don't crowd them into a small stuffy brooder to suffocate for want of fresh air; build a colony house $6 \times 10$ feet in size, 5 feet high in the back and 7 feet in front; put an indoor brooder in it and you have an outfit that will pay for itself with every hatch.

\section{Feeding the Chicks.}

Cover the floor of the house with chaff from under the hay loft. Scatter dry chick food-wheat, cracked corn, 
millet, sorghum seed or any small grains in this litter and let them scratch it out. There are lots of days in April that you can't let the chicks out in the wet; on those days cut pieces of sod two or three feet square and put one in each colony house for the chicks to work on.

At the start get a roll of two foot poultry wire and make a small yard in front of the colony house; enlarge this yard as the chicks grow and when they are six weeks old remove it entirely. The chicks will hustle all day and return to the house at night. When the chicks are six weeks old, feed oats, whole oats, hulls and all. If they don't take to them, starve them to it. Oats is one of the best foods on the farm for poultry.

\section{Market the Cockerels Early.}

As soon as the cockerels weigh two pounds each, ship them to market and give the pullets their room. Keep plenty of clean straw for the chicks to sleep on; don't let

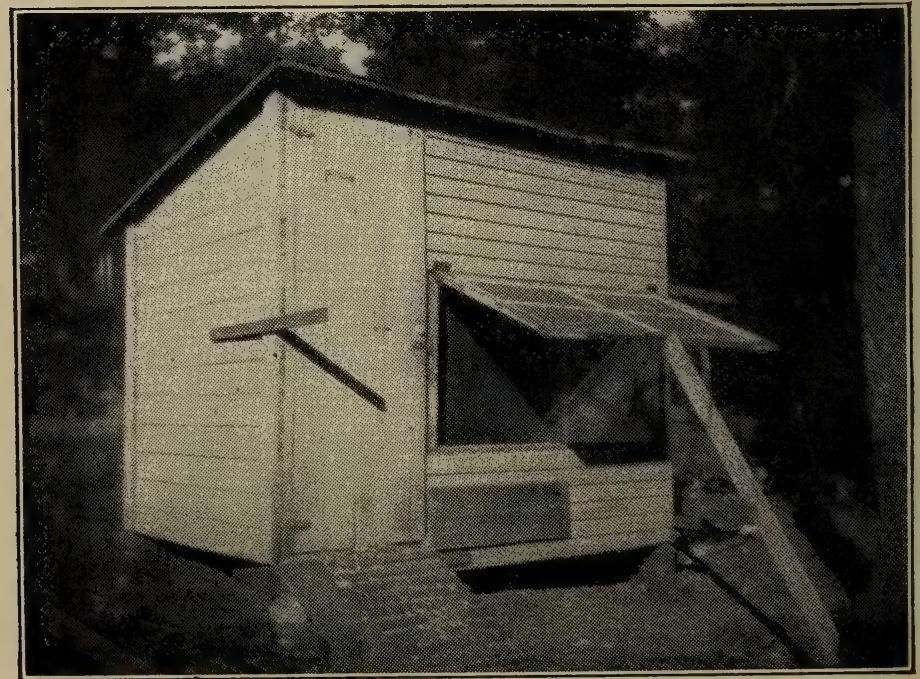

One of the Colony Poultry Houses Designed by L. B. Rich, Described in his Article, "Rearing Heavy Layers." 


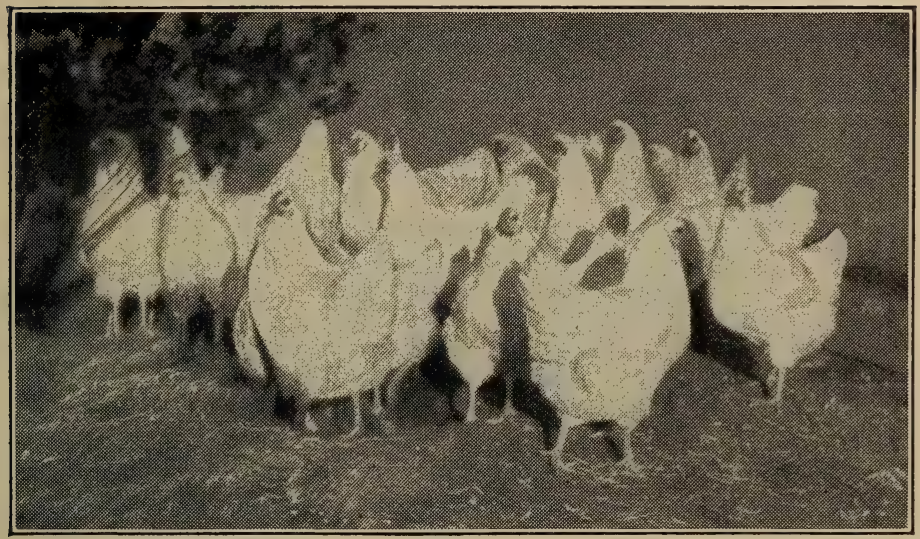

A Group of Early Laying Pullets which were Reared in the Manner Described by L. B. Rich.

them go on to a roost before they are four or five months old. Let them hustle on the farm all day and fill them full of grain at night. Keep them growing every day and when they are six months old, they should be talking about laying and then is your time to do some fine work.

People used to think that if they gave the chicks summer conditions in the winter, they would get winter eggs and the only condition they thought of was heat. Now, as a matter of fact, heat cuts but a very small figure in the production of winter eggs. Fresh, dry air and proper feed and care are of much more importance.

\section{Feeding for Eggs.}

All summer the chicks have had all the green grass and clover they wanted, with bugs galore, for animal food, and they must have this same material in some form during the winter to produce the eggs. Early in the fall fix a box or hopper to contain dry bran and beef scraps, mixed half and half by measure, where they can get all they want. Throw some clover hay to them, or, better, fix a rack to hold it and keep the rack full; they will eat all but the wood. Drive some nails into the sides of your pens, and each day jab some rabbage, mangels, beets or 
any roots you can get on them and watch the hens eat. Keep plenty of straw on the floors for them to work in and scatter all the grain they will eat in the straw and let them work it out. Wheat, oats, barley, corn and speltz are all good grains to feed; give them a variety and don't be afraid of overfeeding if they have to work for it. Above all, don't be afraid to give them plenty of fresh air.

\section{To Improve the Flock.}

In the fall, as the pullets begin laying, you will find some six weeks difference between the time the first one starts and the last one from the same hatch. Leg-band those first layers and the next year breed from them. Follow this up and in a few years you will have a strain of fowls that you can be assured will lay in the fall and winter. Don't get the idea that if they lay in winter they won't lay in the spring, for you will find that the hen that lays the most eggs in the winter will also lay the most during March, April and May.

Eggs in winter depend on breeding, raising, feeding, and housing. You can make a straw shed, muslin the front, and get just as many eggs as though you had a $\$ 1,000.00$ hen house.

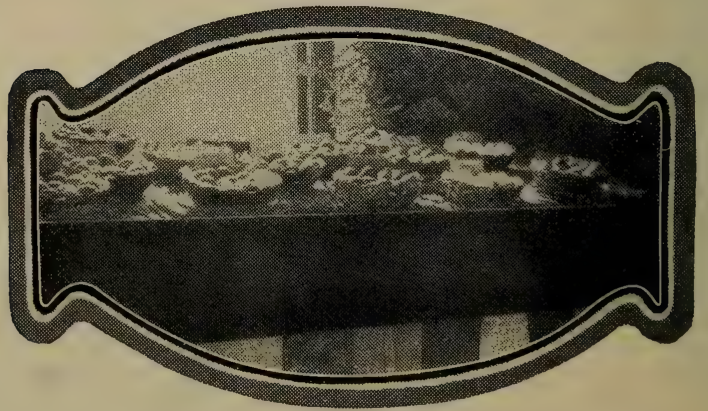




\section{CARE OF THE FUTURE LAYERS.}

\section{A Description of the Care and Foods Required to Produce}

Rapid and Uniform Development in the Prospective Egg

Producers-the Value of Range and Fresh Airthe Preferred Styles of Roosting Coops-the

Foods to Feed-Changing to Winter Quarters.

\section{By H. A. Nourse.}

It is generally conceded that the best egg yields can be secured from pullets and the problem of caring for them, in order to produce early and continued laying, is an important one. The highest prices for this product are obtained during the fall and early winter, and the poultryman's income is increased or diminished in many cases by the number of eggs he secures in November, December and January. While foods play an important part in the development of the pullets, the environment and roosting accommodations are deserving of more than passing notice.

\section{The Proper Environment.}

Although very good pullets can be raised in limited quarters, free range is desirable, both because it is conducive to healthy, vigorous growth and because it reduces appreciably the labor of caring for the flock. Up to the time when the ground freezes, the birds can find considerable nourishment, both animal and vegetable, which acceptably fills the place of much that must otherwise be bought and paid for. Bugs and worms, together with dry berries and green vegetable growths fill a want that cannot be as well supplied by the feeder.

Exercise plays an important part in the well-being of . all poultry and the growing stock in particular. Any de- 
vice or method intended to promote exercise in flocks confined in yards is not nearly so effective as the opportunity to run free over the broad acres of the farm, or a tract of considerable area on the plant of limited acreage. It is the vigorous pullet that lays the eggs and the exercising pullet is the most vigorous.

\section{Healthful Accommodations.}

In most latitudes where the poultry business is successfully carried on, the weather continues comfortable during the month of October and the maturing pullets are better off in the fields, with roosting coops in which to find shelter and protection at night, than they are in the permanent houses and yards. Fresh air is as necessary during the night as it is in the daytime, and coops so constructed as to admit plenty of it, and at the same time protect the flock from drafts, are to be desired. The writer prefers coops about $3 \times 6$ feet on the ground, 3 feet high at the rear and 5 feet in front. These require but little framing and may be covered with tongued and grooved lumber with the roofs covered with some waterproof fabric to keep them dry. The north side and both ends should be tightly boarded; but the south side may be covered with three-inch slats, placed two inches apart. If there is danger from animals, the front may be covered with inch mesh wire netting outside the slats or the slats may be dispensed with entirely and the wire supported by an occasional upright. Each coop should be provided with a door of convenient size which will be most convenient if placed in the center of the front. The door should not be solid, but made in the same manner as the remainder of the front side.

As cold weather approaches and the nights become chilly, a curtain of light cotton cloth, or of burlap, may be rigged to cover the front of the coop when necessary to protect the inmates from cold winds or from storms.

\section{Crowding is Dangerous.}

One of the principal dangers to flocks of maturing chicks is from crowding. Frequently the broods are allowed to remain in the small coops in which they were 
placed when hatched until they are removed to winter quarters. Crowding into these coops at night, they become overheated and lose more strength during the hours when they are supposed to rest than they gain in the daytime. Food furnished a flock so housed produces but

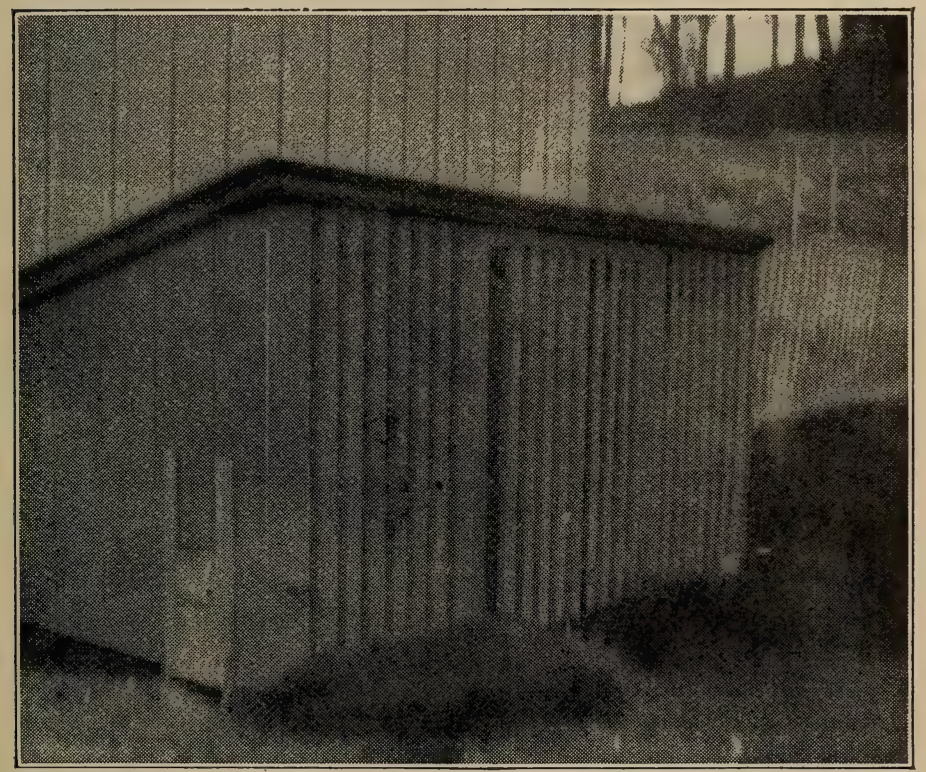

A Slat Front Roosting Coop with a Door in the Middle of the Front, Recommended as Summer Quarters for Growing Pullets.

indifferent results and the birds would be far healthier were they allowed to roost in trees.

We not infrequently find a large flock crowded into a roosting coop which is tightly built and of which the doors and windows, either from a mistaken idea of the protection required against the elements or in order to make them safe against intrusions of animals, are tightly shut every night. Before the youngsters have been confined in such a place half an hour, the air within is wholly unfit 
to breathe and its condition in the morning is best described as filthy. On opening such a coop to liberate the chicks in the morning, it will be noticed that the confined air is heated almost to the suffocating point and laden with impurities. The result of such housing is lowered vitality, accompanied by colds and a strong tendency toward roup. To expect paying results from such flocks is scarcely reasonable. It pays to furnish healthful conditions.

We believe it is the opinion of most poultrymen who depend upon the production of market eggs for all, or a substantial part, of their income that the sooner after November first the developed and nearly developed pullets are placed in the quarters that they will occupy during the winter, the better will be the results obtained. The writer's experience is closely in line with the above, except with respect to localities where the weather continues warm and the pullets have to be confined to the houses, or houses and small yards, if placed in winter quarters. In latitudes where the ground freezes, cold winds blow, hard rains are probable and snow possible, November first is not too early to move the profit makers from the coops to permanent houses.

\section{Housing the Egg Producers.}

The main reasons for putting the pullets in their winter quarters are: to accustom them to the new environment before the majority of them begin laying in order that egg production need not be interrupted by the excitement incident to a change later; to better provide shelter from severe weather; and to furnish more room per bird, under cover, where each can obtain more exercise and have a better chance to receive food and water, during stormy days when they must be confined to the buildings.

To take pullets from free range and place them in quarters where they must limit their wanderings to small yards is too great a change, a fact that will be apparent to any poultryman who will observe a flock carefully when such a change is made. The change of ration from that containing much of nature's food, found in the flelds, to one wholly prepared by the most careful and intelligent feeder, affects the digestion more or less. 
For these reasons the pullets should be given their liberty, after they are accustomed to the houses, every day when the weather is fair, unless the ground is covered with snow. Mere cold will not hurt them, if the ground is bare, for if accustomed to the houses they will seek shelter in them if uncomfortable outside. If not "house-broken" it may be necessary to call or drive them in if the temperature falls suddenly or a storm comes up.

Very likely the weather will be such that the pullets can have free range, with comfort to themselves and satisfaction to their owners, two-thirds of the days before December first.

\section{Do Not Close the Houses.}

Too many make the mistake of closing their houses at night when the pullets are introduced, and a few fail to open the windows and doors during the day.

There are two things which are essential to the success of any method intended for the prevention of colds-they are, freedom from drafts and a plentiful supply of fresh, pure air. A supply of good air can be obtained without danger from drafts if the north side, ends and roof of the house are tightly built and fresh air is admitted through the south side. In buildings that are narrower than they should be for economy or convenience, a strong south wind may occasionally blow against the fowls on the roosts, or storms may beat in through open windows. Either will cause trouble but may be prevented by placing a frame, filled with light cotton cloth or burlap, in the spaces made by opening the windows. Air will pass through this material, but drafts will not.

\section{Ventilate Freely.}

Roosts which are not located at the back of the pen, or farthest from the windows, are not in the right place and should be changed. Close the doors at night and leave the windows open more or less according to the weather, but be sure that the minimum of open space is sufficient to make the house practically odorless. During the bright days throw windows and doors wide open; let in all the 
fresh air and sunlight possible, for they are great purifiers and cost nothing.

\section{Foods and Feeding.}

If the pullets are out in the fields every day when the weather permits, feeding is a simple problem. But if they must be confined in houses an effort must be made to supply that part of their food which they would obtain in the fields, if allowed their liberty, and to supply it in a similar form so far as possible.

For flocks enjoying free range, a liberal supply of the principal grains, with fresh water daily, is all that is required. Corn, wheat, and oats fed alternately, one in the morning, one at mid-day, and one toward evening, will produce good results if a dish of beef scraps is constantly in reach of the flock from which they can secure what animal food they need to bring that obtained by foraging up to the requirements of their systems.

Some breeders prefer to feed a damp mash at least once each day. The writer is inclined to favor feeding this mixture in the morning and has found that two parts of cornmeal, three of bran and sufficient beef scraps to make 10 per cent of the mash is a simple and effective combination. If milk can be obtained to mix this mash it is more palatable and produces better results. When mash is fed the dish of beef scraps mentioned above, may be dispensed with, but meat must be provided in some manner if the best

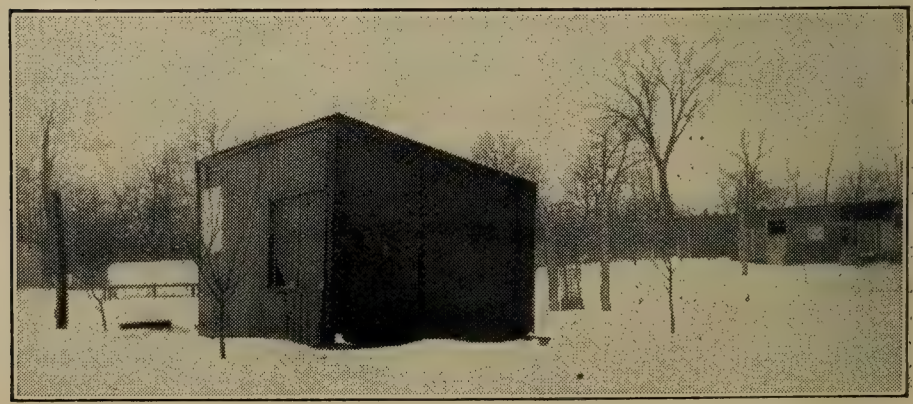

A Colony House for Winter Layers which has a Glass Window, also a Cloth-Filled Aperture to Provide Ventilation. 


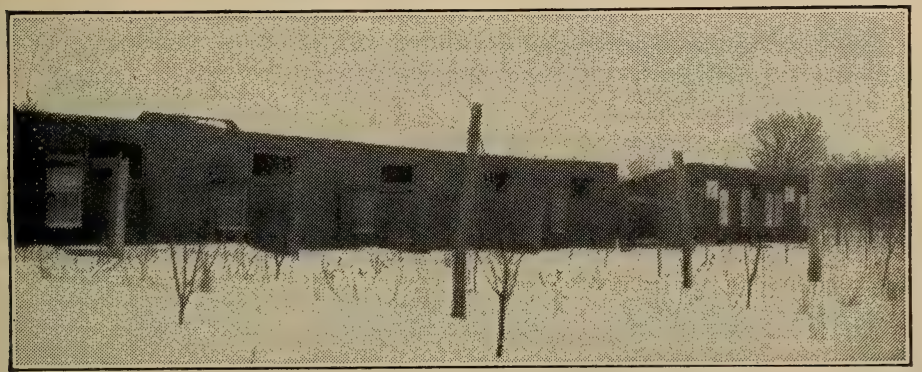

Continuous Houses for Laying Hens, with Part of the Window Space Occupied by Glass and Part by Cloth-Filled Frames.

growth and development are expected.' During the past few years food hoppers have come into quite general use. These are so arranged that dry grains, beef scraps, etc., are held in a sort of reservoir and fed into small troughs at its base as fast as eaten by the chicks. These hoppers are filled whenever empty and are constantly where the chicks can reach them. This method of feeding reduces considerably the time required to care for a large flock and in most cases produces as good or better results than the time-honored three meals a day. Whole and cracked grain of different varieties may be placed in different compartments, or in different hoppers, or may be mixed and fed in one compartment. As a rule the chicks will waste less if it is fed in different compartments for they are less likely to throw out grain that they do not want while searching for that which their appetite demands.

Some poultrymen prefer to feed what they call a dry mash in one compartment of their hoppers; that is, they mix the ground grains and whatever they would use in their damp mash and place it dry in the hoppers. These hoppers are easily constructed by the poultrymen or may be obtained of most dealers in poultry supplies.

These hoppers must be placed in the houses where the pullets can reach the food when bad weather keeps them indoors. It will serve as an inducement for them to return to the buildings at evening.

\section{Provide for the Overflow.}

It not infrequently happens that the poultryman finds 
himself without permanent accommodations sufficient to shelter his entire flock, and is obliged to keep the younger ones in coops until he can so reduce his stock that all may be placed in winter quarters.

The open front coops that are desirable in the fall will not be suitable for use in November in the northern states and Canada. But they can be made suitable by providing each with a temporary front of boards, in which there is a window and a door. Some breeders have colony coops built for this purpose which are, in effect, little houses. They are tightly built and have doors for attendant and fowls, and windows capable of being adjusted for ventilating purposes. One of these coops, three feet wide and six long, equipped with roosts, will accommodate twenty young pullets so long as the weather will permit them to be out half of the time. A dozen may be kept in such a coop well into winter, if necessity compels it, without experiencing much hardship.

These coops are very useful in the spring as quarters for hens with early broods of chicks for which small coops would not be sufficient protection.

Ask a novice in the business of producing market eggs, how a flock should be handled to produce the greatest number in the most profitable season and he will at once think of feeding as the only important feature in the production of this well paying commodity. While there can be no success without proper feeding, it is equally true that, however well-fed a flock may be, it will not produce eggs in paying quantities in the season of high prices unless conditions are reasonably favorable. The environment and general care also have considerable bearing upon the amount of food consumed and therefore affect the profits at two points. Exercise, fresh air, cleanliness, all contribute to the poultryman's success in this work.

\section{Warm Versus Cold Houses.}

It is seldom that anyone advises the use of artificial heat in poultry houses, but some poultrymen strive to build houses which the cold will not penetrate, by building double walls, some solid and some with packing between, hy using double windows, and by stopping every crack and crevice. 
Others are firm in their belief and outspoken in their assertions that houses tightly built on three sides of one thickness of lumber, with perhaps a thickness of paper added, and with fronts in which a large area of muslin takes the place of the area of glass usually provided, are more comfortable for the fowls and therefore productive of more satisfactory results.

The writer's experience with tightly built, double walled houses has been far from satisfactory. One of the best buildings of the kind ever built was tightly boarded inside and outside of the joists, with a four-inch air space between, and was, the winter through, far less comfortable than houses on the same plant which were single boarded, the boards being covered with a roofing material manufactured for the purpose. In a tightly built house without perfect ventilation dampness will collect, rendering the house far less comfortable for the fowls.

There is no question but that the best ventilation is secured in houses in which the place of glass windows is taken by cloth filled frames. Pure air is admitted freely through the cloth and foul air escapes as easily, but drafts are cut off. A poultry house constructed of tongued and grooved lumber, which is in turn tightly covered with a good quality of roofing fabric, will be comfortable and healthful in almost any climate if the area of glass in the front side is not greater than it should be, and if, in addition, there is a small area in the front of each pen filled with heavy cotton cloth. The glass will admit the sun's rays and the cloth will cut off the drafts but admit plenty of fresh air.

\section{The Value of Exercise.}

The majority of poultrymen, of which number the writer is one, believe thoroughly in the value of vigorous exercise during the winter when fowls must be confined for a greater portion of the time to the houses. On bright days it is an excellent practice to shovel away the snow, if there is snow, from in front of the houses so that the fowls can get out in the middle of the day.

Some breeders who have not many fowls to care for put 
straw or other material out in the open air, even when that area is surrounded by snow, and induce the hens to scratch by scattering a little grain in the scratching material. But the poultryman whose time is taken from before daybreak until after dark, seldom does anything of that kind. His fowls must take their exercise indoors and he therefore covers the floor of each pen thick with hay, straw, leaves or other material and buries all whole and cracked grain therein, compelling his fowls to scratch it out.

Exercise loses half its value when not performed in fresh, pure air. On that account the windows should be open, more or less according to the temperature, while the fowls are at work. On bright days they may be thrown wide open, no matter how low the temperature is, for the fowls are far less susceptible to cold, if healthy, when working than they are to the sudden change which follows if they become overheated. In such cases they invariably take cold when inactive. It will not do to close the houses tightly when the first severe weather arrives. Provide plenty of ventilation to keep the air reasonably pure within the building or colds are likely to result and roup is probable.

\section{Green Food Essential.}

It should be remembered that the foods fed in winter are largely preserved; that is, they have been dried or cured so that they will keep and they are to that extent artificial and alone will not keep the fowls in the best condition. Green food must be furnished in liberal quantities and must be of reasonably good quality.

The orthodox method of furnishing green food is to supply plenty of second quality cabbage. While no fault can be found with this vegetable for the purpose, there are others that are as effective and which may be used to advantage by way of variety, for most any vegetable, which keeps well in winter, may be fed raw to the fowls if they will eat it with relish. Owners of orchards, who also keep poultry, frequently store away several barrels of small, but sound, apples to feed to their fowls during the winter. Probably nothing equals mangel-wurzel beets for this purpose; they 
not only furnish a succulent and appetizing substance, but are much stronger in food values than the other green foods. They are heavy yielders and excellent keepers. When visiting a plant in Indiana recently in the month of October, the writer was shown some mangel-wurzels which had been stored in a root house twelve months and were still in excellent condition for feeding.

\section{The Utility of Meat Foods.}

It is generally accepted as a fact that meat in some form must be furnished if the best results in winter eggs are ex-

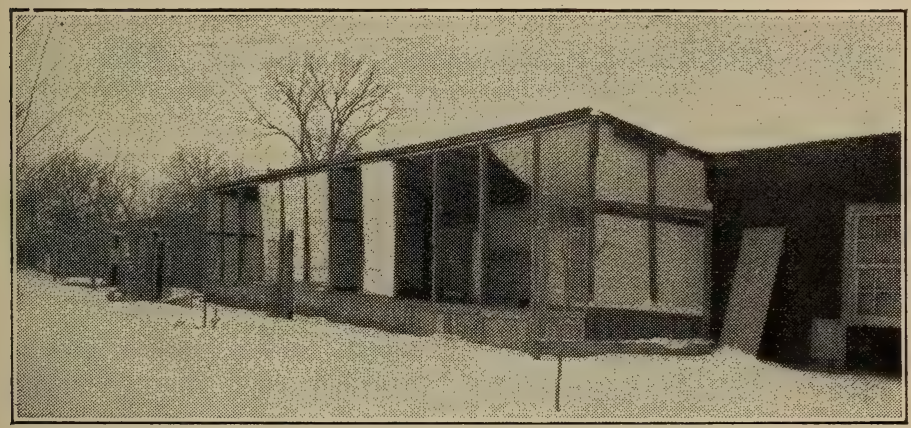

A Temporary Scratching Shed Built in Front of an Ordinary Laying House of the Continuous Type.

pected. For this purpose ground fresh bone easily holds first place in the estimation of the majority of poultry keepers. Such material can be purchased from butchers at a price ranging from a cent to one and one half cents a pound. Sufficient meat usually clings to these bones so that when ground it makes a food that is efficient and not too expensive. Numerous mills are manufactured for grinding these bones. These mills have been so perfected that the grinding of sufficient bone to feed one hundred hens three times a week is but the work of a few minutes and requires no great muscular exertion.

Those who cannot obtain fresh bone in sufficient quantities or who for any reason do not have time to prepare it, 
find in the prepared beef scraps, sold by dealers in poultry supplies, a very satisfactory substitute. They may be bought in any quantity, will keep indefinitely in a dry place, and are convenient to handle and to feed. Owners of small flocks containing a dozen to thirty birds often find the meat scraps left from their tables and kitchens sufficient to furnish all the meat required by their fowls.

\section{Kind and Quantity of Foods.}

No rules for feeding fowls can be formulated which apply in different cases with equal success. One poultryman having had excellent success when feeding certain foods will sometimes decide that he has discovered the true secret of success and will publish his manner of feeding. Those who read and repeat his method fail to secure as good results. That is due to different environment, care, etc.

Two men living in the same neighborhood, handling the same varieties of fowls and using the same methods of housing and caring for their flocks will use different methods of feeding, yet one will have as good success as the other.

There are, however, certain grains and combinations of grains which are necessary to produce good results under any and all conditions. The principal grains fed are corn, wheat, oats and barley and they in their various combinations are sufficient to produce a good yield of eggs, if the green food, meat, etc., are furnished and if the fowls are properly cared for. Variety, although necessary, is usually secured by alternating these grains, though additionl varieties are fed at times in limited quantities, with good results. It is evident that less of the damp mash mixtures made from ground grains are being fed as time goes on. The tendency is to furnish most of the grain ration dry and whole or cracked, in order that it may be fed in a deep litter to promote exercise.

It is also claimed by those in position to know that too much feeding of damp mashes impairs digestion. The majority of successful poultrymen may be divided into two classes as regards their manner of feeding: one class feeds dry food entirely and the other a combination of dry and 
mash food. Of the first the greater number perhaps place their beef scraps and dry bran in hoppers where the fowls constantly have access to it and bury the remainder of the food, which is whole and cracked grains, in the litter.

Of those who still cling to the use of mash, part feed it in the morning and part feed it at night. A few believe that mašh should be cool when fed and others desire to feed it warm.

The best results, from the writer's experience, have been obtained by the use of a judicious combination of the two methods. Whole and cracked grain are fed in the litter in the morning, as soon as the fowls leave their roosts. Corn, wheat and oats, furnished alternately, with an occasional feed of barley is used for this purpose. At noon on very cold days, more grain is buried in the scratching material in order that the fowls may have more opportunity to exercise and hasten the circulation of their blood, thereby protecting them to some extent against cold. If ground green bone is fed, noon is the time to feed it. At night a mash made up of two parts corn meal, three parts bran, one and one half parts steamed green cured clover, and beef scraps added to make ten per cent of the whole, mixed with water or milk, has always produced satisfactory results. For the vegetable part of this mash, cooked and mashed potatoes, beets, carrots, turnips or any combination of these varieties is desirable and may be used at very slight expense.

We are frequently asked about the quantity of food needed by each fowl. This question can never be definitely answered because fowls of the same breed, in the same pen, will consume different amounts, and two pens of the same variety, kept under apparently the same conditions, will require different amounts of food at different times. It is a safe rule to feed in the litter no more grain than the fowls are willing to scratch hard to obtain and to feed no more mash food in the troughs than will be quickly consumed. Clean water should always be provided and in such a manner that the fowls cannot scratch dirt into it. Grit, shells, and charcoal should always be accessible. 


\section{FROM FALL TO WINTER QUARTERS.}

\section{Sound Advice On the Care of Fowls at the Beginning of Cold Weather-The Advantage of Fresh Air . -Foods Which Must Be Furnished.}

\section{By L.. B. Rich.}

November is the month when many people, with the best of intentions, use such methods in caring for their fowls that they put them in such condition that they will lay hardly an egg all winter.

Until this time the birds have been ronsting in open front colony houses, trees, old sheds, and in fact almost everywhere on the place. Don't now put them in a tight, warm house, with windows closed and no chance for fresh air to get in. Of course you must put them into the house, but remove the windows entirely, (if you are so unfortunate as to have any) and leave them off until the thermometer records zero weather. Don't be afraid they will freeze. What do you suppose they have been putting on all those new feathers for? Not for looks alone surely, but for protection against cold; and after nature has provided a good warm coat.for your birds, don't make it uncomfortable and unhealthy for them to wear it.

Just keep your think-tank working, and you will soon know the folly of using tight, warm houses.

\section{Muslin Windows for Zero Weather.}

When zero arrives stretch common muslin in the openings where you had windows. Put it on frames and hang the frames so that they will swing in and up. On bright, sunny days, no matter how cold it is, swing them up and let the sunlight shine directly into the house. It will purify the litter and the birds enjoy it.

I can hear you say, "that won't do for my Leghorns." That's where you are wrong. A breeder at Duluth, Minn., has wintered his Leghorns in a house with muslin windows for three years, with excellent results. 
During the summer and fall the forls have had all the clover, grass and bugs they wanted. Now if you do not supply them, just as soon as they are penned up, with green stuff and animal food, in some form, don't look for eggs.

\section{Feed Green Food and Meat.}

Build a small rack, like those farmers feed sheep in, and fill it with clover hay; the fowls will eat everything but the woody stalks. The possession of a clover cutter is an advantage, but one can do without it. Once a week a feed of chopped onions will do worlds of good.

Animal food can be supplied in the form of skim-milk, if you have it; if not, get some prepared beef scraps from any of the supply houses and keep it before your birds all the time. One hundred hens will eat one hundred pounds of good scraps in thirty days. Keep also a box of dry bran where the fowls can always reach it.

Feed as many kinds of grain as you can get but feed it in deep litter, so the hens will have to scratch for it. Do all these things and you will get winter eggs if your stock has the winter laying ability in them, but do not expect a hen that has laid only in spring and summer to produce daughters that will lay in winter, for they won't do it

\section{How to Provide Exercise.}

When the fowls are out in the fields, or in large yards, they obtain sufficient exercise; but when snow, or extreme cold, makes it necessary to shut them in houses, some means of exercising must be furnished or the health of the birds will suffer.

The best way to compel exercise is to cover the floors of the houses with cheap hay, straw, leaves, hay chaff, corn husks, or any material in which hard grain can be buried and from which the fowls can scratch it out.

If a moderate amount of grain is fed at each meal the flock will work vigorously several hours each day and their productiveness will increase considerably.

Be sure that the windows are open so that plenty of fresh air is admitted while the hens are at work. Don't be afraid that the fowls will take cold while exercising. 


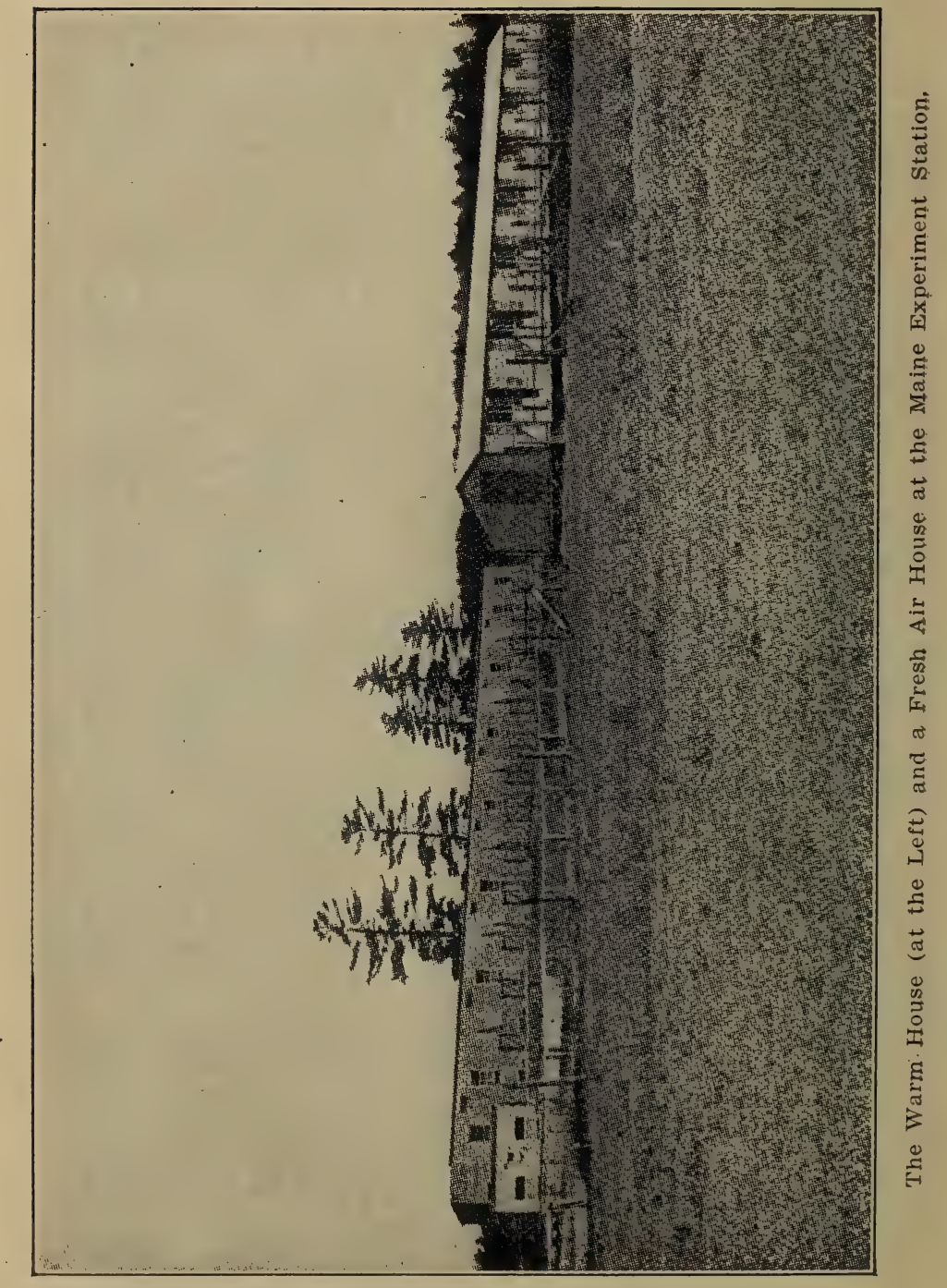




\section{HOUSES FOR LAYING HENS.}

\section{A Description of the Equipment in Use at the Maine Ex= periment Station-The Good Qualities and Defects \\ Brought to Light by Experiments-How a Satisfactory Building for Layers Was Finally Constructed.}

\section{By G. M. Gowell.}

Two styles of houses are in use at the Maine Station. One is a thoroughly made double walled building, $16 \times 150$ feet in size. It is always kept above freezing by a water heater and a flow and return two-inch pipe, running the length of the building. This building was constructed with especial reference to comfort, health and productiveness. Small, well made houses with single walls had formerly been in use, but they would get white with frost in cold weather, if shut up close enough so the birds did not suffer from cold during winter nights. When the weather moderated, the white frost would change to water and the straw litter on the floor would become damp and clammy. The birds showed their dislike for the damp straw by keeping off from it as much as they could. Such houses were unsatisfactory, and so the large warmed house was built. It was a decided improvement over the cold ones, because it could be ventilated and the birds not suffer with the cold. But it was not possible to secure sufficient ventilation, even though the house was moderately warmed, to prevent the presence of considerable moisture in the bedding.

Good yields of eggs were obtained from hens kept in that house and the losses of birds were not excessive. The hens showed, however, that they were not in the best condition by a little lack of color in comb and energy in action. This house has not been abandoned, but is not prized for laying hens. Since breeding cockerels cannot be car- 
ried over in the other houses, without danger of chilled combs, they are wintered in this warmed house until danger from chilling is past.

\section{The First Fresh Air House.}

In seeking for some better system of housing the birds one of the small close houses, formerly used, was changed into an open house. The building was 10 feet wide and 25 feet long. An opening 3 feet wide and 15 feet long was made close up under the plate, and was left open every day in winter, except when the snow or rain blew in. At night the opening was covered with a framed curtain made of cotton cloth. An elevated roosting closet along the entire length of the back of the building was made warm by packing the walls with hay. A close fitting frame cloth curtain shut them in at night.

It did not freeze in the closet and the birds apparently did not suffer for lack of air. They seemed to enjoy coming out of the warm sleeping closet, down into the cold straw, which was never damp, as the whole house was open to the outside air and sun every day. There were no shut off corners of the floor or closet that were damp. This building was used through three winters with 50 hens in it each year and did not have a sick bird in it. Not a case of cold or sniffles developed from sleeping in the closet with its cloth front, and then going directly down into the dry straw, in the cold room, and spending the day in the open air.

The birds laid as well as did their mates in the large warmed house. Their combs have been red and plumage bright and they have given every evidence of perfect health and vigor. While they are on the roosts, in bed, they are warm. They come down to their breakfasts and spend the day in the open air. Such habits of life seem to work equally well with brute or man.

After having used this so-called pioneer house one year, a house was constructed 12 feet wide and 68 feet long. Its front and back walls were 5 feet high and the roof was evenly divided. It was divided into 2 rooms, each 34 feet long. The elevated roosting closets extended along the entire back of each room and they were constructed in the same 
manner as the one in the pioneer house. The partition between the 2 rooms was made of 2 -inch mesh poultry netting. There were 4 openings in the front of the building, 2 in each room, equal distances apart. Each opening was $3 \frac{1}{2} \times 8$ feet in size, fitted with frame cloth curtains, to be used only on winter nights and stormy days, in the same

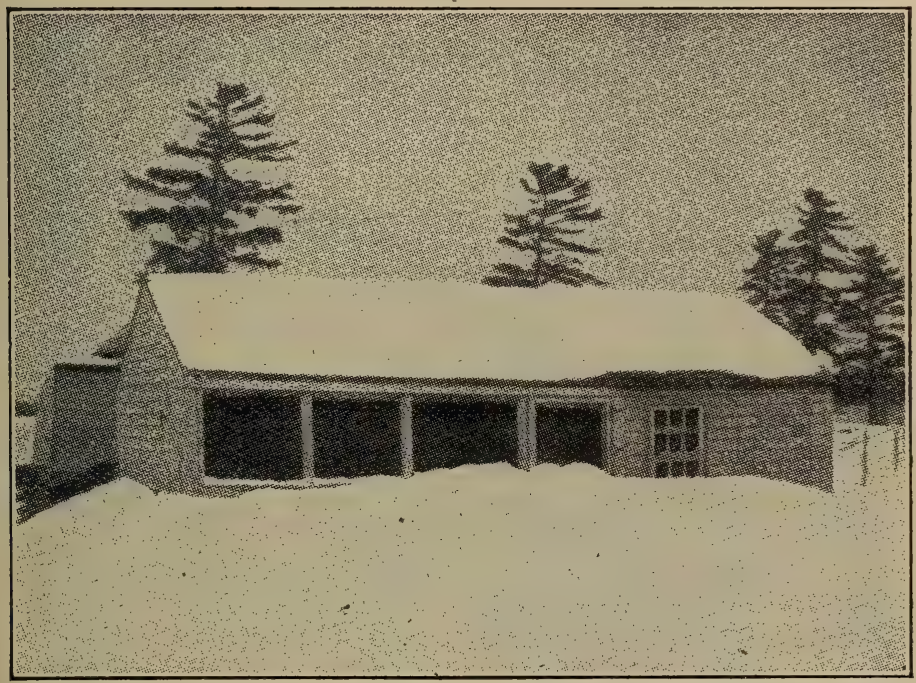

The Original Fresh Air (Curtain Front) Laying House at the Maine Experiment Station, Described by G. M. Gowell.

way that they were in the pioneer house. These openings were put up close to the plates and came down to within $11 / 2$ feet of the floor. There were no glass windows in the building.

\section{Currents of Air Proved Troublesome.}

This house was not satisfactory. There were currents of air from one end of the building to the other, even when there was little wind outside, and when the wind was high in winter the loose snow would be sifted in and distributed over a large part of the floor, dampening the litter and mak- 
ing life uncomfortable for the birds. The wire partition between the pens was replaced with one of close boards, and conditions were bettered; but each of the pens still had two openings, about 8 feet apart, and the same troubles from currents of air and sifting snow continued, although somewhat lessened. One of the openings was closed by screwing glass windows on the outside. This left each of the rooms with one opening and one large glass window.

This change entirely corrected strong air currents through the building and sifting snow, except in heavy storms when the wind is strong from the south. Of course the large opening allows the wind to blow into the room, but as there is no outlet for it except where it came in, there are no drafts of air across the birds to cause them to be uncomfortable and take colds.

Another difficulty remained; the opening came down to within $1 \frac{1}{2}$ feet of the floor, and the birds, sunning themselves on the floor or scratching in the litter, were in the direct course of the outside air as it came into the room and they tried to find sheltered corners where they might be more comfortable. On this account the width of the opening was reduced from $3 \frac{1}{2}$ feet to 2 feet by ceiling up the lower part of it. This gave a bulkhead 3 feet high, sufficient to protect the birds on the floor from the direct inflow of outdoor air and they were happy.

One objection to this house still remains; its front wall is too low to allow room for a large opening, high enough so that the sun can shine in and back across the floor to the back wall during the short days in winter, when the sun runs low. This feature in construction seems to be of the utmost importance, for dependence is had upon the sunshine and pure outside air to keep the floor litter dry and the elevated roosting closet clean. The entire front of the roosting closet being open, leaves no dark corners where the air and light cannot do their thorough cleansing.

Experience with the house showed its several bad features On the other hand, the pioneer house, which had been in use for three years, gave great satisfaction, and the same general plan was adopted in the construction of a large house. 
This house, designated as No. 2, was built three years ago. It is 12 feet wide and 150 feet long and is divided into 20 feet sections. In each section, with its floor surface of 240 feet, 50 pullets have been wintered each year, most successfully.

\section{Wide Houses are Most Satisfactory.}

Two years ago another house was built on the same plan, except that it is 16 feet wide instead of 12 . It is 120 feet long and consists of 4 sections or houses, each $16 \times 30$ feet in size. There is no separate walk through the building, but in the close board partition, separating the pens, are doors, hung with double acting hinges, which allow them to swing both ways and close automatically after the attendant passes through. Each pen has a floor surface of 480 feet and gives ample accommodation to 100 hens. All of the hens in these two open front houses, in flocks of 50 or 100, averaged laying 144 eggs each last year, and the birds were in excellent health. The front curtains were open all of the time every day, except the very stormiest in winter.

While the same plan is common to all of these open front houses, the width has been increased in each succeeding one built. The first house was 10 feet wide, the second 12 feet, the third 16 feet in width. The laying and breeding house at Go-Well Farm, to be described, is 20 feet wide and is more satisfactory than the narrower houses, because of economy in cost and its greater housing capacity in proportion to its length, which reduces the labor required in caring for the birds, by having them in square rooms rather than in long narrow ones.

The poultry plant at the Station is devoted to experiment and research work. There are many questions relating directly to commercial poultry operations that "are left untouched because the Station plant is already taxed to its capacity.

When the Go-Well poultry farm was established last year, the opportunities were so good for studying poultry subjects on a purely commercial plant, where the entire energies of the place are devoted to this one business specialty 
that arrangements were made with its owner which enables the Station to study the practical application of many of its own findings on an extensive, intensive business plant. Of the hundred acres of land comprising the farm, thirty acres immediately at, and overlooking the village of Orono was fallowed and tilled for a year, then seeded to clover and grasses, in order to bring it into good condition for poultry farming.

\section{A Laying House for 2,000 Hens.}

During the summer of 1905 a laying house was built to accommodate 2,000 hens. It is 20 feet wide and 400 feet long. It is on the same general plan as houses Nos. 2 and 3 at the Experiment Station. House No. 2 is 12 feet wide; house No. 3 is 16 feet wide, and this one is 20 feet wide. The widths have been increased in the last 2 houses, as experience has shown the advisability of it. At first it was thought the houses should be narrow so they might dry out readily, but the widest house dries out satisfactorily as the opening in the front is placed high up, so that.in the shortest winter days the sun shines in on the floor to the back.

The economy in the cost of the wide house over the narrow ones, when space is. considered, is evident. The front and back walls in the narrow house cost about as much per lineal foot as those in the wide house, and the greatly increased floor space is secured by building in a strip of floor and roof, running lengthwise of the building. The carrying capacity of a house 20 feet wide is 66 per cent greater than that of a house 12 feet wide, and it is secured by building additional floor space only. The walls, doors and windows remain the same as in the narrow house, except that the front wall is made a little higher. Three sills which are 6 inches square run lengthwise of the house, the central one supporting the floor timbers in the middle. They rest on a rough stone wall, high enough from the ground so that dogs can go under the building to look after rats and skunks that might incline to make their homes there. The stone wall rests on the surface of the ground. The floor timbers are $2 \times 8$ inches in size and rest wholly on top of the sills. All 
wall studs rest on the sills; the front ones are 8 feet long and the back ones 6 feet 6 inches long. The roof is unequal in width, the ridge being in 8 feet from the front wall. The height of the ridge from the sill to the extreme top is 12 feet 6 inches. All studding is $2 \times 4$ inches in size, and the rafters are $2 \times 5$. The building is boarded with inch boards and

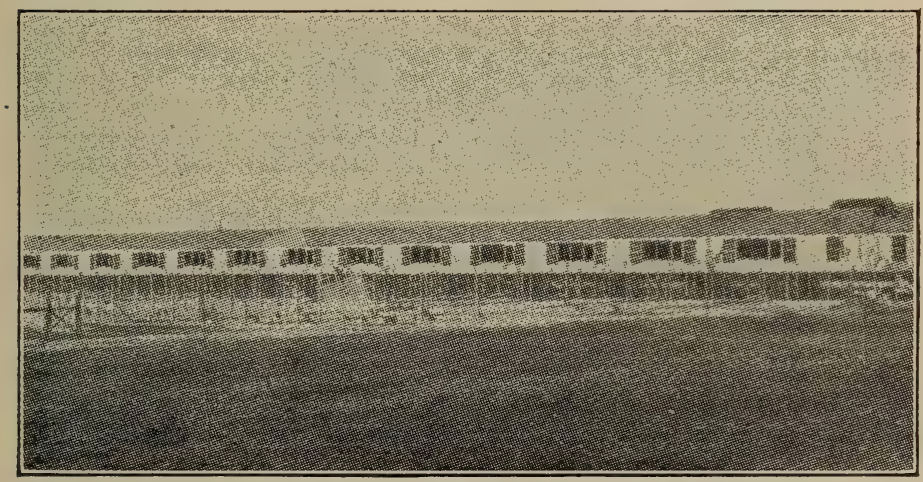

A Section of the "House for Two Thousand Hens," Described by G. M. Gowell.

papered and shingled with good cedar shingles on walls and roof. The floor is of two thicknesses of hemlock boards, which break joints well in the laying.

\section{Tight Partitions Separate the Pens.}

The building is divided by tight board partitions into 20 sections, each section being 20 feet long. All of the sections are alike in construction and arrangement. The front side of each section has two windows of 12 lights of $10 \times 12$ glass, screwed on,. upright, 2 feet 8 inches from each end of the room. They are 3 feet above the floor. The space between the windows is 8 feet 10 inches long and the top part of it down from the plate, $3 \frac{1}{2}$ feet, is not boarded, but left open to be covered by the cloth curtain when necessary. This leaves a tight wall, 3 feet 10 inches high, extending from the bottom of the opening down to the floor, which prevents the wind from blowing directly on to the birds when they are on the floor. A door is made in this 
part of the front wall for the attendant to pass through when the curtain is open. A door 16 inches high and 18 inches wide is arranged under one of the windows for the birds to pass through to yards in front. It is placed close down to the floor. A similar door is in the center of the back wall to admit them to the rear when that yard is used.

A light frame, made of $1 \times 3$ inch pine strips and $1 \times 6$ inch cross ties, is covered with 10-ounce white duck and hinged at the top of the front opening, which it covers when closed down. This curtain is easily turned up into the room where it is caught and held by swinging hooks until it is released.

The roost platform is made tight and extends along the whole length of the room against the back wall. It is 4 feet 10 inches wide and 3 feet above the floor, high enough so that a person can get under it comfortably when necessary to catch or handle the birds. There are three roosts framed together in two 10-feet sections. They are one foot above the platform and hinged to the back wall so they may be turned up out of the way when the platform is being cleaned. The back roost is 12 inches from the wall and the spaces between the next two are 16 inches. They are made of $2 \times 3$ spruce stuff, placed on edge, with the upper corners rounded off. The roosting closet is shut off from the rest of the room by curtains, similar to the one described above. For convenience in handling, there are two of them, each 10 feet long. They are 3 feet wide and are hinged at the top so as to be turned out and hooked up. The space above this curtain is ceiled up and in it are two openings each 3 feet long, and 6 inches wide, with slides for ventilating the closet when necessary. There is a door in every partition, placed 5 inches out from the edge of the roost platform. They are 3 feet wide and 7 feet high; they are divided in the middle, lengthwise, and each half is hung with double acting spring hinges, allowing them to swing open both ways and close.

\section{Construction of Nests and Feed Troughs.}

Ten nests are placed against the partition in each end of the room, in two tiers. They are of ordinary form, each nesting space being one foot wide, one foot high and 2 feet 
long, with the entrances near the partition, away from the light, and with hinged covers in front for the removal of the eggs. Each section of five nests can be taken out, without disturbing anything else, and cleaned and returned.

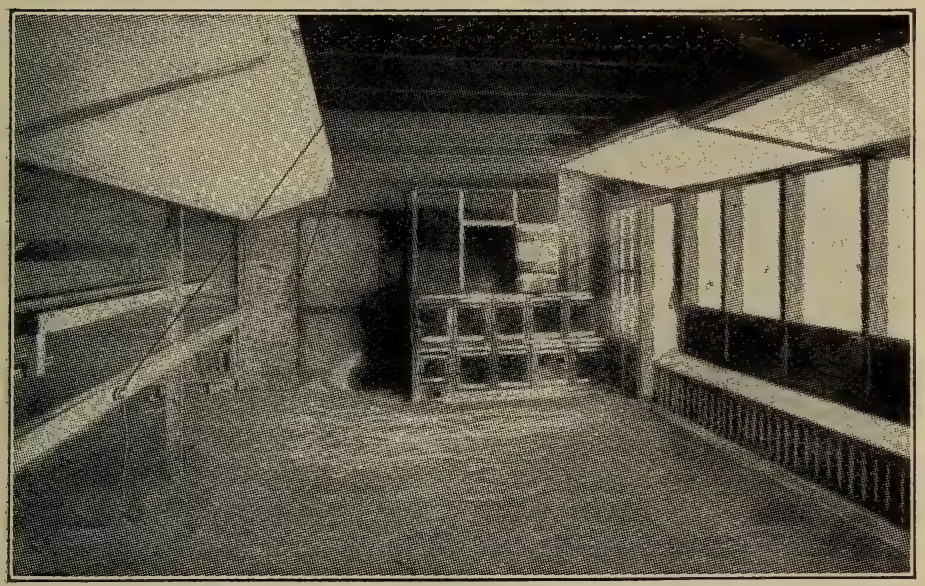

Interior of One of the Pens in the "House for Two Thousand Hens," Described by G. M. Goweil.

Troughs are used for feeding the mixtures of dry meals, shell, bone, grit and charcoal. The bottoms are made of boards, 7 inches wide; the ends being of the same width and 18 inches high. The back is of boards and the cover is of the same material and slopes forward sufficiently so the birds cannot stay on it. A strip 5 inches wide is nailed along the front edge of the bottom to make the side of the trough. Pieces of lath are nailed upright on the front, 2 inches apart, between which the hens reach through for the feed. A strip 2 inches wide is fastened to the front of the trough at an angle of about 45 degrees to catch the fine meal that the birds pull out and would otherwise waste. They clear it up from this little catchall and so waste is mostly prevented.

\section{Feeding by Rail.}

Two lines of $4 \times 4$ inch spruce are arranged as an elevated 
track above the doors. The track extends the entire length of the building and being faced with narrow steel bands on top, a suspended car is readily pushed along, even when heavily loaded. The platform of the car is $2 \times 8$ feet in size and is elevated a foot above the floor. All food and water is carried through the building on this car. The ten iron baskets, into which the roost platforms are cleaned every morning, are put on the car and collections made as the car passes through the pens to the far end of the building, 400 feet away, where the roost cleanings are dumped in the manure shed. As the car is pushed along, the guard at the front end comes in contact with the doors and pushes them open and they remain so until the car has passed through, when the spring hinges force them to close again. This car is a great labor saver, as it does away with nearly all lugging by the workman. It has enabled one man to take good care of the 2,000 hens from November to March, except on Saturdays, when the litter has been removed and renewed by other men.

At one end of the building there is a temporary food ana water house for dish washing and scalding and where the car remains when not being used.

\section{An Outside, Elevated Walk.}

There is a walk outside of the building extending along its entire front. It is 4 feet wide and is made of 2 -inch plank; it is elevated 2 feet above the floor of the building, which allows the doors, through which the birds pass to the front yards, to be opened and closed without interference. The door which opens out of each room through the curtain section, is above the outside walk and necessitates stepping up or down when passing through, which is not a very serious objection, as the door is used but little in the daily work, but mostly in cleaning out and renewing the floor litter. A guard of wire poultry netting, a foot wide along the outside of the walk prevents the birds from flying from the yards up to the walk. The advantages of the elevated walk over one on a level with the sill of the building is that it is unobstructed by gates, which would be necessary were the low walk used, to prevent the birds from passing from one yard to another. 


\section{FEEDING THE LAYING HENS.}

\section{Feed Fattening Foods Sparingly-Green Food and Grit Are Essential-A Good Mash-The Best Grain is Cheapest to Feed-No Success Without Fresh Air.}

\section{By Victor D. Caneday.}

We are now entering upon a season of the year when the question of feeding is a very important one, and while it is a fact that we cannot write any definite rules that will hold good in all cases, still by giving our experience we may benefit those who as yet have little confidence in their ability to feed and care for a flock of hens so as to obtain reasonably good results in winter egg production. In fact, in the first place we have learned that while a variety of food is desirable, marked changes in kind and quantity of food is one of the most certain things to cripple the egg record. The less changes and the more gradual the changes (when such are necessary) that one makes in either the care or feeding of a flock, the better the egg record will be. Another thing, our work with the biddies has taught us that ordinarily there is more danger of overfeeding with soft foods than with whole grains, therefore, we are very careful to keep within safe bounds as to the quantity of soft food given the fowls. To prevent overfeeding with grain, the whole grain should all be scattered in a litter in the scratching sheds or rooms so as to compel the hens to work for what they obtain. There is no one thing the equal of exercise to keep a flock in fine, healthy condition.

\section{Avoid Fattening Foods.}

To prevent the hens becoming too fat we avoid feeding fattening foods such as corn, barley, buckwheat, etc. We feed more oats than anything else to the mature hens, as it is the very best grain for egg production we have. We begin in the molting season to feed a little wheat with the oats and in winter feed about one-third wheat and two- 
thirds oats, but in summer weather we feed nearly altogether of the oats. Of course one must be governed by the condition of a flock which depends considerably upon the kind of range they have. We endeavor to have all our stock on good grass range in the summer time and keep them well supplied with green food: such as cabbages, mangels, sugar beets, cut clover, etc., in the winter months. One thing that is never allowed to become empty is the grit box. Perfect - digestion goes a long way towards success in feeding and good sharp grit is an important essential in accomplishing that end with poultry.

\section{Corn is Fed in the Mash.}

The only place for corn in our bill of fare for the laying stock is in the morning mash, the ground grain of which is composed one-half corn and oats and one-half bran by measure. We formerly used shorts or middlings, but never seemed to obtain as good results as we have when using the bran and ground feed. Bran is a fine regulator and we quite often, when the flock is showing a lack of appetite, or at times when conditions of weather have been trying, give them a warm bran mash-never give food to fowls hot. Bran scalded is quite laxative and is a great aid in keeping the fowls from becoming constipated or the system clogged with overfeeding. The foundation of the mash is made up of potato parings, table scraps, small potatoes, or any vegetables available, thoroughly cooked, chopped fine and mixed with the ground grains to a crumbly consistency. We mix the mash as dry and crumbly as we can and never feed it wet.

\section{The Quantity of Food Required.}

We feed at the rate of a quart of whole grain to each six fowls, and one large iron spoonful of soft food to every two fowls per day. One must note if the flock is getting too little or too much by examining the scratching shed floors occasionally and watching the condition and appetite of the hens. However, we find there is little need of any very great variation from these amounts, but no one will be able to measure out feed to hens with a machine and obtain good results. Every flock needs watching, and if we were to 
hire everything else done, the feeding we would feel compelled to personally attend to. We formerly fed green cut bone, but had so much difficulty in obtaining it, and in the summer time it was so often spoiled that we have been using meat meal, which is no more expensive and as far as we can see, from about a year's use, accomplishes fully as good results both in health, vigor and egg production.

\section{Nothing Equal to Oats.}

There are some people foolish enough to believe that oats are liable to injure fowls by swelling and packing in and piercing their crops. We have yet to find the person who has ever known personally of such a thing happening, and in all the time we have fed whole, dry oats we have never had the slightest reason to believe the oats were any more injurious to their crops than wheat, and we feed nearly all whole oats to our hens. There is no whole grain equal to oats as an egg producer, and when the poultry keepers get to feeding it more generally we shall not hear so many complaints of overfat hens and poor layers.

One important consideration in the feeding of oats is to feed good, plump, heavy grain. The quality of oats is not so apparent to the inexperienced as would be the quality of other grains. We endeavor to always buy the heaviest oats possible and all grain of first quality we consider the cheapest in the end.

In the conclusion of these thoughts on feeding for eggs, we desire to say that some of the most common causes of failure in obtaining eggs in the winter is lack of fresh air. The hens should be allowed to run out whenever the weather is warm enough to not freeze their combs and the houses should be aired out thoroughly in the warm part of the day, every day during the winter except when it is so cold that it is entirely impractical. We keep our house open (have wire netting, one inch mesh, on windows) the year round just as much as the weather will permit. If these directions are followed with a properly constructed house, free from drafts, and the fowls are not allowed to crowd too much on the roosts, colds and roup will be unknown diseases, except they be introduced through infected birds. 


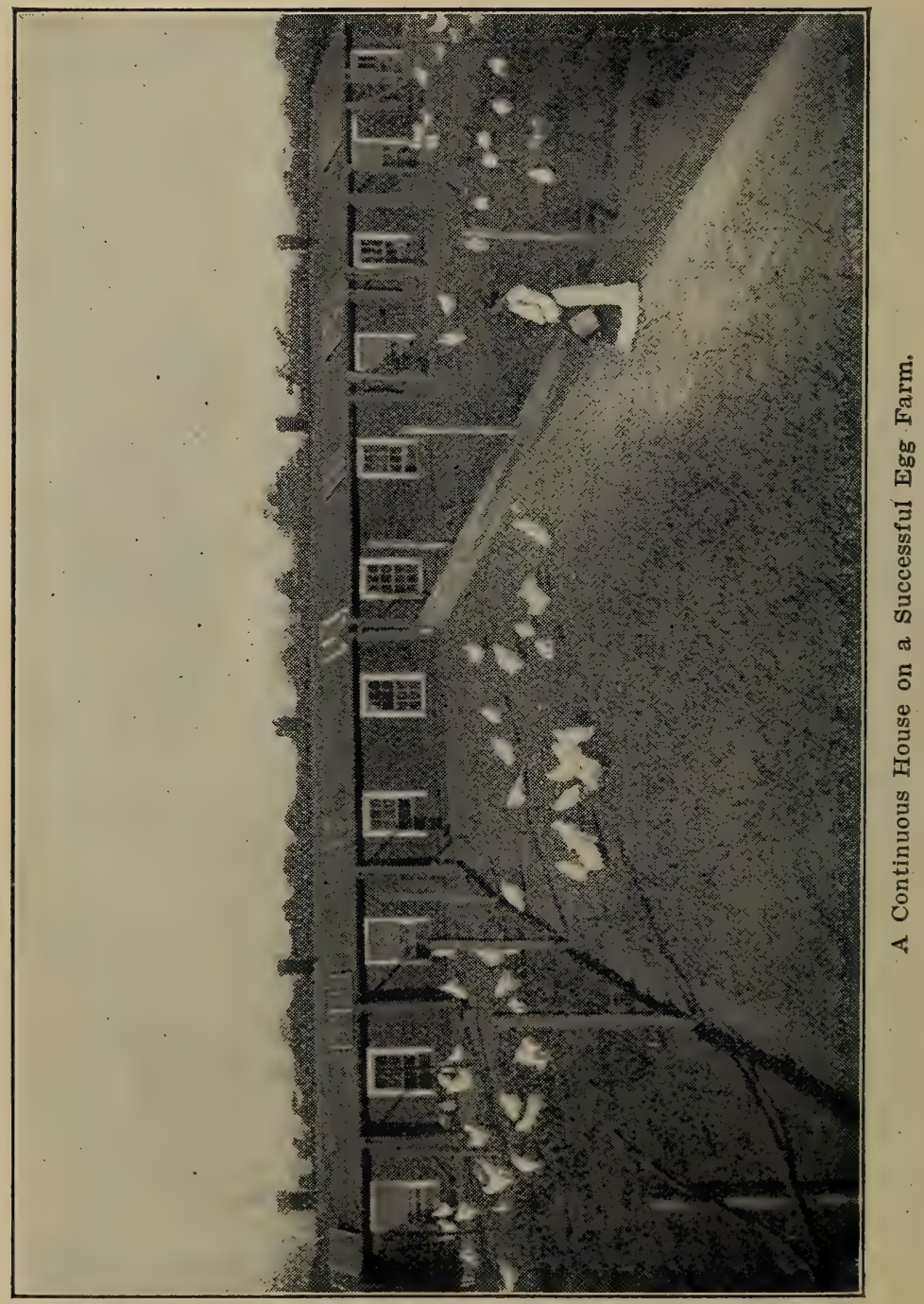




\section{FEEDING FOR WINTER EGGS.}

How Several Prominent Poultry Breeders Care for and Feed Their Fowls to Obtain the Greatest Number of Eggs in the Season of High Prices-A Symposium.

\section{Methods of Feeding That Are Effective During the Cold Minnesota Winters. \\ By E. S. Person.}

While I have never made any great effort to get my hens to lay early in the winter, from all my experience I know that it can be done, right here, during our cold Minnesota winters, with the proper care, housing and food. I have been mostly concerned in producing strong, fertile eggs for myself and my customers after the first of January, and, while in some years eggs will be better than in others, I have never had very much trouble in accomplishing that result.

My methods are very simple and right here let me say that I do not believe in using a lot of patent, so-called "egg foods." I do not doctor my fowls very much and do not have to. I feed good whole grain which is always thrown in deep litter, with occasionally a mash of ground food and steamed cut clover. After the grass is gone and hens and pullets are taken from their range in the fall, it is necessary to provide a goodly supply of green food in some form. We are using for this purpose, sugar beets, cabbages, turnips, onions, small potatoes and even the peelings from the vegetables and apples used in the kitchen.

If eggs are the only object, I should say feed this mash every evening an hour or so before dark. Let them have all they will eat up clean and remove the troughs after the fowls have gone on the roosts at night. For the morning feed there is nothing like whole oats in deep scratching litter. 
At noon give a small feed of whole wheat and about twice a week this may be changed to whole or cracked corn. Barley may be substituted for oats part of the time, if desired, but the birds do not take to it quite as well. Green ground bone should be fed about twice a week, or, if that is not obtainable, beef scraps should be before them all the time. It is of course absolutely necessary to supply them with grit and oyster shell, or its equivalent, and pure water at all times. My fowls also get all the milk they will consume every other day.

My houses are built on the continuous laying house plan, the pens are from eight by ten to twelve by fourteen feet. in area, some are double boarded and stuffed with wild hay; sides and ceiling; others have tarred paper with drop siding on outside, and patent lath, plastered on the inside. All have earth floors with stone or concrete foundations extending into the ground from eight to twelve inches. Everything is kept as clean as we can keep it. All the houses. are whitewashed inside, and the roosts, etc., are sprayed with lice killer once a week. The houses all face the south and the windows are open whenever the weather will permit. No male birds are allowed with the hens until I am ready to save eggs for hatching and mate up the breeding pens in February.

\section{Supper by Lantern Light is a Feature of this Method. By M. W. Baldwin.}

I will own up right now that specializing for winter eggs is not in my line; at the same time I generally put aside. one pen for fresh eggs and from that pen always get what I'm after. This particular pen is generally made up of a lot of early hatched pullets, and occasionally a few hens of pronounced laying ability. The house they occupy is about the poorest in my establishment, but is patched up for winter so that it is free from drafts, and their roosting quarters are double-walled, papered and curtained, so they sleep warm. During the day they have the run of a big, dry 
room with louse dust floor, bedded about a font, or more, deep with alfalfa; into this litter is scattered grain and grit. Every night after I have had my supper and enjoyed a cigar, we go the rounds. Our pen of layers gets a late supper of warm corn, and twice a week a good feed of raw beef (beef lungs); they also get a drink of water that has had the chill taken off.

Anyone who has not tried this night method of feeding, will doubt its usefulness; but if you wait and consider the long night and the short day you will see how very necessary an extra meal is, and it will astonish you how quickly the birds learn to watch for the lantern. In fact they are generally off the perch and waiting my coming long before I get to their quarters. Another great advantage is that the birds get to be remarkably tame, and the egg poulterer knows what that means. If I'm short of accommodations for males I allow one in that pen, but always thought that the hens laid better without the company of a chanticleer than with one.

As to what I feed I can give no formula, for I have to depend on the feed store, but I give all the variety that is possible, making wheat the staple. I feed no mashes or condiments.

Watering is the hardest problem, for even in my double walled, plastered houses, drinking founts freeze; the birds are given a drink at noon and get a good drink again at night, but I am hoping that some clever person will devise. a simple but serviceable drinking fount that can be heated sufficiently to keep the drinks from freezing in our coldest. weather.

So for winter eggs, I allow plenty of room and light, a warm sleeping place, an extra feed by lamplight, and a social chat of course. Have kept no records in late years of what my egg pen does for me during the winter; but a dozen pullets will, I believe, average pretty close to seven eggs a day, handled this way. We manage to get along without buying any eggs all winter, and I really prefer that my stock birds reserve their energies for spring business. A hen that will lay 150 eggs in 160 days during the spring and early summer is much more valuable to me than 
one that lays 30 eggs in 60 days during winter and keeps up much the same gait during the rest of the year.

\section{Wa:m Houses and Good Feeding Make Hens Lay in Cold Weather. \\ By S. V. Johns.}

I give my birds the best of care during September and October; I feed oil meal and crushed sunflower seed during the molting season, but no meat of any kind, and I let my hens rest while molting. After the molting is over I feed during the month of November, in the morning, a warm mash of corn, uats and bran, ground, with a little of some good prepared poultry food and some beef scraps. During the middle of the day I feed plenty of cabbage, and in the evening I feed wheat which puts their blood in good condition and improves their flesh.

During the winter we feed wheat for breakfast which is thrown in a litter of straw, a foot thick, in the scratching shed and the work of scratching it out keeps the fowls warm. I hang a head of cabbage in each pen of twenty birds. I use a green bone cutter and give them green cut bone three times a week. For the evening meal I give a little shelled corn. We have used these methods for years and have always had eggs to sell all winter and the birds have always been healthy.

Some may desire to know about the construction of my poultry house. It was built with a shed roof having a three foot pitch. The outside of the frame work is covered with tar-paper, with drop-siding to the weather. Tar-paper is also placed on the inside of the frame work and ceiled over with boards. The roof is covered with rough boards, then with a laver of tar-paper and shingled, the shingles being laid five inches to the weather. Board floors are used.

\section{Methods That Make Winners and Layers in South Dakota.} By A. J. Keith.

My winter laying house is very warm, boarded on inside and outside of the studding. There is tar-paper on the 
outside which is in turn covered with matched siding and well painted. The house faces south, has plenty of light, storm door and storm windows. A five-foot board platform extends in the north side of the house from east to west. This is screened in, the nests rest upon it and the eggs are gathered without going among the birds. The roosts are one and one-half feet above the floor of the coop and under the platform, with droppings board under the roosts which is kept clean and has fine ashes frequently scattered on it. The dirt floor is cleaned once a week and

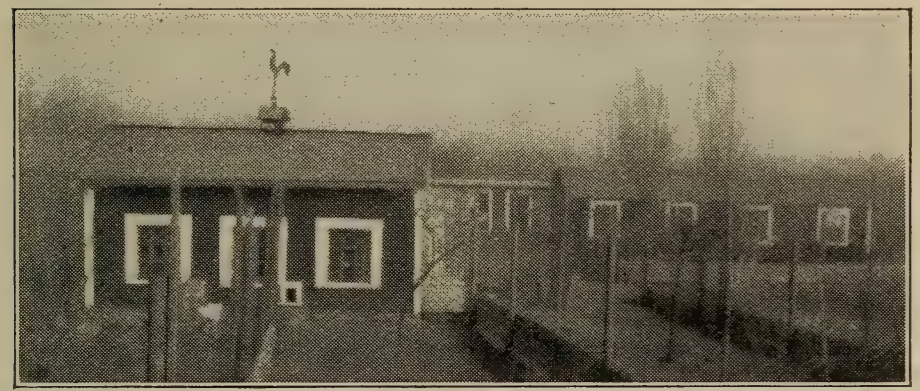

Buildings of a Village Poultry Keeper who Secures Enough Profit to Pay the Family's Meat and Grocery Bills.

fresh straw put in to the depth of nine inches, making a fine scratching place. Once $\approx$ week a mixture of kerosene, napthaline flakes and crude carbolic acid is sprayed on roosts, droppings boards and walls. Twenty-below-zero weather outside will not freeze water where the birds roost.

The morning feed is oats scattered in litter. About twice a week a hot mash of boiled potatoes, vegetables, bran, shorts and barley flour, occasionally seasoned with salt and pepper, is fed. At noon I feed a light feed of wheat scattered in the litter. Ground fresh bone is given three times a week, about two and one half ounces a week per bird. At evening I feed either wheat, barley or corn and on very cold nights a hot mash, same as described for feeding in the morning, but never two hot mashes on the same day. Occasionally the corn is fed warm. Charcoal, shells and grit are kept before the birds always. Cabbages 
are hung from the ceiling where the birds are obliged to jump to reach them.

In cold weather the birds are allowed to run out but little and then only during the middle of the day and in yards with board protection on north. I sometimes give them warm water early in the morning. The amount of food fed varies according to condition of each pen. Ven-

- tilation is important: I use openings at the top of the coop and also at the bottom.

Under the above ration and treatment, eight o'clock on a twenty-below-zero morning will often find 75 per cent of the birds on the nests doing their duty. Last February I mated one pen and commenced saving eggs on the twentieth. The first of March I sent 116 eggs to Minnesota. These eggs were gathered twice a day for the temperature was below zero all the time; 108 eggs were reported fertile. The warmth of the coop is apparent from the fact that the eggs were not chilled.

I might say that each year I cull very closely, keeping only the best shaped young birds for layers and those of the old ones that have proved layers as pullets.

Vigilant care and kind treatment bring a high percentage of eggs each day.

\section{A Laying Strain and Good Care are Necessary for Success- Lice Spoil the Profits. By Mrs. M. E. Ellison.}

In order to succeed in this work there are certain things that must be right. First, the person that has the care of the fowls; second, the fowls; third, the houses; fourth, the foods. To begin with, a person that does not love our feathered friends had better find some other occupation, as the birds very soon know who their friends are.

I do not think there is as much difference in the breeds of fowls as in the strain. So be sure you have a laying strain; one that has been bred that way. Get them hatched early so they will be well matured and ready for business before cold weather sets in. I keep Buff Rocks and Single Comb Buff Leghorns and find that March and April hatched 
Rocks are the ones that make the winter layers of that breed. The Leghorns are all right hatched in April and May as they mature sooner. Keep them growing, do not let them get stunted for they never fully recover from it.

I have never found it difficult to get eggs in winter. When I have done my part as I should, biddie has always done hers. I know when I am-not bringing in the much desired basket of eggs that some of the necessary ration has been neglected. A hen can no more lay eggs without the necessary material for their production than a cow can give milk if fed on dry hay alone.

Look well to what you feed, and how you feed it, and watch results. I have had very satisfactory results from the following method of feeding during the short cold days in winter. At about three P. M., I feed warm grain which is principally wheat, with barley and corn at times for a change, in sufficient quantity to answer for supper and early breakfast. Then about nine A. M. they get a warm luncheon, which consists of one-fourth cut clover, scalded and steamed over night, one eighth corn meal, onc eighth shorts, one fourth cut vegetables. One fourth green bone, ground, goes with this three times a week; the othor threo days I add enough shorts, corn meal and bran to uake its place and moisten with milk if I have it, if not, waicr. I make it crumbly, not soft. Sundays this is omicted and a variety of grain takes its place. This to shorton as much as may be the time required to do the work of caring for the flock on the first day of the week and omitting the mash seems to have no bad effect.

There are many little details in the care of the biddies that must not be neglected; see to it that they are free from vermin that worry and torment them if allowed to live; you cannot have many eggs and lice at the same time. Give them plenty of clean water with the chill taken off, all the grit, oyster shell and charcoal they want. All grain should be fed in a litter; straw or leaves are excellent for this material. They need exercise or they will get fat and lazy. Last but not least, are the houses. They need not be expensive, but warm and comfortable, with plenty of sunlight and fresh air, but no drafts. Do not make the mistake of 
crowding one hundred inco a coop on y large enough for fifty.

\section{Feeding for Winter Eggs is a Simple Problem-Proper Food,} Exercise and Warm Drinking Water Are the Features.

\section{By W. F. Mautz.}

The high prices that are paid for eggs throughout the Northwest during the winter months, make an inducement for every owner of a flock of fowls to endeavor to get as many as possible. To do this, the fowls must be of a strain that are bred to lay, just as Jersey cattle are bred to increase the yield of milk, and fast horses are bred for increased speed. This can be done only by carefully selecting as breeders your best winter layers, of good shape, size and color, and mating them with vigorous, well developed sons of your very best winter layers. A permanent increase in the egg yield will be observed when this method of breeding is followed.

Feeding for winter eggs is not the complicated work some would have us believe, in fact it is very simple, if certain rules are observed, and we have found it just as easy to feed along scientific lines as to feed in a haphazard sort of way. The morning feed consists of two parts oats and one part wheat which is well scattered in litter about a foot deep; this is done in the evening after the fowls have gone to roost, so as to be ready for them as soon as they care to go to work in the morning, our object being to make them work for every kernel that they get. This gives them plenty of exercise which is very necessary in winter when the fowls are kept in confinement more or less. At noon we feed a mash which is made up of ground oats, bran, shorts and wheat middlings; for green food we use cut clover about one-fourth in bulk, which is thoroughly steamed for several hours, after which it is all mixed into a mash to which is added enough salt to season it and hot water. crough to make a dry crumbly mash, not sloppy. All table and all vegetable scraps go into this mash, enough 
of which is fed so that they eat it up clean in fifteen to twenty minutes. In addition to this mash we feed barley well shaken into the litter to make them work for it so as to give them plenty of exercise to digest the mash.

We watch our litter very carefully, and if upon ex-

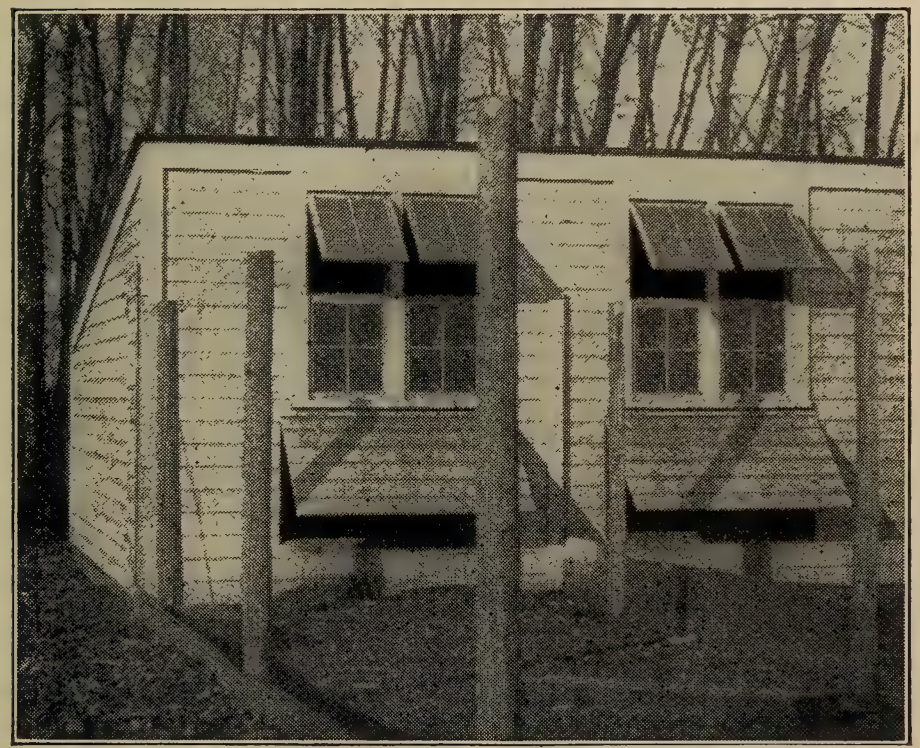

A Section of the Poultry House of W. F. Mautz, Described in the Accompanying Article.

amination we find any grain upon the floor we feed less, and if none is found we feed heavier, but do not pay any attention to it if we find any grain under the litter after the evening meal, as it is our intention to send the forvls to roost with full crops. In the evening before they go to roost we feed wheat well shaken into the litter, all that they will eat. A hen in order to produce eggs in winter must be fed enough to make up the wear and tear of the body and have something left for the production of eggs. We do not believe in over feeding neither do we believe in starving them; any person acquainted with his flock 
can tell at a glance upon entering the yards about what food they will require. Cabbages are hung up for them to pick at and fine chopper potatoes are fed raw; beef scraps, granulated bone, charcoal, oyster shell, bran and grit are always kept before them in hoppers and during cold weather plenty of warm water is furnished them frequently. We wish to lay special emphasis on this for we find when we analyze an egg that a good sized hen's egg weighs about two ounces, and is about 64 parts water and in order to produce eggs, a fowl must have the material necessary. As it is necessary to gather the eggs quite often during the severe cold weather to prevent freezing the attendant collecting the eggs always carries warm water to replenish any fountains that are dry, or are beginning to freeze. Rock salt is also before the fowls where they can get at it at will, and right here let me say that I consider it just as necessary to supply your fowls with salt as it is to supply any other live stock.

This is the method of feeding that was followed the past winter, and we were successful in having our egg basket well filled during the severest winter weather. This winter we feed in much the same manner. For the morning meal we take equal parts of wheat, oats and barley, at noon mixture of wheat, oats, kaffir corn, cracked corn, millet and buckwheat, and the evening meal consists of small cracked corn. For the mash we use one of the prepared mash foods made by a reliable poultry supply house, to which is added all of the table and vegetable scraps, also steamed cut clover.

Our laying houses are shed roof structures well built, seven feet high in the front and four feet high in the rear, facing the south, with a board floor, divided into pens eight by sixteen feet, by board and wire netting partitions, two pens to a house. These pens will each accommodate a flock of twenty-five fowls and keep them comfortable. The roof is made of a good grade of matched lumber, which is covered with a good grade of prepared roofing. There are four windows in the front of each pen with the lower sash stationary and the upper sash hung with hinges at the top so that the sash will swing out below for ventila- 
tion; the doors are placed beneath the windows, and near the floor; they are three by five feet, hung in the same manner as the windows so they will swing out below and make a shelter or awning; this enables us to air the house (even with strong wind from the south, the wind is hardly noticeable in the house) and permits the fowls to pass in and out from the house at pleasure. The roosts are all removable so as to facilitate the cleaning of the dropping boards, which are cleaned daily, and the fight against vermin, for keeping the house clean is a very essential thing. The nest boxes are placed below the dropping boards, with a hinged door in the front which drops down, through which the eggs are gathered, the fowls entering the nest boxes from behind. A muslin curtain is hung in front of the roosts which can be let down during the night in severe cold weather. We also have curtains on the inside of the hinged sash which can be used when necessary; one or both of the sash in each pen are kept partly open when it is not too stormy, and this in connection with the curtains gives us a well ventilated house and one in which fowls will thrive.

\section{"Separate the Sexes, Provide Meat and Green Foods and Plenty of Sunlight," is the Advice of Mr. Bates. By R. G. Bates.}

Most people, who keep poultry, desire a liberal quantity of eggs, especially in winter when the price is high. In order to obtain the best results get birds from a good laying strain, as they have the qualities bred in them. After the second laying season, a female's most profitable age is over and she should then make room for the younger stock. As soon as the cockerels get old enough to annoy the pullets they ought to be separated until the breeding season commences, as they annoy the females which will not lay as well as when separated. . The old males will probably fight if penned together, or with the cockerels, and any valuable birds should be penned separately.

Next in importance is the food. Fowls will not thrive on an unvaried diet, they must have a variety. There are any number of good grains which can be fed, for example: 
wheat, corn (cracked), oats, barley, rye and millet. You can also feed buckwheat, sunflower seeds, peas and beans and also rice for a change. Give them all they will eat readily; circumstances alter the amount.

Besides grain, the fowls need green and animal food. For the latter prepared beef scraps can be used and should be before them at all times in hoppers. Table scraps are also good and milk in any form is excellent but if very sour it should be sweetened with a little common soda.

For green food, clover hay is good; some people steam it before using, while others feed it in the natural condition. Dried lawn clippings are a good substitute for the clover hay. Cabbage or beets are good for a change and now and then chopped onions will be relished.

Be liberal with the water, have it fresh and warm it slightly in very cold weather. Sharp grit and oyster shells are very essential and should be kept before them always. The former is for digestive purposes and the latter to supply material for egg-shells. Charcoal is very good as a bowel regulator and blood purifier and can be fed in hoppers constantly.

Always feed the grain in a litter of straw, hay, leaves or chaff which ought to be found in every poultry house and should be changed whenever it gets dirty. The exercise obtained by the fowls scratching for the grain will help to keep them warm and will also fit them for laying by working off the surplus flesh, besides being a help to the system generally.

The house should be moderately warm, but I do not believe in artificial heat. Don't be afraid that you are going to freeze everything if you leave the windows partly open for a little while. Never allow the drafts to blow on the fowls as they are disastrous to the health of the birds. This can be prevented by having a cloth window which ought to be taken out when the sun is bright and warm. After all the sun is one of the best tonics.

Never crowd fowls or they will not lay well and will be liable to many diseases. Each bird ought to have at least four square feet of floor space and five or six is better if you have the room. Have plenty of sunlight in all parts 
and corners. Be sure and have the windows low enough so that the birds can have a sun bath.

Save some of the common road dust in summer for the dust bath for it will tend to keep the birds free from lice. Last, but not least, keep everything clean. Clean out the houses as frequently as possible. Keep the water dish washed and scald it once in a while. Dust the birds occasionally with a good lice powder, for an ounce of preventive is worth a pound of cure.

\section{Good Houses, Adequate Ventilation, Good Food and Enough of it, Make Healthy, Profitable Fowls.}

\section{By F. H. Williams.}

Having been asked to explain in detail my method of housing, caring for and feeding my Cornish and White Indians for winter eggs, I will describe one of the houses first. In size it is $24 \times 12$, eight feet high in front, and six in the rear. This house is built on a solid cement foundation, raised one foot above the ground, has a smooth cement floor making it absolutely rat proof. The walls are made of rough boards, tar paper and drop siding outside of $2 \times 4$ uprights; on the inside it is lined with tar paper and sealed with matched lumber, leaving a fourinch dead air space between the walls. This makes the building absolutely wind proof and free from drafts.

The front has four large windows six feet apart made of two sashes of six lights each, the lower sash being fitted so it can be raised or lowered. Above each window is an air space eight inches high and the width of the window, covered with white muslin. These are open both night and day. Covering the lower sash of each window is another piece of muslin securely tacked to the sash frame except one corner which can be folded back. During the day, the lower sash is raised, the corner of muslin pulled up and pinned and I have a muslin front house. The fowls go in and out through the window, over the sill, except on stormy or extra cold days, when the muslin is not raised, although the window is. At night the windows are closed 
and ventilation is provided by the openings over each window. Roosts are placed at the extreme back. No dropping broads are used as I consider them an inducement for laziness on the part of whoever takes care of the birds. Partitions are of wire, except two feet at the bottom, which is of boards, to keep males and obstreperous hens from fighting.

Along the entire length of the building, at the top of the back wall, are single coops for training quarters for show birds and surplus males. Underneath these coops are the roosts, made of two four by fours, with the edges rounded. Nest boxes are arranged along the sides of the pens, as are also water cans and feed, oyster shell, charcoal and grit boxes. Dust boxes, good and deep, are also provided. Absolute cleanliness is the rule. All scratching material, which is deep in the pens, is removed once a week and the floors, roosts, coops and sides of pens are sprinkled or sprayed with a good lice killing and disinfecting liquid. New litter consisting of oat-straw, timothy hay siftings, and a bushel basketful of tobacco stems is placed in each pen. Whitewash is used as needed. The same treatment is given the two other houses, one with a dirt floor, the other with board floor. It is needless to say that there are no lice or mites about the premises.

In feeding, dry bran is before the birds in self feeders at all times, so they can help themselves. Bran I consider one of the very best of foods and one would be surprised at the large quantity consumed. The morning feed consists of oats and millet scattered in the litter the night before and buried deep. This keeps them busy until I return from the office at noon, when table scraps, fresh cut beef scraps and a little wheat and cracked corn is fed. At night whole corn is the meal and the birds go to bed with full crops. A mash consisting of bran, cornmeal and a little linseed oil is fed occasionally, but not often as I much prefer the dry feed. Cabbage is the principal green food and a head is almost always in each pen, stuck on a spike just high enough to make the fowls jump for it. Fresh cut bone is also fed three times a week. I have no certain amount of grain to feed, but if the birds seem 
to have a little keener appetite than usual, they get more. I find feeding this way that the fowls are always in good condition being neither too fat nor too lean, seem to be contented, always singing, making the litter fly and laying a good supply of eggs right through the winter.

This system might not do with some breeds, but with the Cornish and White Indians, I find it O. K. Three things are necessary to the welfare of any breed if one

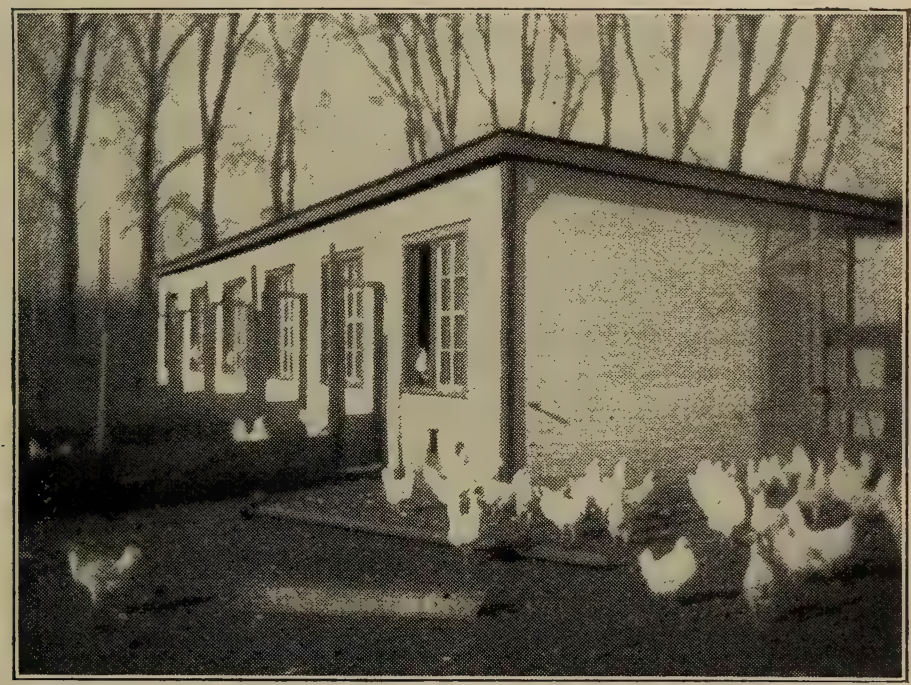

A Well Built, Double Wall House Which Could not be Sufficiently Ventilated to Prevent Dampness.

expects them to do well, and these are: first, absolute cleanliness; second, good quarters; third, a good, generous supply of food and water, grit, oyster shells and charcoal. I firmly believe that a flock of hens or pullets to do well must have all these. If they have the food they want, you will hear them singing their little song almost every day, but you won't if your flock is kept half-starved all day until just before dark. The members of the human race I notice want their food regularly and enough of it and I think our dumb animals and birds have just that 
same inclination. Therefore mine, all of them, dogs, cats, horses and poultry, always have enough.

\section{A Heavy Egg Yield is Not Difficult to Obtain. By A. B. Williams.}

I begin in September to prepare my hens for winter laying, first I shut off the feed from the old hens (only give one third their regular feed) for two weeks. Then I feed heavy for a spell, to start all the hens that are backward about molting to molt; that gets all the hens in good shape to start laying by the last of November. By that time the hens are all housed in a good warm house with plenty of hay and straw over head, so that frost never gathers. I also have double doors and windows; they do not know it is winter.

I feed mostly whole grain; wheat, barley and some corn, with a supply of cabbage, beets and small potatoes always on hand. 'The fowls are seldom allowed out on the frozen ground, but the doors have screens and are left open on all bright days, which keeps the birds in good health. Pullets hatched in May should be housed in their winter quarters before Nov. 1st, and should be helping to fill the egg basket all winter. Pullets as a rule lay the most of the winter eggs, if looked after at the proper time in the fall.

Make your poultry house warm and light, feed plenty but don't fatten your hens, always have plenty of clean water, don't forget to furnish good grit and a dusting place in winter, and you will have plenty of eggs in the coldest weather.

\section{Grit, Shells and Vegetable Foods Are Needed by Laying Fowls -A Good Ration. By R. A. Pike.}

In writing an article on winter egg production I realize that it will not be of much interest to poultrymen who are getting a satisfactory number of eggs from their fowls, it will, therefore, be of help only to those who are not getting 
as many eggs as they should. In my opinion the reason for not getting winter eggs is apt to be over-feeding and lack of information as to the egg producing qualities of foods. It is possible for a poultryman to give his fowls plenty of food and the best of care, yet fail to obtain winter eggs.

I find that most poultry keepers know that fresh water must be provided; that the house must be dry and free from draughts; that lice must be killed and the house and premises must be kept clean and disinfected. These things are generally known but if not lived up to the balance of this article will be of little value. I also find that many people do not know that both grit and oyster shells should be before the fowls at all times. Many think that one takes the place of the other or that if sand or gravel is provided only shells are required. Grit is crushed rock about the size of small corn, the edges are sharp and good grit is composed of rock that remains sharp until entirely worn away. Grit is the hens' false teeth; it grinds the food so that it can be digested and its use will save at least one fourth of the feed bill. Gravel does not take the place of grit because it is round and does not cut the food, sand is of little value, even though sharp, for it is so fine that it passes through the fowl without doing the work.

Oyster shells are fed laying hens simply to furnish lime for making egg shells; oyster shells dissolve too quickly to make good grit and are too thin to do good grinding even while they last. Shells are mostly carbonate of lime. Dry bone can be placed before the old and young stock at all times as it is largely composed of phosphate of lime which is what the poultry require for bone building. The lime in oyster shells is different from that in bone and is used by the fowls for a different purpose.

Green cut bones are simply fresh bones with generally a little meat on them, which have been run through a bone cutter. Green cut bone has all the value of dry bone and in addition is a great egg producer and flesh builder on account of the meat, fat and marrow. The general rule for feeding it is one ounce a day to each grown fowl or two ounces every other day. When fresh bone cannot be had, beef scraps, meat meal or blood meal make excellent sub- 


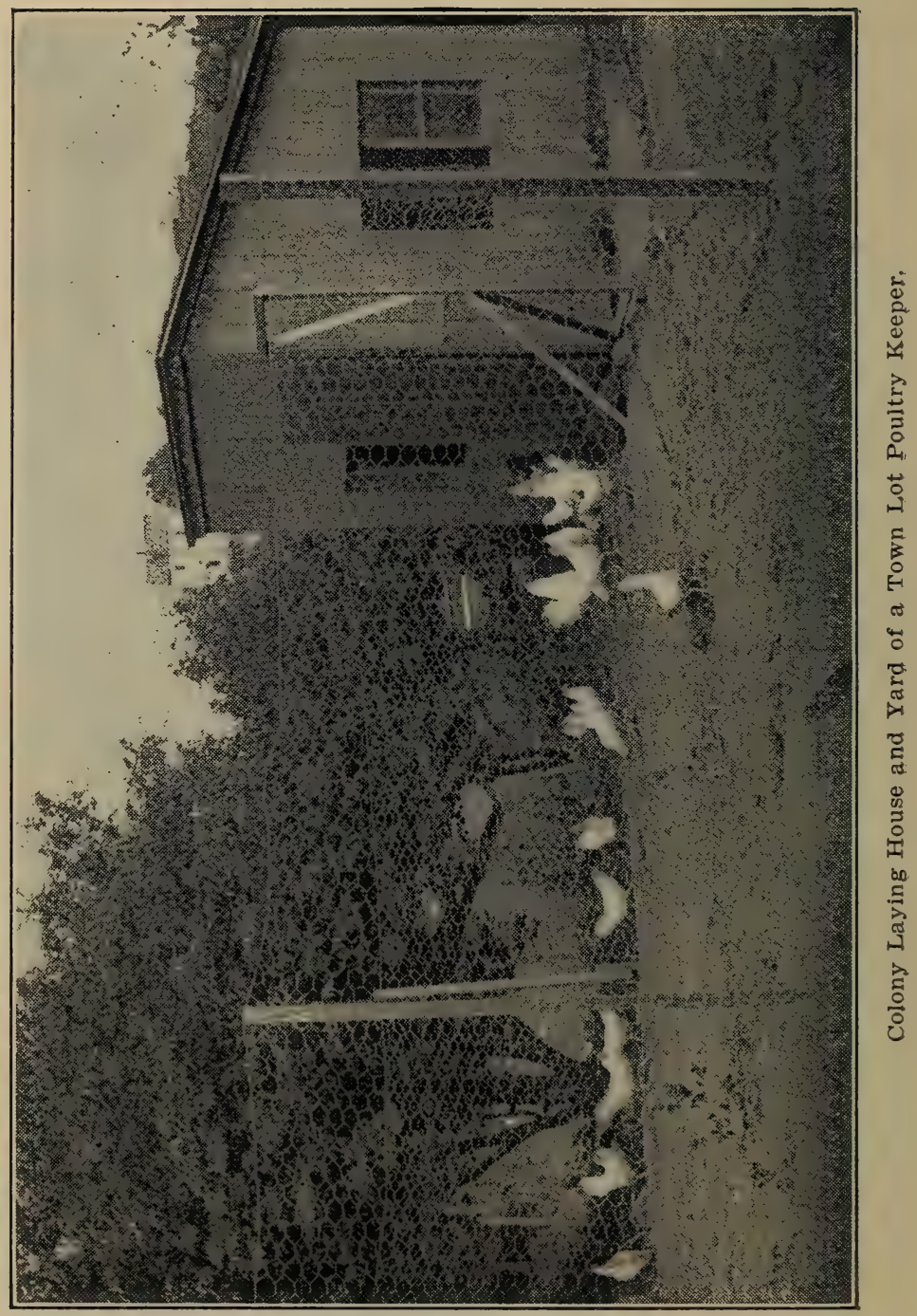


stitutes. Hens lay best in the spring when green food is plentiful and in the winter either alfalfa meal or roots of some kind should be given at least every other day. As a regulator and blood purifier nothing is better than granulated charcoal and it is not expensive. It should be within reach of the fowls the year round. Hens lay very little while molting. Sunflower seed fed every other day during the molt will furnish the oil necessary for new feathers, and a good prepared poultry food fed each day in slightly dampened mash will give the fowls the strength to withstand the weakening process of molting.

The main food for poultry is whole and ground grains and seeds, and I will not attempt in this short article to lay down any definite rules for feeding, but will give my method of feeding in a general way. First, it is important that quite a variety of grain and seeds be supplied, for fowls as well as people require more than one kind of food. The proper way to feed grain is to scatter it in the litter so that the chickens will have to exercise to find it. Some poultrymen claim to get best results by feeding only dry grain while others feed a mash either morning or night. Personally I prefer scattering millet and small grain in the litter in the morning as this will keep the fowls busy most of the day and the exercise will warm them up and keep them in health. At noon give a light feed of green cut bone and coarse grain. Just before roosting time feed a mash composed of one fourth alfalfa meal, one fourth bran, one fourth ground oats and one fourth coarse corn meal. Add to this your table scraps and a little prepared poultry food. Feed only what will be cleaned up in ten or fifteen minutes. In mixing the mash scald with boiling water but do not make it sloppy. The mash should then be covered and allowed to stand until cool enough to feed. I would only feed a mash during cold weather depending on grain and seeds during the warm months. My reason for feeding mash at night is that it warms the fowls and can be easily digested while they are at roost.

To put it all in a nut shell, provide variety, do not overfeed and do not use shrunken grain or half spoiled food; if you want eggs that are sweet and of good flavor use the 
best food obtainable. Your little account book will tell the story at the end of the year.

\section{Sunlight, Pure Air and Exercise are as Necessary as Good Foods.}

\section{By A. J. Saterstrom.}

"How do you manage to get your hens to lay so many eggs in winter?" is a question frequently put to us by our neighbors. There is a time of the year when we are all planning for winter eggs. We wish to give a few hints along our experience in securing them. We believe most any variety or breed can be made to lay in winter by proper care and housing. As our regular business allows us but limited time for the care of our fowls we cannot keep a large number; we expect to winter about one hundred hens each winter.

For several years our hens would not yield to the care we gave them as well as we thought they should and we finally concluded that the fault was with the house. We built the house from the best material and employed a good carpenter, but, although it was warm, it seemed dead and gloomy. We had put the windows quite a way up from the floor and ventilation was not very good. So we went to work and cut the windows down to fifteen or eighteen inches from the floor and made them twice the former size; we also cut a hole in the south wall twelve by forty-eight inches, near the ceiling and made two flues, four by six inches, reaching through the roof and ceiling and down to within ten inches of the floor. That made excellent ventilation and we now have a house with plenty of sunlight in it as well as a constant flow of fresh, sweet air.

We give our hens fresh water in the morning, leaving it in the basins until next morning, when the basins are cleaned and refilled. We keep the water basin so that the hens cannot step into or soil the water and high enough so the fowls cannot scratch any straw into it, thus keeping before them at all times a supply of clean water.

We use no artificial heat but had no ice on the water except once or twice, all last winter, although we kept 
the twelve by forty-eight space in the wall open all winter with but a thickness of burlap tacked over it.

We do not believe in soft feed in this climate. We have no fixed ration but feed a variety, comprising oats, wheat, barley, a little corn, mangels, cabbage, rutabagas, clover and scraps from the table. At times we feed the grain mixed and then again separate. We feed three times a day, usually oats in the morning, wheat at noon and barley or oats and corn mixed at night. We also throw in some millet occasionally. We feed all our grain in a liberal supply of straw which is exchanged for clean as soon as it gets dirty. We fed green cut bone or meat scraps two or three times a week and some charcoal. We keep grit and oyster shell always before the fowls as well as a dust bath with some sulphur sprinkled in it. We never use any medicines or condiments as we very seldom have an ailing fowl, and when we do we use the hatchet. We clean the dropping-boards on a certain day every week.

With this kind of care we get a goodly number of eggs every day all winter. Lots of sunlight, pure air, water, and plenty of exercise, together with plenty of food in a reasonable variety will make most any hens lay in winter, provided they are from a laying strain. Don't be afraid of feeding too much to laying hens; it requires food to make eggs but be sure to give plenty of grit and avoid too much corn.

\section{Fresh Air, Exercise, and Cut Green Bone are Important}

\section{Features in This Poultryman's Method.}

\section{By Alfred A. Ziemer.}

The question asked by poultrymen at this season, seems to be, "How shall I house, feed and care for my hens to get the best results in winter eggs?"' When cold weather sets in eggs are high in price and some people wonder because their hens don't lay; but they may take it for granted that such instances are always the results of wrong 
methods of housing, feeding and caring for their hens. I have always found that when the poultryman does his part and cares for the fowls properly, they will not fail to produce plenty of winter eggs.

My manner of housing, feeding and caring for my own flock has proved very successful. My houses are fifteen by thirty feet in size, simple, but well built of matched boards covered on the outside with prepared roofing and lined with tar-paper. This makes a very tight, warm house. Two-inch mesh wire netting is stretched on the under side of the rafters and the space between the roof boards and the wire is packed with oat straw which keeps the house warm and free from dampness. Curtains made of muslin are drawn at night in front of the roosts, making it comfortable for the sleeping fowls during cold nights and at the same time admitting plenty of fresh air for the fowls to breathe. I cover the ventilating areas and the windows with same material to cut off drafts and to keep out cold winds. This muslin, however, does not prevent plenty of air getting into the house and I consider pure air of great importance as a means of preserving the health of the fowls. Each house is divided in three parts by wire netting partitions, making each compartment fifteen by ten feet on the floor and sufficient for twenty fowls. The windows are on the south side, admitting plenty of sunshine, which is better for the fowls than medicine. A dust bath is provided in each pen and the roost platforms are cleaned every morning.

In the morning I feed oats, wheat, barley and some kaffir corn and other small seeds scattered in chaff which covers the floor. This encourages the bird to scratch and thus obtain exercise, which is very needful for health and productiveness, and neglecting it is sufficient cause for a lack of eggs in cold weather. As man must earn his bread by the sweat of his brow or he will not appreciate it, so the hen that does not have to hustle for her food will not have a. wholesome relish for it.

At noon my fowls receive a mash of bran, ground oats, barley and cooked potatoes, moistened with milk. For the evening meal, they are fed shelled corn, oats and barley. 
I want to say a word in favor of green bone for laying hens. $I$ believe it is more effective as an egg producer than any other one thing that can be fed. Every poultryman whose desire it is to get winter eggs should not fail to feed it.

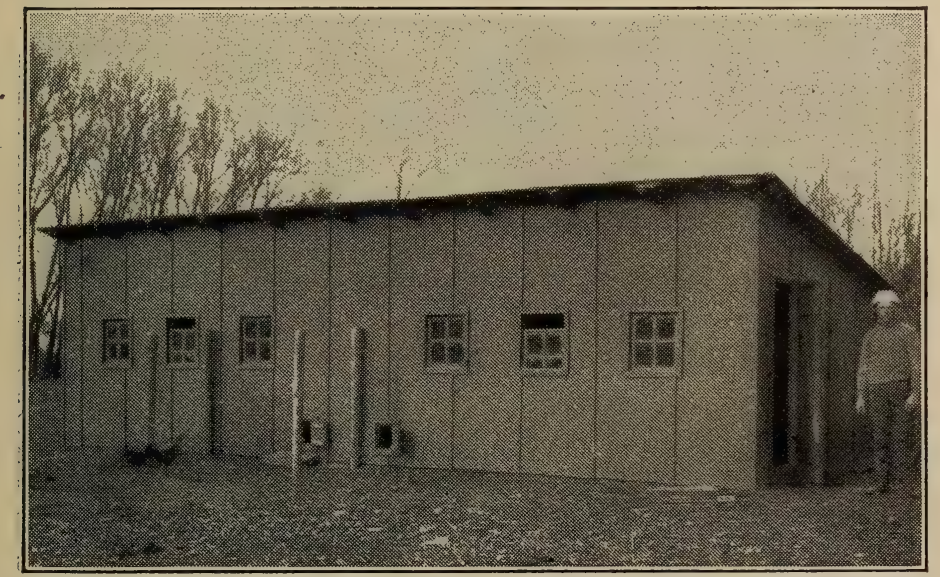

One of the Laying Houses on the Poultry Farm of A. A. Ziemer. Note the Small Area of Glass.

Cabbage and other green food is before my fowls almost all the time and clover, grit, shells and charcoal are where the fowls can reach them any time. Pure, fresh water is provided frequently. Hens cared for in this manner will not fail to produce their share of eggs in winter. None of our varieties of Buffs have ever failed to lay a liberal number of eggs in the severest weather. Don't expect your hens to lay well unless you care for them well.

\section{A Combination of Mash and Dry Grains Makes a Good Ration. By D. W. Harberts.}

My method of caring for and feeding fowls for eggs in winter is as follows: I have my houses warm and perfectly dry and large enough so there will be no crowding. 
The windows are arranged so that the birds receive the benefit of the sun the greater part of the day. I have a large scratching room, where they have plenty of room for exercise, which I fill with straw or leaves to the depth of eight or ten inches. In one corner I have a dust box filled with dry road dust and at times put in a little lice killing powder. I have the dust box set so that the sun shines on it, as a hen likes to dust herself in the sun.

I give warm water to drink early in the morning and also at noon, which assists to warm them up. In the morning I give a mash composed of bran, ground corn and oats to which I add about half as much fine cut alfalfa or clover and about one half to one ounce of fresh cut green bone for each hen. I pour boiling water over this mixture to scald it and then mix in some milk. I feed this mash in a clean trough, about all they will eat in fifteen or twenty minutes. At noon I scatter wheat, barley, millet and sometimes oats in litter where they must scratch for it. At night I give them shelled corn in the same way, just what they will eat up clean; they go to roost with full crops. I take care that they do not get too fat. I mix all the table scraps with the morning mash and keep grit and charcoal before them at all times. I have used this method of feeding in winter for a number of years and always get a nice lot of eggs.

\section{Barley is The Principal Food Fed by this Successful Breeder. By M. Keller.}

To promote winter egg production I keep my coops as clean as possible, for if filth is allowed to remain in them, or dead fowls are left to decay there, it is useless to expect the hens to lay well. My coops are cleaned at least twice a week and air-slacked lime scattered on the floors to absorb the dampness and purify the air. As soon as the ground is frozen the fowls are kept in the coop. They will not lay if allowed to run around in the cold.

Barley is the principal food furnished but we never keep them on one food constantly. We keep the coops bedded with nice clean straw and the barley is scattered 
in it so that they have to work for it. We also feed corn, but not shelled. A very good way to get green food is to take an old quilt or blanket, lay it down on the cellar floor, put two or three pounds of barley on it, then wet it thoroughly and allow the barley to sprout. After the sprouts are from one-half to three-fourths of an inch.long, feed them to the hens once a day. This will answer for the green food that they get in the summer.

My birds always have good clean water and all the milk we have to spare. Cabbage is also given them once or twice a week.

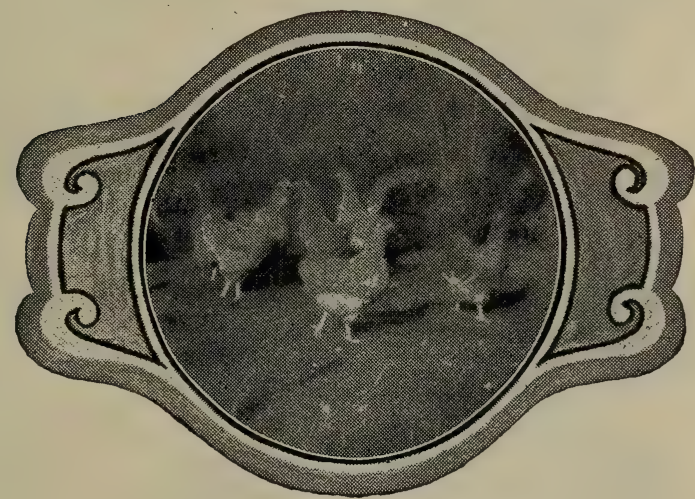




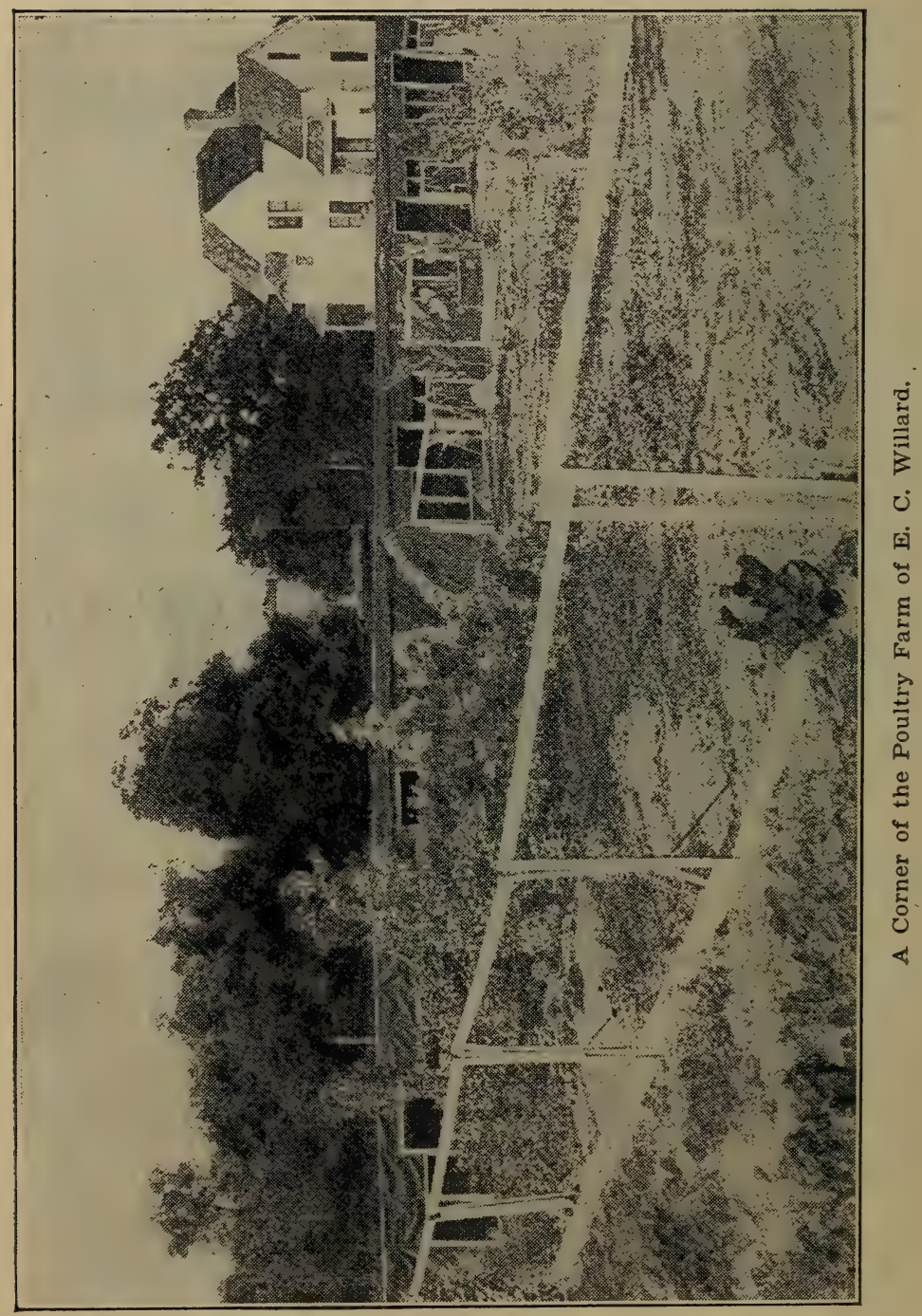




\section{FILLING THE EGG BASKET.}

\section{How a Well Known Breeder's Standard=Bred Fowls are Housed and Fed to Produce Plenty of Eggs When Prices are High.}

\section{By E. C. Willard.}

A cut of part of our laying house, which is 192 feet long, is presented herewith. It is built on a wood foundation. The frame is of $2 \times 4$ pieces. The walls are of waste lumber, box lumber and hemlock boards, with single-ply tar paper inside. The roof is made of shiplap, and the whole outside is covered with prepared roofing. The partitions are built of common boards, except a door three feet wide at the south. The door is made of netting stretched on a frame and is hung on double-acting spring hinges. The house has eight pens, each $10 \times 24$ feet. Each pen has a doorway in front, $4 \frac{1}{2} \times 6$ feet, and four openings, each for a twelve-light, $8 \times 10$ glass, window. At the bottom of the doorway there is a board door, $41 / 2 \times 4$ feet, opening outward and the space above is closed by a muslin screen during severe weather and when storms would beat in. We keep the whole doorway open in mild weather and on bright days in real cold weather. We have wire screens to be used to confine the fowls when the door is open, if necessary. And we try to keep a space in front of each pen clear of snow during the winter, so that the hens can get out in the air. The floors are of dirt and sand, covered with straw to a depth of six or eight inches in winter.

The furnishings in each pen are a long feed box, a refrigerater pan for water, set in the partition so as to serve two pens, nests of various sorts, droppings boards and perches. Two pens are provided with burlap curtains to enclose the roosts, but we did not find it necessary to use them last winter. It is our intention to leave one half of the glass out of this house this winter, filling the openings with muslin tacked on light frames. The breeding 
houses are about the same as the laying houses, except that the pens are smaller. We have about fifty pullets in a flock in this laying house. We find this style of house quite convenient, very satisfactory and not expensive.

\section{Feeding the Layers.}

We feed good, sound grain, wheat, oats, parley, cracked corn on the cob, all fed in the litter. We are now feeding nearly one-fourth corn and in the dead of winter we feed it five times a week for the evening meal. Two evenings we feed boiled oats in troughs. The other grains are fed in about equal parts for the morning feed which is scattered in the litter either after the fowls go to roost at night or before they get off the perches in the morning. We keep grit, shell, charcoal, beef scraps and dry mash (made after the Mass. Experimental Station formula) before the fowls. in boxes all the time. During the latter part of the morning we feed vegetables, including cabbages hung by strings. from the roof, and sugar beets, mangel-wurzels or turnips. stuck on nails in the walls. Part of the time we give clover and twice a week a feed of chopped onions. The clover is sometimes cut and steamed, but more often it is fed dry and uncut. They eat more of the steamed clover, but it. is quite satisfactory dry and uncut.

The hens are treated the same as the pullets, but are not fed so much food. Our methods are very simple and can be put into operation by anyone.

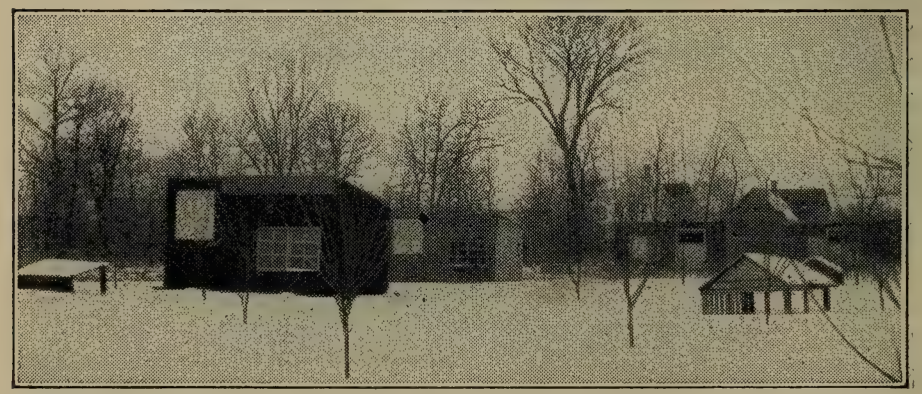

A Group of Colony Houses on the Poultry Farm of E. C. Willard 


\section{A FEEDING EXPERIMENT.}

\section{Results of a Two=Months Test of Dry Mash Fed in Hoppers Versus Damp Mash in Troughs, Conducted at Minne= sota State Experiment Farm, Crookston.}

\section{By Gus Walters.}

Experiments were in progress for two months, from Dec. 12, 1905, to Feb. 12, 1906, to ascertain the cost of egg production and the efficiency of different methods of feeding.

Two pens of White Leghorn pullets (50 to each pen) were made up a week before the experiment began so the fowls of each pen would get accustomed to surroundings and kinds of food. Equally good birds were put in each pen (nearly all of an age) before the experiment began. Both pens of pullets gave practically the same number of eggs per day for several days before the test commenced.

Pen No. 1 was fed the ground meals dry in a hopper or box so the fowls could help themselves at all times. The box contained two compartments; in one was put all the meals mixed together and in the other the beef scraps.

Both pens were fed the whole and cracked grains scattered in the litter of straw on the floors, about one-third as much at the morning feed as at the night feed.

Pen No. 2 was fed the ground grain in a mash daily, at noon, mixed with warm water and fed in troughs, all they would eat up clean in about ten minutes. The pounds of food each pen of fowls ate during the two months was as follows:

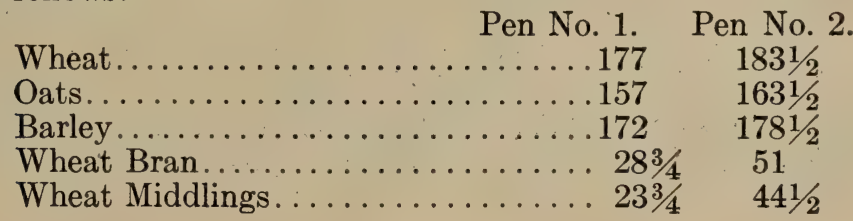


Ground Barley ................ 283/4

Beef Scraps ................ 69

Cut Green Bone............... 13

Alfalfa Hay.................. 11

Oyster Shells................. 20

Grit.................... 13

It will be seen that those in pen No. 1 ate more beef scraps and less of the meals than the fowls in pen No. 2 . We think that if the pullets in pen No. 1 had been fed by the dry feed method from the time they were hatched in spring until the experiment began; they would have been more accustomed to the kind of food and would not have consumed so much beef scraps, but more of the meals, which would have given better results. Pen No. 1 pullets appeared not to relish or like the dry mash as well as the pullets in pen No. 2 did their damp mash at noon.

The following table shows the cost of food and the results obtained from each pen:

Pen No. 1. Pen No. 2.

Cost of food for 2 months.........\$6.857 \$6.844

Dozens of eggs received, total....93 $7-12 \quad 1011 / 2$

Value of eggs at $27 \mathrm{c}$, a verage price, $\$ 25.28 \quad \$ 27.45$

Average number of eggs per day ... $18.2 \quad \ldots 19.6$

Nutritive ratio of food consumed.. 1:4.1 $\quad 1: 5$

It was noticeable at the close of the experiment that the pullets in pen No. 2 were in better condition of health than the pullets in pen No. 1. This we think was due to the fact that the birds in pen No. 1 ate too much beef scraps which made the ration too narrow or stimulating, but if the beef scraps had been mixed with the meals in the same proportion as in the damp mash fed to pen No. 2, we think that they would have done equally well. Another pen of Leghorn pullets was fed the same as pen No. 1 pullets, except that the beef scraps were mixed with the meals in about the same proportions as in the damp mash that pen No. 2 received.

This third pen of pullets did as well as pen No. 2 as regards egg yield and condition of health at close of experiment, but as it contained varying numbers and for other reasons, we did not keep an accurate account of food consumed: 


\section{THE TRAP NEST.}

\section{Its Use Enables the Poultryman to Weed out the Barren and Unprofitable Hen.}

\section{By G. I. Lytle.}

Every poultry keeper has no doubt had the desire to know the individual record of each of his fowls. Heretofore it has been impossible to gratify that desire, as no one could afford to pen each of his fowls separately. The advent of the record nestbox has now made it possible for every poultry keeper to know the exact number of eggs produced by each of his hens.

The desire to know is the result of a natural inference that individual records would show that hens vary as much in the number of eggs laid as different cows vary in tho amount of milk produced or horses in their speed. Without doubt, there is more difference in the laying qualities of various hens, for only the best cattle and horses have been used as breeders for years, while poultry keepers havo not known whether the eggs they used for hatching were from hens that laid 200 eggs a year or only twenty.

A difference in the number of eggs means a decided difference in the amount of profit. $\mathrm{A}$ hen which lays only fifty eggs a year hardly pays for her feed, and the owner receives nothing for his labor or money invested in buildings, etc. A hen which lays 100 eggs a year pays for her feed, interest on the money invested and a small return for the labor, while the hen that lays 150 eggs a year yields a profit for her additional fifty eggs that is clear profit. The hen that lays 200 eggs a year must yield a handsome profit; in fact, it is over 100 per cent. Every poultry keeper should know the exact number of eggs laid by each fowl in his flock, that he may keep only the decidedly profitable.

\section{What Tests Show.}

Tests made with record nest boxes show that there are at least two hens in every twenty that never lay, and eight 
more which only lay enough collectively to pay their way. The other ten produce all the profit, which is diminished by the expense of the two which never lay. The conclusion is that half of any flock will produce more profit than the whole flock, which is true. The only question is to know which hens to keep and which to dispose of.

As a sample, an egg record made by a pen of my fowls during the month of July, when record nest boxes were first placed in that pen, shows the conditions existing in every flock before it has been sifted by the use of a nest box which gives the individual record of each fowl.

This record was made somewhat after the heaviest laying season, but it shows very accurately the relative laying qualities of the different hens, as proven by the succeeding months.

There were two hens, No. 3 and 6, which laid no eggs during the month, nor did they at any time thereafter.

The contrast between the good layers and the poor layers can be seen in the following columns:

Hen No. 3 laid................... 0 eggs

Hen Ho. 6 laid................... 0 eggs

Hen No. 16 laid..................... 1 egg

Hen No. 9 laid. . . . . . . . . . . . . . . . 6 eggs

Hen No. 19 laid................... 8 eggs

Hen No. 14 laid.................... 10 eggs

Hen No. 18 laid. .................. 15 eggs

Hen No. 20 laid.................. 17 eggs

Hen No. 2 laid..................18 eggs

Hen No. 8 laid..................19 eggs

Total.................... eggs

Hen No. 1 laid....................19 eggs

Hen No. 7 laid. .................20 eggs

Hen No. 12 laid. ...................22 eggs

Hen No. 13 laid...................22 eggs

Hen No. 17 laid..................22 eggs

Hen No. 5 laid. ...................23 eggs

Hen No. 4 laid..................24 eggs 
Hen No. 15 laid.....................24 eggs

Hen No. 10 laid.....................25 eggs

Hen No. 11 laid,$\ldots \ldots \ldots \ldots \ldots \ldots \ldots \ldots 26$ eggs

Total..................... $\overline{227 \text { eggs }}$

The ten poor layers produced a total of only 94 eggs, a little over nine eggs apiece, while the ten good layers produced 227 eggs, or nearly twenty-three eggs apiece. The ten poor layers more than paid their way in summer, but fell behind in winter, so that the value of their eggs for the year was less than the expense of keeping them. The good layers in summer proved to be the good layers in winter also.

As a result of the use of record nest boxes for two seasons my egg yield this year, for the same number of fowls, has been well on to double what it was before putting in record nest boxes.

\section{The Direct Benefit.}

A record nest box will accomplish the following with any flock: It will show which are the barren hens; it will show the exact number of eggs produced by each laying hen; it will enable the owner to keep only the ten prolific layers out of every twenty hens, and to thereby increase his profits; it will enable the owner to place twenty prolific layers where he now has ten prolific layers and ten poor layers, and to thereby more than double his profits with the same buildings, ground, feed and care; it will make it possible to use only the eggs from the best layers for hatching, and to thereby produce a prolific laying strain. 


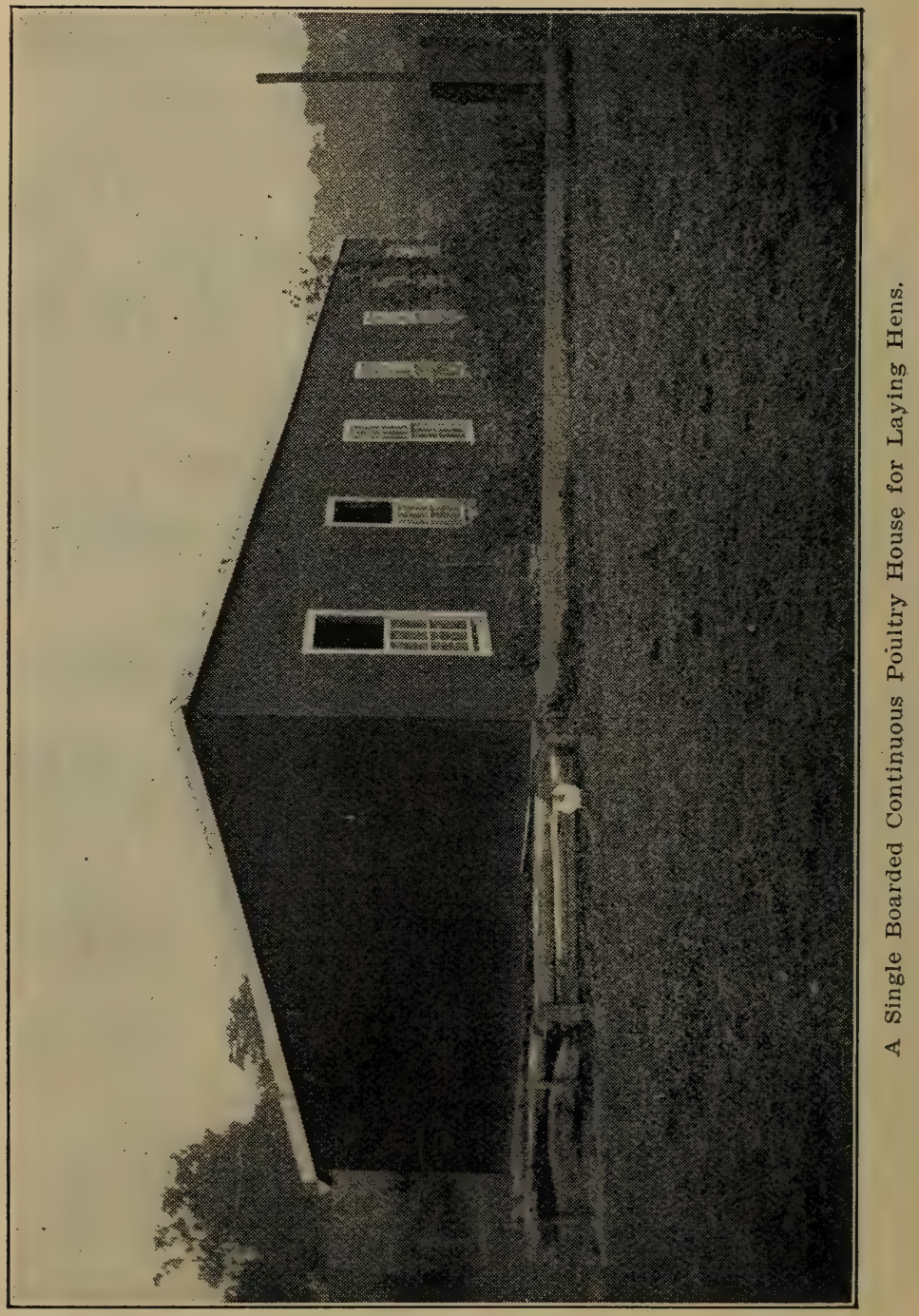




\section{PRESERVING EGGS.}

\section{How Eggs are "Put Down" in the Season of Greatest Pro= duction, When the Price is Low, to Keep Until the Price is High.}

\section{By E. F. Ladd.}

At the present time eggs are largely packed in lime, salt and other products, or are put in cold storage for winter use, but such eggs are very far from being perfect when they come upon the markets, and frequently more than one-half of them are unfit for use, if we are to judge from the condition of most markets. A method to be generally employed must be simple, cheap, and the eggs, when wanted for use, must be of good quality.

There was need for a simple method of preserving eggs; one which would enable the farmers or the consumers to put away eggs during the summer months when they are plentiful and command but a small price, to be used in times of scarcity when the price of eggs rules exceptionally high. For this reason we were led to make experiments in preserving eggs by various means. Of the methods tested, water giass was the most promising and our experiments continued through several seasons with most satisfactory results.

The shell of an egg has a very thin coating of mucilaginous, albuminous matter upon its surface that seems to protect the eggs for a considerable time from atmospheric action or the introduction of the germs of decomposition. If this coating be removed immediately after the egg is deposited, while still warm, the keeping quality seems to be much reduced, or if eggs that become soiled in the nest are washed, this albuminous coating is softened and the life of the egg shortened thereby.

\section{Water Glass the Best Preservative.}

It is believed that in water glass we have a preservative which will, when used for preserving eggs, give better satis- 
faction than any other method available for those who desire to keep eggs for any great length of time.

Eggs put down by this method have been kept from three to nine months, and the eggs have come out in better condition than by any other method tested. When strictly fresh eggs only have been put down, at the end of six months they have invariably come out in better shape than the average market eggs supposed to be fresh.

This method has been tested, in a commercial way, in nearly every state and part of our country, and we have not had to exceed eight adverse reports. One party in Maine reports that during the summer of 1903 he put down, by this method, 6,000 dozen of fresh eggs, and, in the following December and January, he was selling these eggs, receiving the highest prices paid for strictly fresh eggs, and was frequently told that they were the best to be had. We might quote from such trials made during the past threc years by parties in North Dakota, California, Carolina, New York, etc., but the general tenor of all is about the same.

After experiments made with solutions of various strengths, and under varying conditions, we found that an 8 to a 10 per cent solution of water glass would preserve eggs very effectually, so that at the end of eight months eggs that were preserved the first part of the summer appear to be perfectly fresh. In most packed eggs, after a little time, the yolk settles to one side and the egg is then inferior in quality. In boiling eggs preserved for eight months in water glass the yolk retained its normal position in the egg, and in taste they were not to be distinguished from fresh, unpacked store eggs. Again, most packed eggs will not beat up well for cake-making or for frosting, while eggs from a solution of water glass seemed quite equal to the average fresh store eggs of the market. It should be borne in mind that in these experiments only fresh eggs were used for preserving; no egg was more than four days old. Eggs that have already become stale cannot be successfully preserved by this or any other method so as to come out fresh. 
Water glass (Sodium Silicate) is a very cheap product that can usually be procured at not to exceed fifty cents per gallon, and one gallon will make enough solution to preserve fifty dozen of eggs, so that the cost of material for this method would only be about one cent per dozen. Waterglass is sodium and potassium silicate, sodium silicate being usually the cheaper.

\section{Eggs Must Be Fresh.}

The eggs to be put down by this method must be fresh and not stale store eggs. A few stale eggs will soon injure the entire lot. One party reports that he put down two lots of eggs, fifty gallon jars in each case; one lot strictly fresh eggs, the other contained some stale store stock and the first was a complete success while the second lot came out about like the ordinary packed eggs, some fair, some spoiled.

A good grade of water glass must be used. Some of the cheap water glass contains so much of free, uncombined alkali that the eggs preserved in such solutions become watery and acquire a bad flavor. I prefer water glass in the form of heavy white jelly which flows like heavy cold molasses. Of this grade of water glass somewhat less is needed than when the thinner produce is employed. The dry powder water glass has not as a general rule dissolved fully in hot water. and for that reason has not proven as satisfactory as the first named product.

Galvanized iron vessels, crocks, jars, etc., may be used in which to preserve the eggs. Wooden kegs of good quality are satisfactory, but these must be thoroughly sweetened by scalding with boiling water.

There have been a few complaints that barrels have not been entirely satisfactory as the water glass dissolved some products which deposited on the eggs. I am inclined to think this may have been due to the presence of glue used as sizing for the barrel. When the barrels have such a coating it might be well to char the inside of the barrel by placing in it a few shavings saturated with kerosene oil and then throwing in a lighted taper and allowing the sides of the barrel to become charred. This barrel well burned 
and then thoroughly washed should be free from any gluelike products.

\section{Preparing the Solution.}

For those who may desire to test the method I give the following directions:

Use pure water that has been thoroughly boiled and then cooled. To each ten quarts of water add one quart or slightly less of water glass. When the heavy jelly-like solution is used, three-fourths quart of water glass will be ample.

The solution may be prepared, placed in the jar and fresh eggs added from time to time until the jar is filled, but, be sure that there is fully two inches of water glass solution to cover the eggs.

Keep the eggs in a cool, dark place and well covered to prevent evaporation. A cool cellar is a good place in which to keep the eggs.

If the eggs are kept in too warm a place the silicate is deposited and the eggs are not properly protected. Do not wash the eggs before packing, for by so doing you injure their keeping quality, probably by dissolving the mucilagenous coating on the outside of the shell.

For packing use only perfectly fresh eggs, for stale eggs will not be saved and may prove harmful to the others. All packed eggs contain a little gas and in boiling such eggs they will crack. This may be prevented by making a pinhole in the blunt end of the egg. To do this hold the egg in the hand, place the point of a pin against the shell of the egg at the blunt end and give the pin a quick, sharp blow, just enough to drive the pin through the shell without injury to the egg.

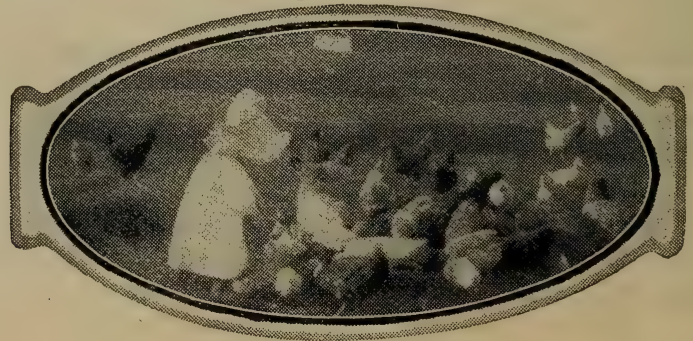




\section{REGULATING THE MOLT.}

\section{A Successful Molt is Necessary for the Well=Being of the Profitable Fowl-The Required Care and Food.}

\section{By T. F. Rigg.}

Fowls which have been properly fed, housed and otherwise cared for molt in August and September, and while such stock demands some special attention at that time there is no need of any loss. Fowls molt in accordance with the law of nature, and molting is no particular strain upon an entirely healthy fowl.

We must keep in mind all the time that we are, in a great measure, rearing and keeping our domestic poultry under unnatural conditions. The fowls of the air and the woods and the prairie molt slowly. This is a wise provision of nature. These birds are subject to all the changing conditions of the weather. Nature does not rob them of all, or practically all, of their feathers at once, as man's treatment of fowls very often robs the fowls of their entire coat of feathers.

I spend some time every fall in search of the prairie chicken, the quail and the duck. There is never a time when the experienced person could detect by handling one of these birds that it was in a molt. Nature not only protects them against cold, but never for a day takes from them the power of rapid flight by having them drop all the old feathers at once.

We, as breeders of poultry, can practically regulate the molting of our fowls. Where proper attention is not given, the stock often suffers during the molting season. In all his operations the successful fancier-let us designate him as the man who succeeds, for then we. will more strongly impress the reader-knows that the different stages through which his fowls must pass crowd upon one another very rapidly. It is, after all, but a brief time from chickenhood 
to maturity, when a chick becomes a fowl. The fancier so feeds and so handles his stock that it is fully able to meet the requirements of the different stages through which it must pass. And so, when the molting season comes his fowls are in condition to molt properly. He has brought them to this period fully prepared for the ordeal through which they must pass.

\section{"Rugged" Fowls Molt Best.}

How has he accomplished this? Well, an answer to this question would necessitate the covering of the whole field of fowl management. Let me tell you in brief how I have handled my stock, and as the work has annually been satisfactory in results, it may be that it will prove of interest and profit to you. In the first place, the stock has been bred right, coming down along the line for years from absolutely healthy and rugged stock. This is important. Then as newly hatched chicks, as growing chicks, as breeders, they are handled and fed and housed so as to develop their every faculty. But let us more particularly refer to the management having a direct bearing upon the molting of the fowls. From the day the stock is placed in the breeding pens we feed heavily, and by so doing we are sustaining every element in the fowl's nature, flesh, blood, bone, muscle, feathers, etc., and are getting an abundance of eggs. If we did not thus sustain the various elements in the fowl we could not and would not secure a liberal supply of eggs. Here is where a great mistake is made by many. Here is where the theorist in his writings as regards feeding for egg production overlooks a fundamental law of nature. It is a fact beyond dispute that it is during the period of the most heavy feeding, when that feeding is proper, that we secure our greatest egg production. The various organs of a hen must be working in harmony with nature's requirements before she can possibly give nature's full output. A hen cannot possibly lay an abundance of eggs unless all her being is supplied fully with the food elements required. There is no product which can be fed to a hen that she can convert entirely into eggs. She must draw upon her food for the maintenance of all her being, and so 
we keep in mind in selecting our food rations the fact that our fowls will in the fall be in molt. We are feeding them all the time to meet this condition.

Fowls when properly fed begin to molt in August This early molt is the effect of what is sometimes called high feeding, but what is really proper feeding. Such fowls, by reason of the correct feeding, and the housing from rains and exposure, are in such a condition that they molt early, for, being strong and rugged and healthy, nature finds every requirement at hand and proceeds to business. It is another illustration of men working hand in hand with nature, aiding and abetting. That is all.

Now, as to bringing about this condition. Our practice has been to feed such rations as will thus put the fowls in this condition. This means that oats, both ground and whole, some corn meal, some oil cake meal, some beef scraps, raw bone, and like foods, have been daily given the fowls.

\section{Use of Oil Meal.}

We would not be without oil cake meal. It is one of the most valuable foods in all the list. It will keep the growing chicks in perfect condition so far as their bowels are concerned; it prevents loss of chicks by bowel trouble, the trouble that carries off a very large per cent of the chicks which die; it is rich in feather making properties, and gives the plumage a gloss that cannot otherwise be obtained. Not only this, but the fowls are supplied all the time with a blue grass and clover range. We have been building up the fowl in every particular, bone, blood, muscle, etc., and this ration, this care, supplies, according to nature, the very material necessary for feather making at the time of molt. 


\section{THE FORCED MOLT.}

\section{A Description of the Method Used on Several Successful Egg \\ Farms to Produce Early Shedding and Rapid \\ Feathering, that the Fowls May Lay in the Season of High Prices.}

\section{By H. A. Nourse.}

Inducing an early molt is comparatively a new operation in the business of poultry keeping. If we mistake not, the first to publicly describe the practice, was the prosperous proprietor of a New York egg farm. This man was in demand as a lecturer at agricultural institutes and it was during his lecturing tours that the method was first made public.

The advantages of such a method are manifest. As a rule the best layers of the first year molt late in the following fall. This applies with equal force to yearlings and twoyear-olds. Molting late, they naturally molt slowly, and before they have entirely produced their new plumage and recovered the strength lost in the process, and are in condition to produce eggs, the best of the season of high prices is over. During the latter part of the summer when the price of eggs is low they can readily be spared from the ranks of producers and at that time molting should take place in order that the fowls may recover their wonted productiveness before the beginning of cold weather.

Obviously the hens could not molt successfully while in full lay. Therefore the poultryman conceived the idea of turning these fowls loose in the fields to search for most of their food, feeding them only so much grain as was necessary to support them and that of a non-fattening nature. Under such treatment the egg yield decreased rapidly until it was represented by zero and the fowls themselves were rather thin in flesh, yet their blood was good and they possessed 
abundant vigor from their free life in the open air. At this point they were returned to the yards and fed heavily of food containing rather more carbonaceous material than usually is found in rations prescribed for laying fowls. This heavy feeding, with little exercise, induced a rapid shedding of the feathers and often in two weeks the discarding process was practically complete. This done, a strengthening, feather-building ration was furnished, including bone-forming foods for the bony structure of the feather, sufficient fat or canbonaceous material to maintain the heat or energy of the body and protein for the support of the muscles and tissues. More exercise was given, a run of considerable area provided with sufficient shade being preferred. Of course, other conditions were favorable. All sorts of vermin were kept down and the fowls were made comfortable by conditions conducive to health.

This procedure made comparatively short work of the molting season and in two months from the time of turning the fowls loose on the range, they appeared with a brand new coat of feathers and with healthy, vigorous bodies. If, then, the process began the first of August, the fowls were ready for business the first of October and laying well one month after. This plan, with slight variations, is, in use today on numerous large and small egg plants the country over and enables the poultryman to secure a heavy egg yield from his yearling and two-years-old hens at a time when eggs are money, and a time when otherwise the hens would be in full molt, or just recovering, and absolutely unproductive.

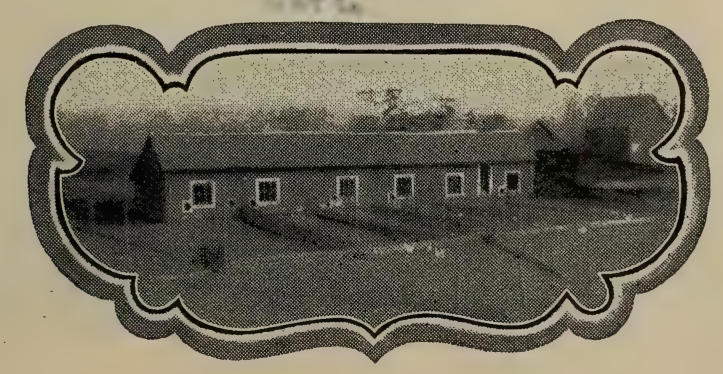




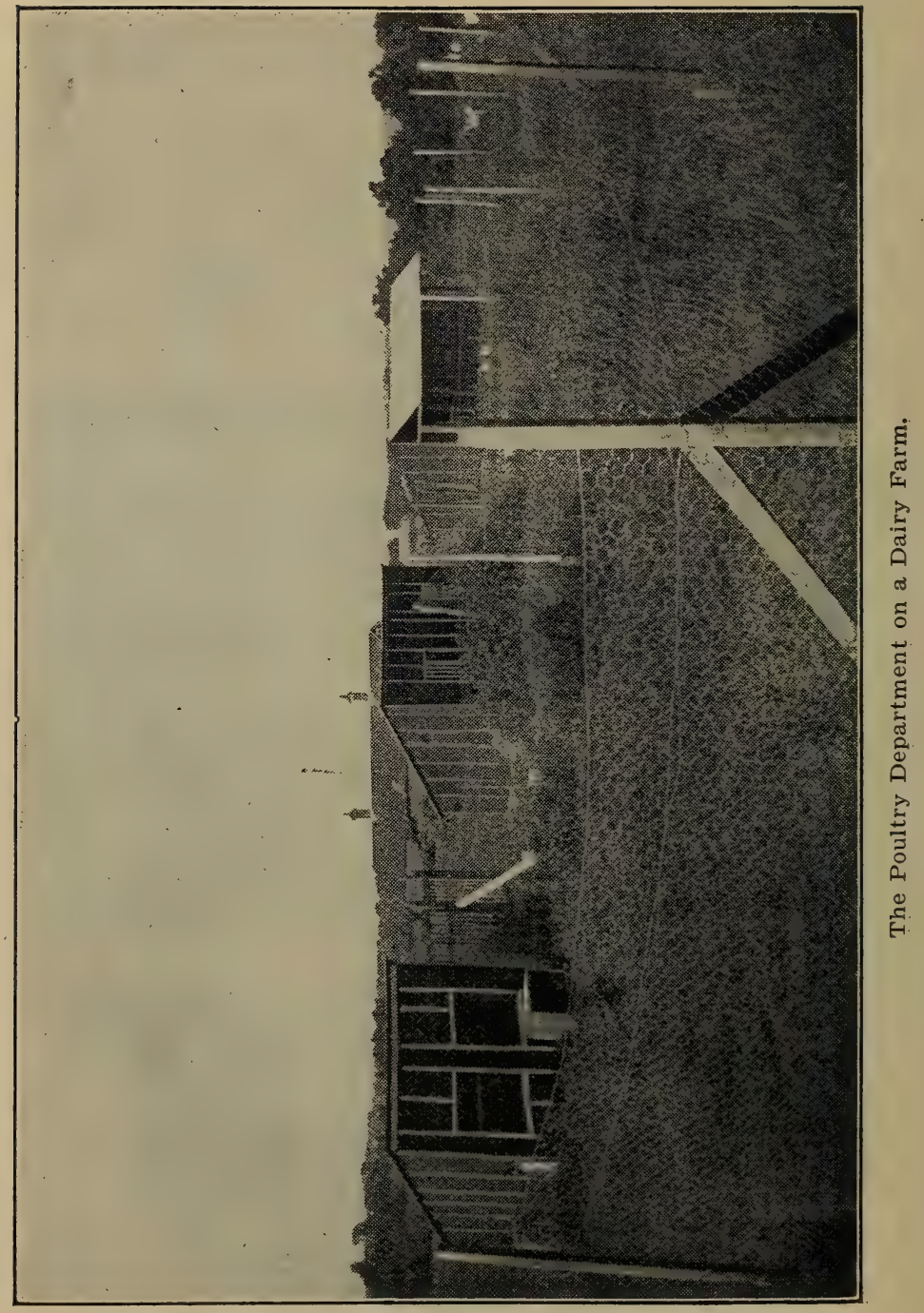




\section{THE 200=EGG HEN.}

\section{The Standard=Bred Hen That Will Lay Two Hundred Eggs in Twelve Months is a Reality-How She is Produced and Cared for.}

\section{By Victor D. Caneday.}

The question whether the 200-egg hen is a possibility seems to be having more than usual attention from the poultry press. There is evidently a growing faith among the more careful breeders as to the realization of the hen that can lay 200 eggs in a year. Naturally there are some who are skeptical with regard to such heavy laying, but probably most of the skepticism is due to a misunderstanding of the different writers.

Much which has been written, while not untrue, might be quite misleading to the casual reader. We do not think that anyone really believes the time will come when the average hen (take them right through the country as they run) will lay 200 eggs per year, although some might gather that idea from some articles which have been written on the subject. The 200-egg hen is a product of careful breeding and proper care just as truly as is the exhibition fowl, and there is not much more danger of the average hen becoming a 200-egg hen than that the average thoroughbred fowl will become an exhibition specimen.

A hen capable of laying over 200 -eggs in a year today is a phenomenal layer and has become such by careful, painstaking breeding, or else has been given unusually good care to accomplish that result. The beginner who starts into the poultry business expecting to get an average of 200 eggs per year from his hens will find he has made an awful blunder in his calculations, even though he purchased the best laying stock in the country to start with. Most beginners will be safer in estimating their first two years' egg product at 100 eggs per hen per year. We have made it one of 
our chief aims in breeding to breed for the best layers, and, among other things, we have learned that to obtain the maximum number of eggs from a flock of hens in a year they must be given a pen with ample room, and not be allowed to mingle with other fowls, nor other fowls be allowed to mingle with them. Everything must be as regular and systematic as clock-work in both care and feeding. Any

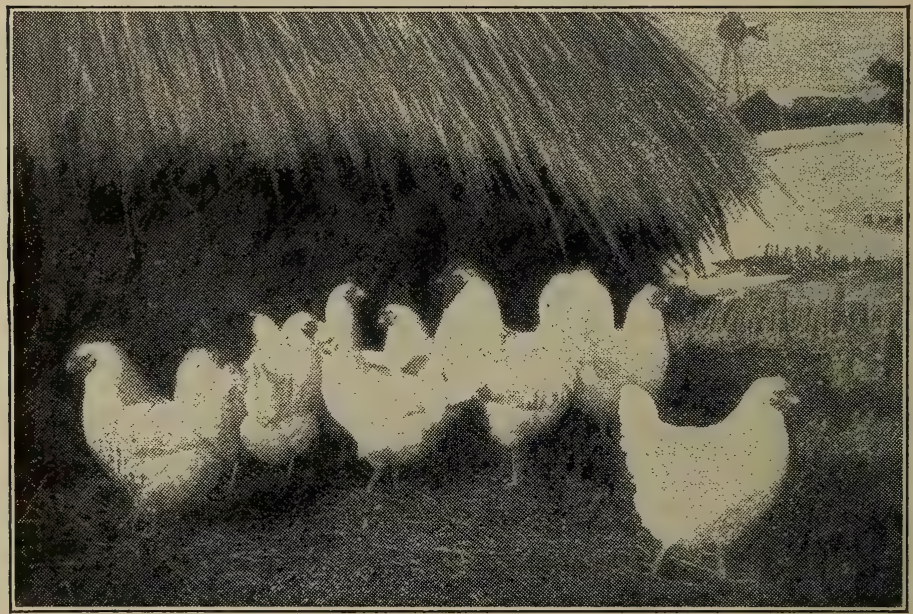

A Vigorous Male and His Family of Winter Layers Taking Out-Door Exercise in Mid-Winter.

sudden cnange of feed or unusual condition of any kind is quite apt to stop the most of the flock laying for from two weeks to a month.

Occasionally there are hens which will continue to lay pretty regularly when the conditions are such that the other members of the flock are non-producers. It is from such specimens the 200-egg hen must come. But their progeny, while having the continuous egg-laying habit, will vary considerably, some being much more persistent than others. By carefully selecting the most persistent layers from year to year and mating the best laying hens with males from equally prolific dams, the average egg yield of a flock can be wonder- 
fully increased; where the principal aim is to get the maximum egg yield, it is entirely possible to bring the average up to 200 eggs per hen per year. True, there are other things besides breeding which enter in; the hens must be properly reared so as to have rugged constitutions and their keeper must be an expert on the lines of feeding, care and housing.

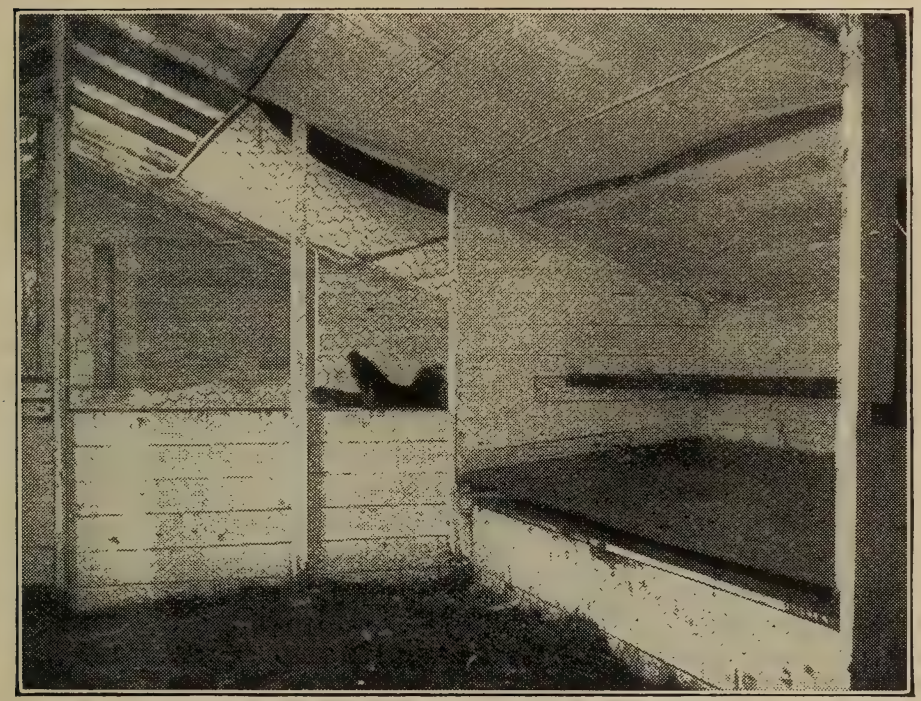

Interior of a House for Winter Layers, Showing the Roost and Roost Platform with Curtain to let Down in Front.

We have often wished that we could afford to give a pen of hens a fair show for a full year's record. We feel confident the results would be such as to establish the fact that careful breeding and good care easily produce a flock of 200egg hens. When we first began breeding poultry we found a very great variation in the hens as layers, some actually not laying fifty eggs in a year and one hen, which was a beauty and won second prize at the poultry show, was practically worthless as a layer. We found such hens fine eating on the table, but chose the best layers for breeders, and today the most of our breeding hens have records of from twenty- 
four to twenty-nine eggs in a month; several have laid from 150 to 165 eggs in eight months, and some have laid over 200 eggs in a year without special care or housing.

\section{Laying Versus Breeding.}

It is needless to say we have great faith in the possibility of the 200-egg hen, but we do not believe that one can obtain such large egg records from their fowls year after year and use them for breeders at the same time successfully. We now select our best layers by their best month's records and are confident that a hen which is capable of laying from twenty-five to twenty-nine eggs in a month would be able, under proper management, to lay 200 or more eggs in a year.

There is one other feature of this 200-egg hen subject where there seems to be a misunderstanding. Most writers who claim the 200-egg hen is possible, base their calculations on her first year as a layer, that is, they claim she is able to lay 200 eggs in one year. from the time she comes to laying maturity. There are not many hens which will give as good results in egg production the second laying year as they can in the first, for several reasons. In the first place if pullets commence laying in October or November they will often not molt until they have gone through the full twelve months, especially if they are carefully fed and housed. In fact, a good laying pullet is quite apt to molt later than the rest of the flock, and, of course, by so doing adds that much to her first year's record while deducting it from the second year's work.

Then there are some writers who seem to carry the idea that there are times when the weather is so cold that it is impossible to get a hen to lay a single egg. A good laying hen, when properly housed and fed, will not pay much attention to the extremes of temperature. In fact, the most of the secret of obtaining winter eggs is in preventing the flock feeling the extremes of temperature, by exposing them as much as possible in mild winter weather and taking care to keep them comfortably housed in the extremely cold weather. For such reasons as these it is clearly evident the average hen will not soon become a 200 -egg hen, because most flocks are too miserably housed and cared for in the winter for them to lay at all except in the mildest weather 
when they are comfortable out of doors and can find sufficient food for their purpose.

The use of trap nests and careful record keeping has disclosed the truth concerning the laying qualities of our purebred fowls. A flock which can produce an average of 150 eggs per year for each hen (and that is a mighty good lay-

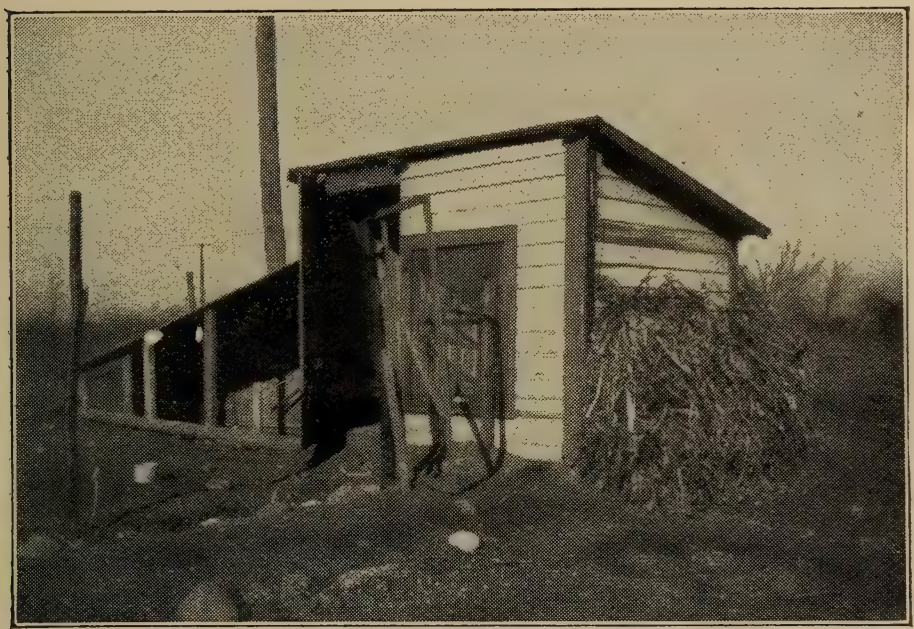

Comfortable Quarters for the Housewife's Fowls, Banked with Corn Stalks and Equipped with an Improvised Open Shed.

ing flock) is almost sure to have some hens in it that are laying 200 or more eggs in the year; but, if the breeder has no way of knowing which hen it is that is his or her best layer, there is very little chance of improving the laying qualities of the flock. The only practical way in which improvement in the laying can be accomplished is by careful selection and mating. Of course care is necessarily limited in its effect. One can give a scrub cow the very best of food and care, but she will not begin to give product in the milk and butter which the same care would bring from a well-bred Jersey of a heavy milking strain. Just so with the laying hena flock of hens which for generations have been selected and mated to produce superior layers will respond much more 
readily and freely to good care and feeding than will a flock which has not been bred and selected systematically for that purpose.

\section{Heavy Laying Requires Strength.}

For the benefit of the amateur we will say here that one should not expect to get strong, rugged young stock from a heavy-laying hen the same year in which her record as a layer is made. Continuous heavy laying is a great drain on the system and eggs from a hen after a long "period of heavy laying are not apt to give good results in fertility or produce strong, vigorous chicks. We know some writers claim that if a hen is properly fed continuous laying need not affect fertility and in part we agree with them, but the difficulty is to feed correctly, to supply the materials upon which the hens can sustain the wear and tear of the body, and at the same time keep up the egg yield. There is a happy medium between the two extremes. Happy is the man who has found it and can so care for his fowls as to obtain the maximum number of eggs from them without allowing them to either become too fat or too thin, for their best good in health and vigor. In isolated cases we know it is possible, but doubt very much if it is in the case of an entire flock unless they are all of one line of breeding with very similar characteristics. The hen which made the best year's record for us gave exceptionally good results in both fertility and vigor of chicks, but we consider that an exception to the rule and would advise the amateur to select his best layers from their monthly records or else breed from them the season following their record year. This is the method we adopted when we first began breeding standard poultry (at that time we did it through force of circumstances), but after several years of experience we are satisfied that it is the best method for the poultry breeder to follow. 


\section{RHODE ISLAND EGG FARMING.}

\section{A Description of the Primitive Equipment and Methods Used on Little Crompton's Famous Egg Farms-Buildings are Positively Cheap-Cracked Corn is the Principal Article of Food-Profits Average Seventy=five Cents to One Dollar a Hen.}

\section{By Arthur C. Smith.}

If one were to seek the soundest and surest business proposition in the entire field of poultry culture, he would be compelled to choose between rearing the winter softroasters as demonstrated by the South Shore poultrymen of Massachusett's and market egg production as conducted on plants of Little Crompton, Rhode Island. The first has been explained frequently, but the latter, the oldest and best established paying poultry enterprise in the United States, has seldom been described to the readers of poultry literature.

Little Crompton is a township in Rhode Island, at the most southeasterly point in the state. On the map, the southern portion of the territory that comprises the town appears to have been put there to separate Buzzard and Narragansett bays. To visit this most interesting poultry colony, in many respects the most interesting in the country, at least so considered by Mr. Edward Brown, the English poultry authority and writer, one must leave the train at Tiverton, R. I., and then procure a team for a drive of at at least twenty-five miles, if he wishes to see any considerable part of the colony. It is aptly termed a poultry colony, as nearly every resident has poultry, either as the main product of the farm or as an important side issue.

The drive from Tiverton around Little Crompton on a fine day is a very pleasant one, taking in asit does the scenery of both shores of the east channel of Narragansett bay. About five miles from Tiverton station and not far from the line that separates the two towns, the visitor comes to the 
top of a hill overlooking much of Little Crompton and below him is spread out many little farms, perhaps a score or more, each with its group of poultry cottages, all much the same in appearance. All are wood-colored, that is, none are painted, and so few whitewashed that they are scarcely noticed. We shall see these houses more in detail on closer inspection.

\section{The Original "Red" Section.}

The largest plants winter about twenty-eight hundred hens. These are all Rhode Island Reds. Both Single and Rose Comb varieties are kept. This breed was originated right here on these very farms and is well adapted to egg farming; though as bred on most farms it is not as large as other standard American breeds it is yet large enough for a good, salable market fowl. This bird is, undoubtedly, a Mediterranean-Asiatic cross with the brown Leghorn representing the Mediterranean blood and a rather undetermined quality representing the Asiatic. The writer has seen females much resembling these from crosses of Brown Leghorns and Light Brahmas. There is no apparent reason why a Cochin cross could not be used with Brown

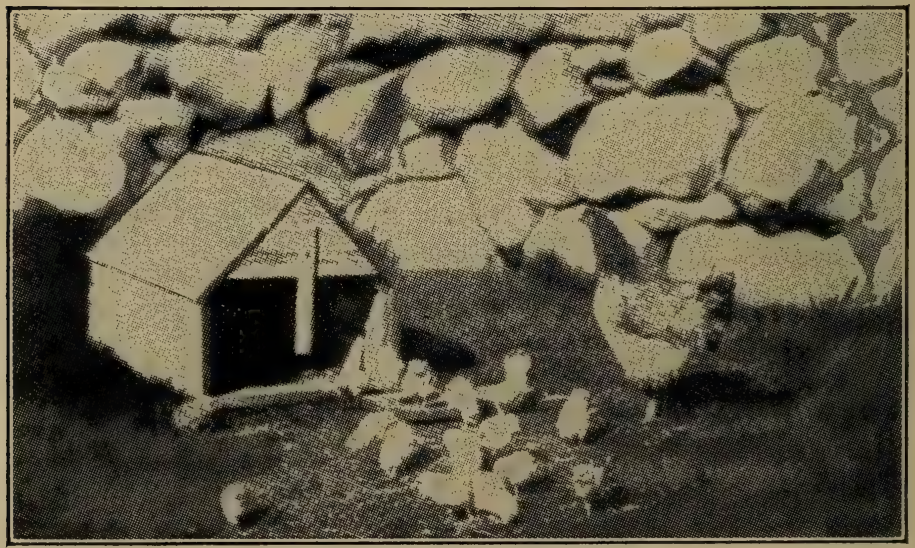

A Sample of Primitive Brood Coop Used on One of the Colony Egg Farms Described by A. C. Smith. 


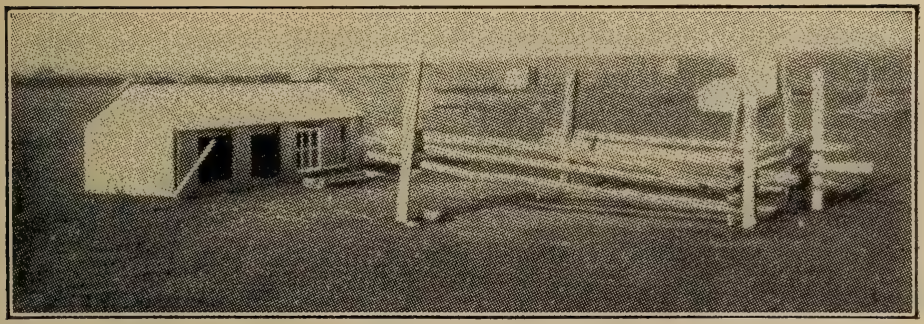

A Typical Laying House Found by A. C. Smith on his Visit to a Rhode Island Egg Farm.

Leghorns to produce a variety of the same characteristics as the Rhode Island Reds possess. However, the whole matter seems to be problematical and we must take these farms as we find them with the established Rhode Island Reds-good layers and fairly good market fowls.

While the great majority of these farms breed Rhode Island Reds exclusively, yet there are exceptions. The Light Brahmas are the second favorites. We also find White Wyandottes and particularly do we find Pekin Ducks and Embden Geese.

\section{The Houses are Cheap.}

As stated, these are not built for ornamentation. They are not built by men who have burdensome incomes to reduce. They are built by men inculcated with the savethe-coppers spirit, and look it. All are -of much the same general plan, built of rough, square edged hemlock boards, both roof and walls. They are about all of the pitch roof style and while they vary in length are in almost every instance ten feet wide. Some are ten feet long, more are twelve or fifteen, and many are twenty. A great deal of ingenuity is displayed in the minor details of fittings. The roofs are in some cases covered with waterproof paper, but in most instances they are not. The hemlock boards. are laid up and down close together, and battened, sometimes with lath, sometimes with wider stuff, and again, with other boards, in which case the course underneath is not laid very close together. There is always one win- 
dow in the south side, sometimes more, according to the length, and a door. The walls are between three and six feet high, generally nearer six than three. Just outside the door we find a crate, often a common strawberry crate, for cooping broody hens until they desist. Except in severe weather we also find a bucket for water and a feed trough, also just outside the door.

\section{The Inside Fittings.}

The interior has the necessities, nothing more. You always find a bank of a dozen or so nest boxes on the wall,

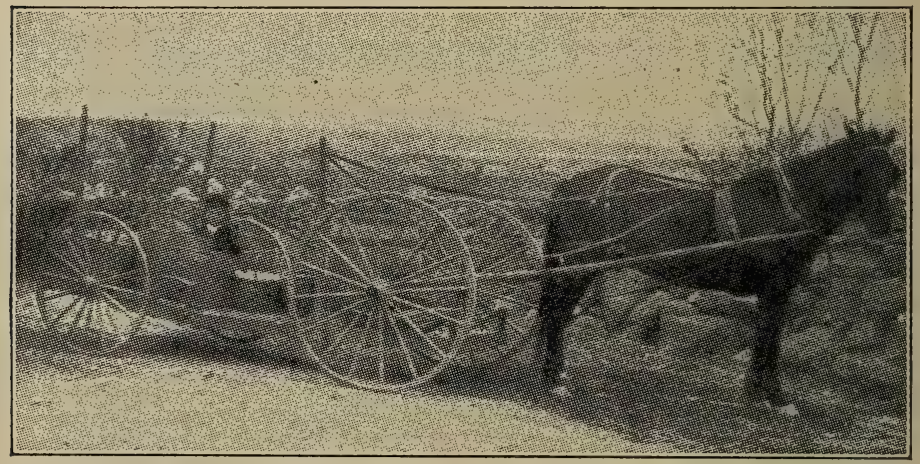

Equipment for Distributing Food and Water and Gathering Eggs on a Rhode Island Egg Farm.

a hopper or two for feeding grain and scraps and the roost poles. The latter generally rest on cross pieces nailed to the walls and are usually at the west end of the house, about two feet from the ground, for the floor of these houses is always sand, loam, or a mixture. There are seldom any droppings boards, the droppings collecting on the ground. To prevent them being scratched all over the floor a board six or eight inches wide is placed on edge across the floor of the house. As these houses are thoroughly cleaned but twice a year, the odor that would arise from the droppings creates a problem. It is this fact that makes the elimination of drop-boards advisable for there is less odor where the droppings fall into loam or sand. Occasionally sand or loam from the opposite end of the house is shoveled 
over the droppings, thus deodorizing the house for the time being. In the spring and fall these houses are thoroughly cleaned. The sand or loam that forms the floor is taken out, the inside walls whitewashed and clean sand or loam put in. That which has been taken out is used for fertilizer on grass land.

\section{Location and Capacity of Houses.}

These houses are located in the fields, usually fifty to one hundred feet apart. The number in each field depends upon

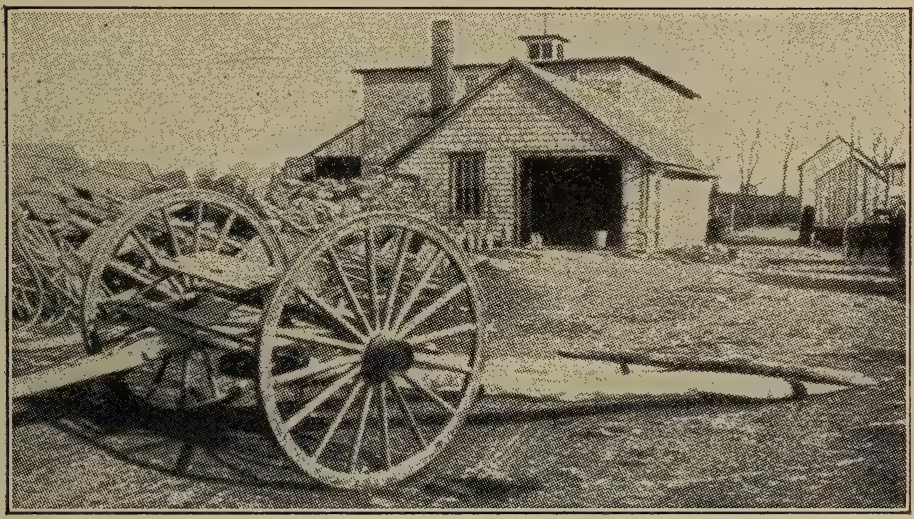

Device for Moving Colony Laying Houses From one Location to Another on a Rhode Island Egg Farm.

the size of the field and the notion of the proprietor. We saw none located so close together that the growth of grass in the fields was affected by the number of hens. They are generally placed in rows so that a team can be driven handily along the front of each pen. Each house contains from twenty-five to fifty fowls, usually about thirty-five. The size of the house that contains the latter number is usually ten by twelve or fifteen feet.

\section{Methods of Feeding are Simple.}

These flocks have a hopper of cracked corn before them at all times. A great many flocks also have all the beef scraps that they will eat, also in hoppers. They are fed, too, 
a mash of corn meal and bran which sometimes contains boiled vegetables. This is mixed at night if it is to be fed in the morning or mixed in the morning if to be fed at night. Two trips a day are generally made by the feeder. In the morning the hens are fed mash, or given a little barley or wheat to scratch for, and watered. At night when the eggs are collected, mash or scratch feed is given, according to whether or not mash was fed in the morning, and in freezing weather the water buckets are emptied.

\section{Incubating and Brooding Done By Hens.}

The incubator agent has not invaded this section, or must have been repulsed if he has, for the old hen seems to be good enough for these poultrymen. Two or three thousand chicks are raised on several of these farms, but the natural method holds sway. The hens are usually set in a house or barn fitted up for the purpose. They are fastened on the nests and let off at a certain time each day. The nests are usually arranged in rows and tiers.

The hen and her brood usually occupy a small separate coop of simple design and often crude. The accompanying photographs show instances of the very primitive construction found here. The hen is confined to these coops. The chickens run during the day, but are confined during the night as a precaution. The small chickens are usually put near to the farm buildings where it is convenient to feed them several times a day. The method of feeding is the old one; mash that has cooked over night in the morning and broken grains three or four times during the rest of the day. Of late the prepared dry chick feeds are used somewhat.

\section{Cracked Corn a Staple Food.}

The larger chicks are moved farther away where they get splendid range. Their houses are of the box-like type, usually about six-feet square and from four to seven feet. high. These chicks are fed mash in the morning when released from the coops and have hoppers of cracked corn always before them. Beef scraps are fed in limited quantities, usually mixed with the mash of corn meal and bran. 
By this method the larger chicks feed themselves with the exception of the morning mash. At this time they are also watered unless there is running water in the fields in which they range.

These methods read as though devised by the king of lazy men. As little work as possible is put into "keeping hens," but those people make up by keeping "a large number. The regular routine work on a large hen plant at certain seasons of the year is done by one man before nine o'clock in the morning and after four in the afternoon.

\section{One Dollar per Hen Profit.}

These poultrymen do not expect to realize over one dollar a year per hen and probably not that. They believe that there is more money in keeping a large number in this rough fashion than in "fussing" with a less number. It is plain to be seen that if a man keeps two thousand hens and realizes seventy-five cents to one dollar each, he can live comfortably, and these people do live comfortably. Crude as are the buildings for the live stock, the dwelling houses are neat and attractive.

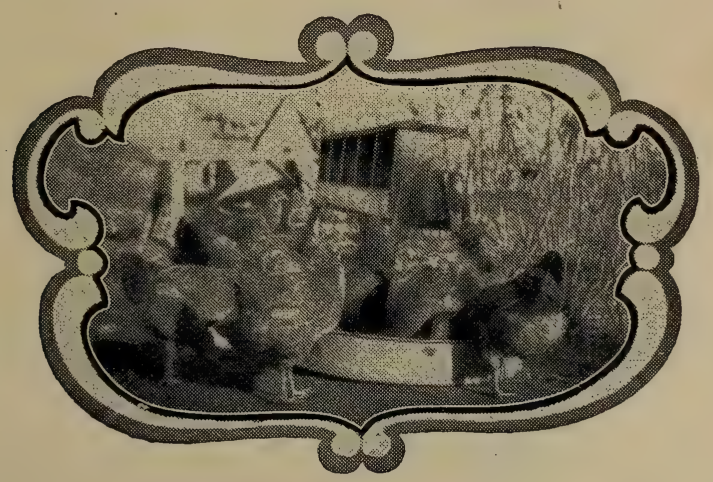




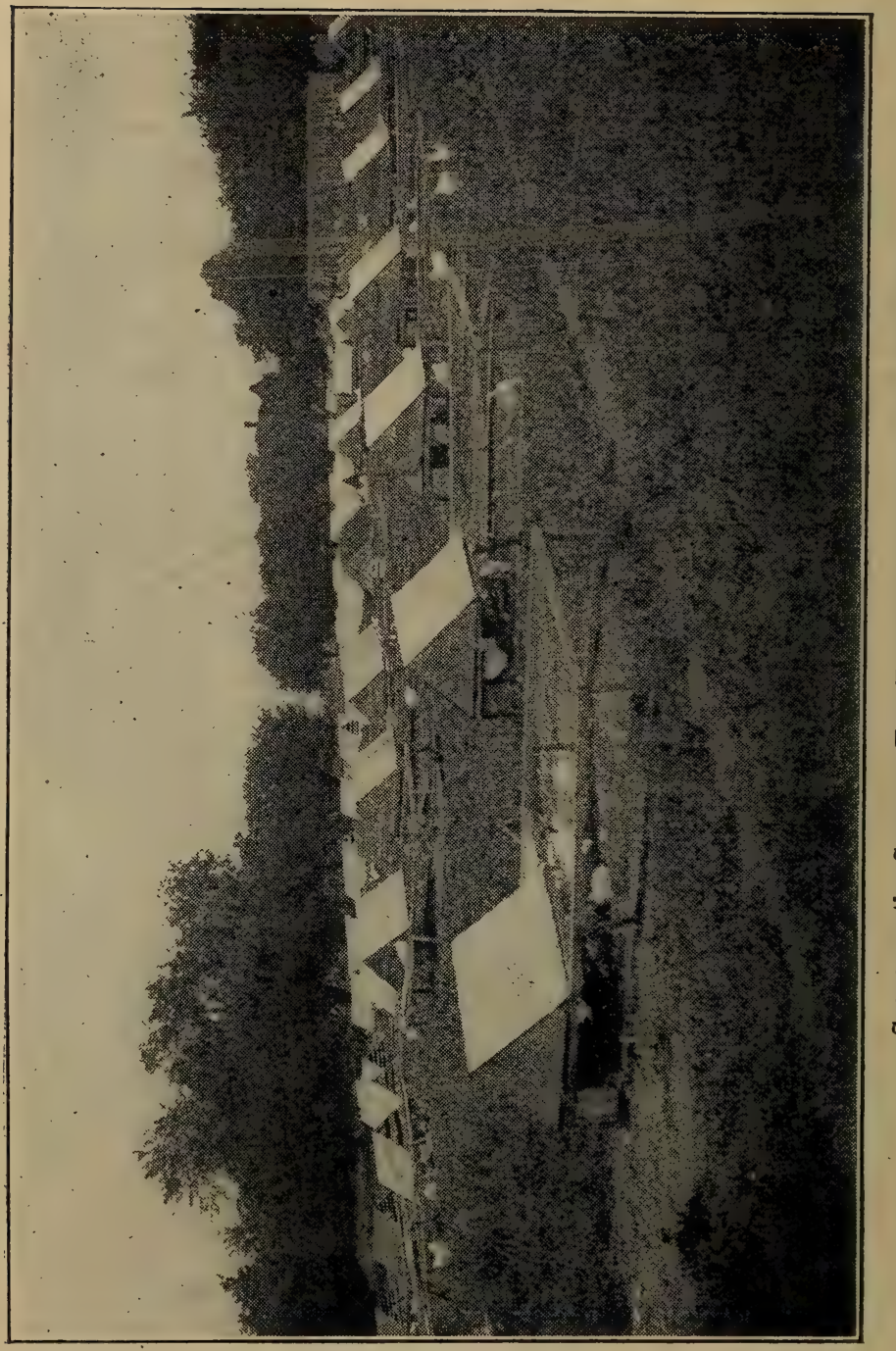

है 


\section{A SUMMER EGG FARM.}

\section{A Poultry Business That Requires No Houses and Rears No Chickens, Yet Pays a Generous Profit Six Months of Every Year.}

\section{By R. G. Williams.}

A poultry business which is continued year after year and yields a satisfactory profit, yet requires no permanent houses, yards, or expensive equipment, is a novelty to most poultrymen. Yet such a business is in operation at Amherst, Massachusetts, and the owner clears as much money on it during warm weather as many poultrymen having more expensive plants make in a full year, and has his winters to devote to other pursuits.

The best of it is that the same scheme can be operated successfully anywhere in the temperate zone, where any other branch of the poultry business can be carried on successfully.

The village poultryman with an acre of ground can, by this method, handle as many fowls during the summer as his co-workers with more land can keep at a profit in the usual manner.

\section{The Equipment Required.}

There is absolutely nothing in the way of accommodations that can be called a poultry house. The fowls are quartered in yards $12 \times 6$ feet on the ground and two feet high, framed of inch pine lumber, three inches wide, and covered on the sides and half of the top with two inch mesh wire netting. Upon that part of the top not covered by wire, a space $6 \times 6$ extending across one end of the yard, is placed a large "A" coop which covers it with the exception of a small space. This space is provided with a lid, through which the attendant can reach into the coop for various purposes. The roost is placed level with the 
top of the yard and directly under and parallel to the peak of the coop.

Each yard contains a nest-box, having three or four compartments. This is placed under the coop and close against the side of the yard which is provided with a door through which the attendant reaches the nests to collect. the eggs. A feed trough and water fountain, or dish, completes the equipment, the total cost of which need not exceed $\$ 2.50$, labor included. If properly made and painted it will last several years. Some years ago cotton cloth, both oiled and not oiled, was tried for covering shelters, but it was not found to be practical and all coops are now made of pine.

Each of these yards with its accompanying coop is. intended to accommodate ten to twelve birds and is moved to a fresh spot once a week. By the time that the fourth move has been made the spot first occupied is ready to be used again.

\section{How the Stock is Secured.}

When the price of eggs begins to drop as the weather opens in the spring most of the New England farmers are willing to dispose of their flocks at any reasonable prices. These fowls are what the summer poultryman wants and he sends men with wagon-loads of coops out to collect them, paying the going market price per pound. Many of these fowls are from late hatches of the preceding season and make good layers during the summer months. A majority of them are thin in flesh, so that hens capable of carrying a generous amount of meat when fat, are secured for the price of small ones. The buyer prefers thin fleshed to fat specimens for the former are more readily put in laying condition and are capable of turning a greater profit when dressed and sold at the end of the season. When the spring is so far advanced that the fowls can be comfortable in these accommodations, each yard, or pen, is given its dozen birds and the season's work begins in earnest.

\section{How the Income is Obtained.}

The majority of farmers' hens are lousy and the first important move after the fowls are brought in is to rid. 
them of vermin. Occasional treatment for lice during the summer is essential, for a lousy hen is not as productive nor can she be supported at the same cost for food. The foods and manner of feeding do not differ materially from those used on the majority of up-to-date poultry plants. Wheat, oats and a little corn are fed dry during the summer and the proportion of corn is increased as fall approaches. From a creamery near by curds and skim milk

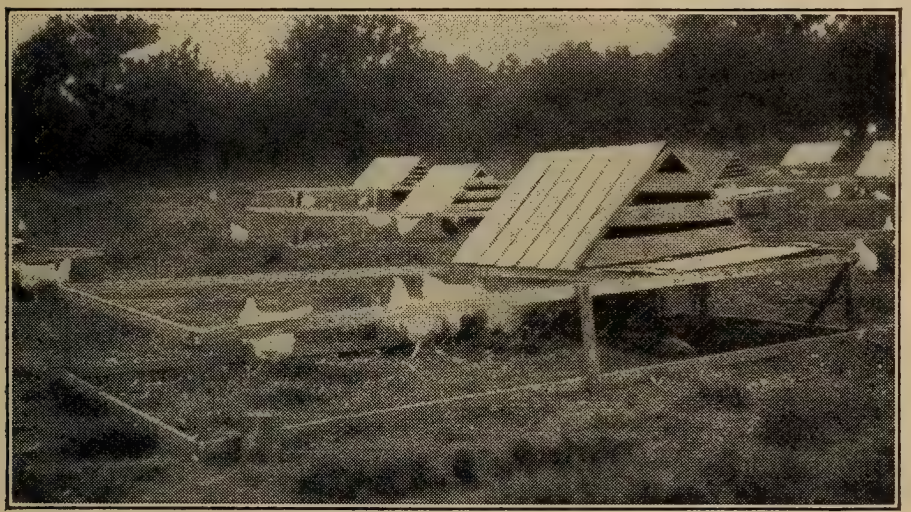

Some of the Coops and Yards Used on the Summer Egg Farm Described by R. G. Williams.

are obtained which furnish sufficient animal food when the supply is adequate. At other times beef scraps are supplied. It is understood that fresh water, grit, charcoal and oyster shells are always before each flock. From these fowls a liberal egg yield is obtained all summer and the product is sorted and shipped to New Haven, Conn., where an average of 30 cents a dozen is received. When the writer visited the plant about September first, the price received was 32 cents.

In the fall when the price is up and just before the hens begin to molt, selling is begun, and before the weather becomes too cold for the fowls to stay in the coops the last one has been shipped and the season's profits counted. A few are sold alive, but the bulk are dressed and shipped wherever the best prices can be obtained. 
The fowls used in this business are of all varieties but Mr. Fred Fuller, the superintendent, believes that results would be better if only one or two varieties of pure-bred stock were kept. He is tempted to raise a few hundred pullets each year from good laying stock and keep them over for the experiment. He prefers White Leghorns where eggs are the sole object, but pins his faith to Plymouth Rocks or Wyandottes where the sale of the fowl is also considered. Mr. Fuller says that a good man can care for 2,000 or more fowls penned in this manner.

The sale of eggs is expected to pay the cost of maintaining the fowls and plant, and the profit is derived from the advance in the priee received for the fowls over that paid for them in the spring. If the stock is properly fattened when sold the gain is considerable.

\section{The Possibilities of the Business.}

To any one interested in practical poultry work, this scheme presents attractive possibilities and to those who, from inclination or necessity, devote their winters to other pursuits but desire to follow some such line during the summer, it should prove both interesting and profitable. The capital required is less than that required to establish almost any agricultural business that will require a person's entire time for its operation and pay him as good returns for his labor. Substantial accommodations for 1,000 hens can be built for $\$ 250.00$ or less, and the fowls themselves, if well bought, should not cost more than $\$ 500.00$. The eggs should pay for the supplies almost from the start and also pay the care-taker a fair price for his labor.

Prices for dressed poultry of good quality are always higher in the fall than in the spring and there should be no difficulty in increasing the average weight of the fowls at least one pound. If that pound of meat sold for 14 cents the profit on 1,000 hens would be $\$ 140.00$, or eighteen per cent for six months on money invested. 


\section{MARKETING EGGS.}

\section{Upon the Sale of the Products Depend the Profits-Whole= sale Versus Retail Markets-Advantages and Disad= vantages of the "Private Trade"-Selecting and Shipping Eggs.}

\section{By H. A. Nourse.}

The profits of the egg business depend finally on the success of the owner or manager as a salesman. The ability to so manage the plant and handle the flock that eggs will be produced in liberal numbers, does not always assure the success of the undertaking. These eggs must be turned into money and although there is always a demand for eggs the amount of money received depends upon the time, place and manner of disposing of them.

Although an extra four cents on the price of a single dozen of eggs is not so material, the difference counts up rapidly as the dozens multiply. From one hundred dozen, for example, the additional revenue would be $\$ 4.00$ or enough to pay for the feed of four hens twelve months. Four cents a dozen, however, is not by any means the limit of difference between the price received by good marketing and that obtained by the opposite. It is by no means uncommon for a premium of ten cents per dozen over the regular market quotations to be paid, month in and month out, for selected stock. Numerous cases are on record, also, of a fixed price of fifty cents per dozen being paid throughout the year, though eggs sold for eleven to forty cents in the open markets of the same city. These are, of course, extreme cases and these prices are obtained by catering to a particular trade, with a fine grade of table eggs.

It is frequently stated that "quality," if sufficiently high, will always find a market at advanced prices, but this does not by any means hold true in the egg business. It is necessary first to produce a high grade of stock and then 
to find a market for it where the customers are especially discriminating and are willing and able to pay a premium for indulging this discrimination.

\section{Catering to the Wholesale Trade.}

A very large per cent of the eggs which find their way to market are turned over by the producer to country store keepers, who forward them to the large cities or to central collecting points, or are forwarded by the producer to commission dealers in the trade centers. This method of disposing of the eggs, while it does not always prevent a profit being made by the producer, prevents him from obtaining a high price for his product, if the product is worth it. Yet this method of marketing has its advantages. The country storekeeper takes them from the farmer's baskets and whenever it is convenient for the farmer to deliver them. The commission dealer also takes them when it is convenient for the producer to forward them and returns the market price, less his commission and the cost of transportion: This manner of disposing of them involves very little labor or head-work on the part of the poultry raiser and that is doubtless the reason why that manner of selling is usually adopted.

Another method of wholesaling, and one which insures better prices if properly conducted, is to deliver the eggs direct to the retail merchants, thereby saving the commission dealers' and storekeepers' profits. To do this successfully it is necessary first to locate a dealer who has the patronage of discriminating buyers, families who demand a good article and are willing to pay for it. To supply this trade satisfactorily, the dealer must obtain eggs which he may depend upon and be able to guarantee. Such eggs can seldom be obtained from the regular wholesalers and he is obliged to look to the producer for his supply. This, however, places additional responsibility upon the producer; he receives higher prices and he must deliver a high grade of eggs. In some cases, too, it is necessary that the producer be able to deliver a certain number at regular intervals throughout the year for the dealer has certain customers who require a steady supply in all seasons. To furnish this the producer ought 
to have two sets of fowls, one flock of early molters and one of late molters.

The choice between the methods of wholesaling depends largely on the time that the producer can give to the business. If he is prepared to cater to the higher class, the advance in price will usually be sufficient to a little more than pay for the extra labor involved. If, on the other hand, he is not able to fulfill these conditions, but finds it more desirable to produce the eggs as cheaply as possible and to get them off his hands with the least expenditure of time and labor, on account of other business, then the method of shipping to commission dealers or selling to country storekeepers may prove more profitable. It is true, also, that when a specialty is made of producing eggs during the season of high prices, which is during the months of November, December, January and February, it does not pay the consumer to bind himself by any bargain to furnish eggs the year around at a certain price, or to furnish so many eggs each day or each week, because in the very season he intends to produce the greatest number the highest prices will be paid and the demand is such that it is by no means difficult to find a purchaser.

\section{Supplying a Retail Trade.}

The retail trade, or the business of selling direct to the consumer, has not yet assumed any considerable magnitude when considered as a part of the entire poultry business. The consumers in this trade may be divided into three classes; hotels, clubs and private families. Only the high-class and most expensive hotels buy high priced eggs, but they take them in large numbers and pay good prices.

Several poultrymen in the state of New York have derived the main part of their revenue for years from the sale of eggs to the metropolis' finest hostelries.

Clubs which are maintained by the wealthy are good buyers of eggs which they know they can rely on. Of the three classes, however, the best paying and probably the most troublesome is the family trade. In catering to hotels and clubs it is sometimes considered necessary to divide the profits with the one who does the buying, but these pur- 
chasers are as a rule less difficult to contend with than the cook or butler of the private family. The latter always have their friends among the grocer's clerks and butcher's. boys and since many of them also derive a pecuniary benefit from the trade they give to certain stores and meat shops, they are always glad to turn any cause for dissatisfaction toward the poultryman and to shield his competitors. The trade of the individual family at best is not sufficient to warrant the egg man in paying these servants a sum sufficient to procure their good will. Of course these undesirable influences are not always to be contended with and in spite of those that exist poultrymen are doing a lucrative business with hotels, clubs and families, glad to tolerate the petty dissatisfactions while pocketing the additional profits.

The first two classes are rather easier to cater to since eggs are, delivered in greater numbers, one club or hotel often taking all the producer has, and most of the eggs. are shipped by express from consignor to consignee.

The trade of each family is small-comparatively. A few dozen here and a few dozen there require the services of a man and team for half a day, two, three or more times: each week. Occasionally the egg farmer finds it advisaable to take orders on certain days of each week and deliver on the day following. The prices obtained are as a rule well above the figures quoted in the retail stores and markets. As we stated before, fifty cents per dozen is frequently paid the year around and at this price the poultryman can well afford to shoulder considerable extra expense and trouble.

We have described the various methods of disposing of the egg farmer's product and endeavored to explain the advantages and disadvantages of each in such a way that. the reader, after investigating the conditions surrounding him, will be prepared to decide intelligently which method will prove most satisfactory and profitable for him to. adopt.

\section{What High Quality Means.}

To the average person a good egg means a fresh egg and vice versa, yet it is possible for an egg to be fresh, i, e., recently laid, and still be of poor quality. Before an egg. 
is entitled to classification as A 1 it must be uniform in shape, size and color with its mates, clean, and with its contents good. Uniformity, cleanliness, size, shape and color are attributes which assist in its sale by pleasing the eye. The contents of the shell, however, is what people pay the price for and it varies considerably.

An egg less than twenty-four hours old may not be very

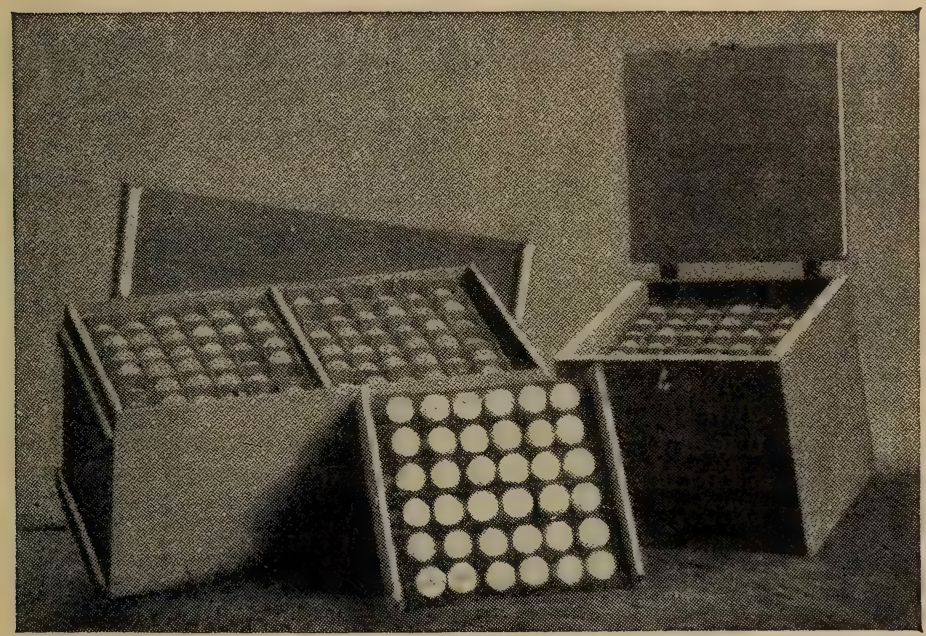

Cases of Strictly Fresh Eggs Ready to be Forwarded to Commission Houses, Retailers, Hotels or Clubs.

valuable as food. Its yoke may be unstable and pale in color, the white may be watery. In the perfect egg, the yoke is comparatively firm within its sack and the white sets solidly around it, both filling the shell very nearly full, leaving the air cell at the large end of the egg decidedly small. This is the product of the healthy hen, well fed and kept in elean quarters.

As good feeding (we mean correct feeding) and clean quarters are required for the health of the hen, the entire matter depends on feeding and care, subjects which have been fully treated in previous chapters. Uniformity in 
shape, size and color is obtained by building a strain of fowls with this end in view. Cleanliness is simply a matter of keeping the nests where the eggs are laid thoroughly clean. Washed eggs are not to be rated as A 1. Washing destroys the fresh appearance of the shell and, by removing a certain glutinous substance from the outside of the shell, detracts from its keeping qualities.

\section{Grading and Shipping.}

Whether eggs are marketed wholesale or retail, through commission merchants or to hotels or private families, the rules for selecting, grading and shipping have the same application. Understanding that all the eggs are fresh, as they should be when they leave the plant of the producer, the first thing to do is to sort them according to size and color. Small eggs and extremely large ones should be counted out and white eggs should be separated from brown ones. This will give us four divisions; white eggs that are off in size and brown eggs that are off in size, uniform white eggs and uniform brown eggs. The latter two divisions are the ones to be sold under the producer's mark and guarantee. The others must be sold as "seconds" and will not suit the more particular trade.

As an extra precaution some shippers candle all eggs before sending them out, even when there seems to be no chance for any egg to be over twenty-four hours old. . This is to guard against the distribution of any eggs which are not correct as to contents, for example those that may not be of the proper consistency, those not full, or those with blood spots. This candling, or testing, is done only when the eggs are to be forwarded to a high-class customer. Consignments forwarded to commission merchants or to retail establishments usually go forward in ordinary egg cases which are not expensive, though occasionally the shipper uses more substantial and attractive cases bearing his name. These are returned to him when empty, the express companies returning them free or charging him a nominal fee.

Eggs forwarded to hotels or clubs usually go forward in better cases. Sometimes in addition they are packed in 
dozen lots in pasteboard boxes which are inclosed in wooden cases of special design. The object of these special cases is to deliver the eggs in good and attractive condition whenever a higher price may be obtained by so doing. It is not our intention to describe the different cases in use, for most of them are for sale by poultry supply dealers and descriptions may be found in their catalogues.

Taken as a whole, the business of grading and shipping

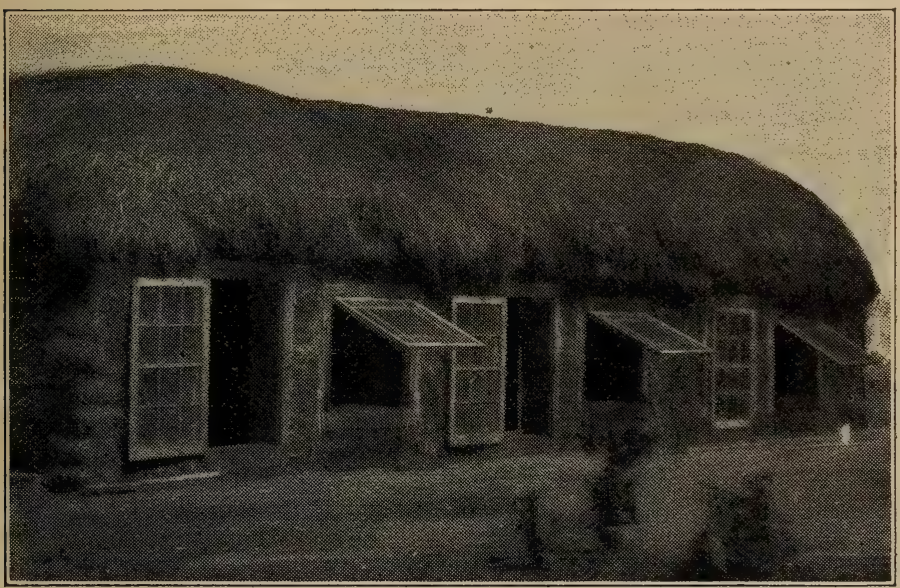

Winter Quarters for a Farm Flock, Built Almost Entirely of Straw, Baled or Loose.

consists principally in so grading the stock that it shall be most attractive and thereby command the highest price, and in so shipping it that it will arrive safely, secure from substitution and in the sort of cases that will serve to recommend the quality of the contents. These are matters which cannot be profitably neglected. Careless sorting or grading is always accompanied by a loss in price, for a mixed lot of eggs usually takes the price of the lowest grade represented. Carelessness in shipping, as well as the use of unattractive cases, will not serve as a recommendation of the eggs nor of the shipper as a man to do business with. 


\section{ADVERTISING TABLE EGGS.}

\section{The Producers, Who Hitherto Have Left Advertising to the Retailers, Are Beginning to Find That Publicity Pays.}

\section{By' H. A. Nourse.}

Until very recently the only desirable publicity that market eggs received was in the more or less spacious advertising of the retail grocer, who seemed prone to regard all eggs as "fresh" until they were proven otherwise. Now the producer, whether he is a village poultryman or an exclusive egg farmer, is beginning to take the egg advertising in his own hands. This is noticeable in the case of those producers who retail their eggs direct to the consumer, or who furnish retail dealers with eggs branded with their name and guarantee.

\section{The Manner of Advertising.}

It may be supposed that this advertising would be done in the papers circulating in the towns and cities where the producer's product is to be sold; but it seems that only a small part of the advertising is placed in periodicals. The greater part of it is done by means of circulars. The advertiser secures a list of persons whom he considers most likely to become customers and mails them his card or circulars, rather than take the chance of their seeing his ad in the crowded columns of the newspaper and rather than pay to have his ad placed before the people of the town as a. whole, 95 per cent of whom he is positive would never be induced to pay an extra price for eggs of the better quality. That extra price is what the advertiser is after.

\section{Points to Bring Out.}

To sell his product at five, ten or more cents a dozen in excess of the price named for so-called fresh eggs by the 
avarage retailer, the producer must convince the prospective buyer that the eggs he is prepared to furnish are really worth the price asked for them. In other words the consumer must be educated. He must be taught that a fresh egg is not simply an egg that is not stale, but one that has been laid within forty-eight hours before it reached his kitchen. He must be told that all fresh eggs are not necessarily of good quality. He must be influenced to prefer large eggs to small ones and clean ones to the other kind, since large ones will go farther when used for cooking and clean ones are more healthful.

The bright advertiser knows that these things are true and makes the most of them. He guarantees that all eggs shall be delivered within a certain number of hours after they are collected from the nests. He guarantees that the food given the hens and the conditions surrounding them are healthful and calculated to enable them to produce eggs of good body and fine flavor. He assures the purchaser that they will weigh so much to the dozen and that they are clean always, because their surroundings are sanitary. Occasionally he calls attention to the fact that the ordinary egg of commerce is a decided uncertainty and that no one knows under what conditions it was produced or what sort of food the fowl that produced it consumed. All these are points which appeal to the lover of good eggs who can afford to encourage a fastidious taste. These points are usually brought out in circulars, but the advertiser in the local papers cannot go so much into the small points.

\section{When Newspaper Space is Used.}

The poultryman who produces eggs in comparatively large numbers and turns them over to retailers to sell for him after marking them with his name and protecting them with his guaranty, usually prefers to do his advertising in the newspapers. He usually runs a card once or twice a week in the daily papers or in each issue of the weeklies. In this space he calls attention to the fact that eggs bearing his trade mark and dated (either on the egg itself or on the carton in which it is delivered) are for sale by certain dealers, and are guaranteed by him to be of high quality. 
Sometimes instead of running a separate advertisement; the producer pays his retailers a certain amount to insert certain copy regarding his eggs in their ads at certain intervals.

\section{Does Advertising Pay?}

Whether or not this pays, and how well it pays, depends upon how well the advertising is done and how well the advertiser is prepared to supply the trade he gains with the eggs he advertises.

In almost any large town or city, there are people who appreciate and can afford to pay for eggs that are above the average in quality, and, as a rule, it is only necessary to get in touch with these people and prove to them that you have that which they are willing to pay for, to work up a considerable trade. If one sells only a limited number of dozens each week an increase of ten cents per dozen will pay for quite a little advertising, and a customer once gained and properly treated, -is usually kept.

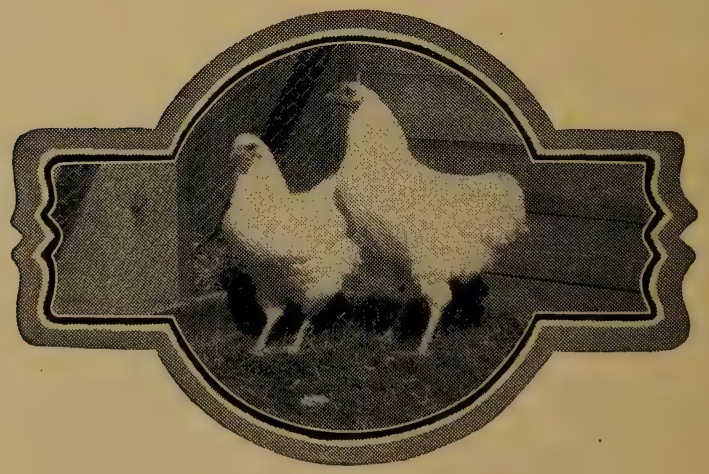


(3) M.

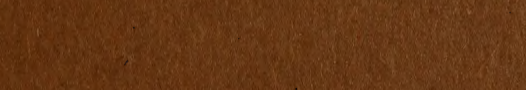




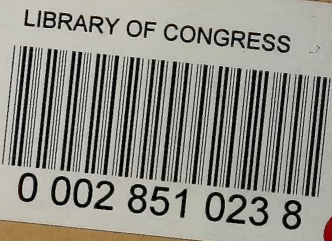

Hollinger Corp. $\mathrm{pH} 8.5$ 